NBER WORKING PAPER SERIES

\title{
TAXING PROPERTY IN DEVELOPING COUNTRIES: THEORY AND EVIDENCE FROM MEXICO
}

\author{
Anne Brockmeyer \\ Alejandro Estefan \\ Karina Ramírez Arras \\ Juan Carlos Suárez Serrato \\ Working Paper 28637 \\ http://www.nber.org/papers/w28637
NATIONAL BUREAU OF ECONOMIC RESEARCH
1050 Massachusetts Avenue
Cambridge, MA 02138 \\ April 2021, Revised May 2022
}

We are grateful to the Ministry of Finance of Mexico City for granting us access to property tax records, to Arturo Herrera for initiating innovative analytical work on tax compliance in Mexico, and to Roberto Carlos Fernández González, Gabriel Portilla Orozco, Lizbeth Rodríguez Luna, Alejandra Aguirre, Emilio Barriga, and Carlos Cardoso for their guidance. We appreciate helpful comments from Stuart Adam, Hunt Allcott, Peter Arcidiacono, David Agrawal, Michel Azulai, Pierre Bachas, Pat Bayer, David Berger, Michael Best, Augustin Bergeron, Pierre Boyer, Marius Brüllhart, Stefano Curto, Don Davis, Manon Delvaux, Aureo de Paula, Rebecca Diamond, Gilles Duranton, Fernando Ferreira, Lucie Gadenne, François Gerard, Guillermo Gruces, Irem Güçeri, Steve Hamilton, Jessie Handbury, Mariaflavia Harari, Andreas Haufler, Anders Jensen, Matt Johnson, Ben Lockwood, Juliana Londoño Vélez, Mohammed Mardan, Tim McQuade, Jakob Miethe, Enrico Moretti, Joana Naritomi, Oyebola Okunogbe, Ben Olken, Andreas Peichl, David Phillips, Dina Pomeranz, Giacomo Ponzetto, Diego Puga, Sander Ramboer, Pablo Saavedra, Dominik Sachs, Guttorm Schjelderup, Modibo Sidibe, Divya Singh, Joel Slemrod, Chris Timmins, Gabriel Tourek, Nick Tsivanidis, NancyWallace, MazharWaseem, JonathanWeigel, FrancisWong, MaisyWong, Owen Zidar, Eric Zwick, Floris Zoutman,and seminar/conference participants at APPAM, Barcelona Public Economics Meeting, Cities Workshop, CURE, EEA, Georgetown University, George Mason University, George Washington University, IAAE, IADB, IFS, IIPF, Johns Hopkins University, Queen Mary University of London, NBER Summer Institute, NBER Public Economics Fall Meeting, NEUDC, Northwestern University, Norwegian School of Economics, the Online Public Finance Seminar, Oxford Center for Business Taxation, Richmond Fed, RIDGE conference, Syracuse University, UC Berkeley (Real Estate), University of Maryland, University of Michigan, University of Munich, University of Notre Dame, Wharton School, World Bank, ZEW, and the Zurich Public Finance in Developing Countries conference. Magaly Sáenz Somarriba and Meghan Howat provided excellent research assistance. The project was funded by the World Bank. Brockmeyer's time was partly funded by UKAID from the UK government through an Accountable Grant Agreement for the Centre for Tax Analysis in Developing Countries (TaxDev) at the Institute for Fiscal Studies (IFS). The findings, 
interpretations, and conclusions expressed in this work do not necessarily reflect the views of the World Bank, the National Bureau of Economic Research, its Board of Executive Directors, or the governments that they represent, nor do they reflect the views of the Ministry of Finance of Mexico City or the Federal Ministry of Finance in Mexico. All errors are our own.

NBER working papers are circulated for discussion and comment purposes. They have not been peer-reviewed or been subject to the review by the NBER Board of Directors that accompanies official NBER publications.

(C) 2021 by Anne Brockmeyer, Alejandro Estefan, Karina Ramírez Arras, and Juan Carlos Suárez Serrato. All rights reserved. Short sections of text, not to exceed two paragraphs, may be quoted without explicit permission provided that full credit, including $(\subset)$ notice, is given to the source. 
Taxing Property in Developing Countries: Theory and Evidence from Mexico

Anne Brockmeyer, Alejandro Estefan, Karina Ramírez Arras, and Juan Carlos Suárez Serrato

NBER Working Paper No. 28637

April 2021, Revised May 2022

JEL No. H21,H26,H71,O23

\begin{abstract}
$\underline{\text { ABSTRACT }}$
The property tax is the most under-utilized tax in developing countries. We evaluate the revenue and welfare effects of the main policy instruments used to raise property tax revenue: tax rate changes and enforcement. Using administrative data from Mexico, sharp tax rate increases, and an enforcement experiment, we show that both policy instruments increase revenue. We then provide a conceptual framework to assess the welfare costs of these policies. The welfare cost of tax increases incorporates changes in compliance and consumption drops for compliant taxpayers. The welfare effect of enforcement includes the cost to noncompliant taxpayers from threats of fines and property seizure, a cost we infer using tax rate and enforcement elasticities. In Mexico, tax hikes raise welfare since revenue gains exceed losses from consumption drops. In contrast, enforcement reduces welfare as its costs overshadow the revenue gains. Welfare-maximizing governments would therefore prefer increasing tax rates over enhancing enforcement.
\end{abstract}

Anne Brockmeyer

Institute for Fiscal Studies

7 Ridgmount Street

London WC1E 7AE

United Kingdom

anne.brockmeyer@ifs.org.uk

Alejandro Estefan

1010 Jenkins Nanovic Halls

University of Notre Dame

Notre Dame, IN 46556

United States of America

mestefan@nd.edu
Karina Ramírez Arras

Ministry of Finance, Mexico

Palacio Nacional

(Calle Correo Mayor esquina con calle Soledad)

Ciudad de México. C.P. 06060

karina_ramirez@hacienda.gob.mx

Juan Carlos Suárez Serrato

Department of Economics

Duke University

213 Social Sciences Building

Box 90097

Durham, NC 27708

and NBER

jc@jcsuarez.com 
We study the design and effectiveness of the most under-utilized tax in developing countries: the property tax. While lower-income countries generally raise less revenue as a share of GDP than higher-income countries, Figure 1 shows that this pattern is much more pronounced for the property tax than for any other tax. This paper studies whether governments in the developing world can increase property tax revenue to provide local public goods and fund infrastructure investment. We focus on the two main instruments used to raise revenue: tax rate hikes and enforcement. Do these instruments lead to increases in tax revenue? Which instrument is more effective at raising welfare?

We answer these questions by combining administrative tax data, multiple sources of policy variation, and a model of optimal property taxation. Our analyses cover all residential properties in Mexico City - the second-largest city in the Western Hemisphere. In this setting, 40 percent of taxpayers are delinquent on their property taxes. We first evaluate whether the government has the administrative capacity to increase tax collections. Using multiple quasi-experimental tax increases and a field experiment varying enforcement messages delivered to delinquent taxpayers, we find that both tax rate increases and additional enforcement raise tax revenue. Our results show that even in settings with significant under-compliance, governments can raise property tax revenue.

To study the welfare effects of property taxation, we develop a model that formalizes the government's trade-off between raising revenue to provide public goods and the welfare cost of different policy instruments. Tax rate increases can generate additional welfare costs to taxpayers in the presence of liquidity constraints, which are prevalent in developing countries. ${ }^{1}$ Property taxes may exacerbate liquidity constraints because they are based on an illiquid stock rather than on a flow of income or consumption. We validate these concerns empirically by showing that following a tax increase, taxpayers are more likely to pay in installments and to reduce their consumption. In our model, accounting for the presence of liquidity constraints moderately raises the welfare cost of property taxation. Nonetheless, our model combined with our empirical estimates indicates that tax rate increases are welfare-enhancing under most assumptions on the value of public goods.

An alternative approach to increasing revenue is to more strictly enforce existing taxes on delinquent taxpayers. Our model evaluates the welfare effects of enforcement by comparing the revenue gains from enforcement to the private costs that non-compliant taxpayers experience through threats of fines and property seizures. To quantify this private cost, we use tax rate and enforcement elasticities to compute the tax increase that would raise the same revenue as the enforcement action. While enforcement raises revenue, our estimates imply that the utility cost to non-compliant taxpayers exceeds the welfare gains from the increase in tax revenue. Our empirical estimates therefore imply that, on the margin, a welfare-maximizing government would prefer to raise property tax rates rather than rely on revenues from additional enforcement.

Our analysis proceeds in four steps. We first construct a simple model of optimal policy design,

\footnotetext{
${ }^{1}$ In Mexico City, less than 20 percent of households have access to credit cards. Appendix H shows that households in Mexico City are imperfectly insured against income shocks. This result builds on the seminal work of Attanasio and Davis (1996) and Attanasio and Jappelli (2001) and its application to Mexico in Attanasio and Székely (2004) and provides evidence that liquidity constraints are pervasive in our setting.
} 
building on Keen and Slemrod (2017). The model is accessible, can be tied to our empirical estimates, and speaks to policymakers' desire to raise revenue while limiting taxpayer hardship. The model studies optimal tax rate and enforcement policies in a context with liquidity constraints. When households are subject to liquidity constraints, their consumption may decline when they pay property taxes. While the government observes the tax liability, households may not comply with the tax due to liquidity constraints or low tax morale.

The model provides two guiding insights for policy. First, liquidity constraints increase the welfare cost of taxation and yield lower optimal tax rates. Second, while enhanced enforcement raises tax revenue, it also lowers welfare by increasing the private costs of tax delinquency through threats of fines and property seizure. These insights imply that a full welfare analysis of the property tax system requires empirical estimates that capture the costs and benefits of relying on different policy instruments, including tax and compliance elasticities, consumption changes, and private costs of enforcement.

In our second step, we estimate the sufficient statistics that allow us to implement our model and evaluate the welfare effects of tax rate changes and enhanced enforcement. Our analysis leverages large quasi-experimental tax hikes, which affect properties in specific cadastral value bands. Figure 2 shows that depending on the year, tax rates increased by between 18 to 47 percent. We use a regression discontinuity (RD) design to estimate short-term responses and a difference-in-differences (DiD) design to estimate medium-term responses. Both research designs yield similar estimates and are bolstered by a number of checks, including that cadastral values are not manipulated, that property characteristics do not change discontinuously around band thresholds, and that treated and never-treated properties have similar pretrends. While our estimates show that governments can raise revenue, we also find that tax hikes significantly reduce compliance with the property tax.

We then study whether enforcement actions can succeed at raising revenue from delinquent taxpayers. To deal with the fact that 40 percent of taxpayers were delinquent on their property taxes, the government of Mexico City applies fines and interest to late payments, occasionally seizes the property of delinquent taxpayers, and conducts enforcement campaigns to encourage compliance. We evaluate the effects of one such campaign using a field experiment in which the tax authority sent enforcement letters to 80,000 delinquent taxpayers. Compared to a control group that received no letters, delinquent taxpayers who received letters emphasizing sanctions and fines displayed triple the likelihood of making a payment. ${ }^{2}$ These empirical results demonstrate that the government is able to raise property tax revenue through either tax rate increases or enforcement. However, our model also considers that these policy tools can cause hardship, either by exerting private costs or by exacerbating household liquidity constraints.

The third step of our analysis provides two pieces of evidence that liquidity constraints affect

\footnotetext{
${ }^{2}$ Variation in letter content allows us to identify enforcement messages that are more effective at encouraging compliance. Letters with female signatories had slightly higher impacts than those signed by men, and letters from fiscal attorneys raised 50 percent more revenue than letters from compliance officers.
} 
the ability of households to comply with the property tax. First, we show that tax hikes affect taxpayers' choice of payment modality. Since households that pay their annual tax liability in full and before a given date receive a discount on their liability, the choice to pay in installments is equivalent to taking out a loan from the government. We exploit an unusual inflection point in the tax rate schedule to show that higher tax rates are associated with a higher likelihood of taxpayers paying in installments instead of paying their annual liability all at once. Conditional on attempting to pay in installments, the likelihood that a taxpayer completes all installment payments is also inversely related to the tax rate. We complement this evidence using a DiD design that shows that tax hikes reduced taxpayers' propensity to pay their tax all at once and increased the likelihood of paying in installments.

To provide a second piece of evidence that property taxes interact with liquidity constraints, we combine administrative records with household survey data on consumption. We use a splitsample instrumental variables approach that leverages the quasi-experimental tax rate variation to estimate the impact of tax payments on consumption. The first stage - the effect of predicted tax changes on tax payments - is statistically very strong and has a magnitude similar to that of our estimates using administrative tax data. The exclusion restriction is that the predicted tax change impacts consumption through the tax reforms only. This restriction is likely to hold because the tax variation is very sharp, and as we show in our regression discontinuity and difference-in-differences analyses, tax increases are otherwise unrelated to other property characteristics and treated and untreated properties have similar trends prior to the tax increases. We find that tax increases affect the consumption of liquidity-constrained households. Doubling property taxes would reduce the consumption of households without a credit card by 7.9 percent. ${ }^{3}$ The estimated impact of tax rate increases on consumption captures the extent to which liquidity constraints increase the welfare cost of property tax hikes and is thus a key ingredient of our optimal tax formula.

The fourth and final step of our analysis implements our model of optimal property taxation and provides guidance to policymakers based on our empirical results. The model shows that even though compliance levels are low, raising revenue through stricter enforcement has negative effects on welfare. This result follows from the fact that the disutility that delinquent taxpayers face from additional enforcement exceeds the utility gains from additional revenue. ${ }^{4}$ By contrast, raising property tax rates to provide public goods can increase welfare. This result is robust to accounting for the potential effects of tax hikes on consumption, as these effects only increase the welfare cost

\footnotetext{
${ }^{3}$ Supporting our interpretation of these results as evidence of liquidity constraints, we find that tax rate changes did not affect consumption among richer households, who would be able to smooth their consumption. This finding suggests that taxpayers perceived the tax rate hikes as temporary, since a permanent tax change would have affected the consumption of all households.

${ }^{4}$ This result is consistent with Allcott and Kessler (2019), who model interventions such as ours and show that they can lower welfare even if they succeed at changing behavior. Meiselman (2018) and Organ et al. (2022) also consider the role of private costs in their welfare analyses of government policies. Our result is robust to underweighing the disutility that delinquent households experience through enforcement.
} 
of tax increases moderately. ${ }^{5}$ Our model and empirical estimates therefore show that existing tax rates are below the optimal tax rate. By providing liquidity to taxpayers, governments can also lower the welfare cost of taxation and implement higher tax rates.

Overall, this paper shows that developing countries can increase their reliance on property taxation to provide public goods and fund infrastructure investment. While additional enforcement increase tax revenue, we find that marginal enforcement actions reduce welfare. On the contrary, since tax hikes increase both tax revenue and welfare, tax rate increases are more desirable for welfare-maximizing governments.

Our results are internally valid for Mexico City and should be interpreted as the effects of large interventions. The tax hikes that we analyze were part of reforms that coincided with a 36 percent increase in property tax revenue (see Figure B.1, Panel A). Our rigorous evaluations of these reforms show that a large part of this increase can be attributed to the causal impacts of tax increases. Similarly, by contacting 80,000 taxpayers, our field experiment reached close to 14 percent of delinquent taxpayers. Finally, because our enforcement intervention was part of a regular enforcement campaign, our results can be interpreted as in-equilibrium effects of existing policies.

Mexico City is a very useful laboratory for studying property taxation in a developing country context. Tax administrations in lower-income countries display weaker capacity. For example, the number of tax audits per capita - a widely used proxy for tax administration capacity — is increasing in GDP per capita (see Panels A1 and A2 of Figure B.2). Mexico fits this pattern well, exhibiting a level of administrative capacity similar to that of other middle-income countries. Households in lower-income countries also suffer from liquidity constraints. The shares of households that have a bank or credit card accounts or that can access loans to finance unexpected expenses are also increasing in GDP per capita. ${ }^{6}$ As with tax capacity, measures of liquidity constraints in Mexico City are broadly representative of places with similar income levels, suggesting that our results are likely externally valid for other developing countries.

This paper contributes to the emerging literature on taxation in developing countries (Besley and Persson 2013, Pomeranz and Vila-Belda 2019). This literature has argued that the optimal mix of tax instruments may diverge from traditional public finance theory prescriptions in a context of limited enforcement capacity (Best et al., 2015). We build on this literature as well as on the tax systems approach of Slemrod and Gillitzer (2013) by taking into account elements of the property tax system that are often overlooked - e.g., implicit loans in the form of discounts or alternative payment modalities - and by considering interactions between tax rates and enforcement policies. ${ }^{7}$ Similar to Basri et al. (2019), we compare the revenue and welfare effects of tax rate and tax administration

\footnotetext{
${ }^{5}$ According to our estimates, doubling property taxes would raise the welfare cost of taxation by 7 percent.

${ }^{6}$ Households in developing countries experience more income volatility (Morduch 1995), have less access to insurance (Jack and Suri 2014; Townsend 1995), and have less access to the formal financial system (Morduch and Karlan 2009; Demirguc-Kunt et al. 2017). Table B.1 describes consumer debt in Mexico City, and Panels B1-B4 in Figure B.2 compare measures of liquidity constraints in Mexico with countries around the world.

${ }^{7}$ Our approach is related to Meiselman (2018) and Brockmeyer et al. (2019), who build on Keen and Slemrod (2017) to examine the effectiveness of enforcement letters to taxpayers in Detroit and Costa Rica, respectively.
} 
changes. While they show that tax administration may be superior for income taxation, the relevant welfare costs of property taxation are different. In particular, we consider private enforcement costs and household liquidity constraints, a key characteristic of developing economies that is empirically important but often neglected by traditional optimal tax theory. In our setting, these forces lead us to conclude that tax rate increases are more effective than enforcement actions at raising welfare. ${ }^{8}$

Our paper is also related to the tax compliance literature (for a recent survey, see Slemrod 2018). This literature has traditionally been concerned with the accurate reporting of liabilities and the impact of detection but has recently noted that payment enforcement is a separate and similarly important challenge, even in the US (Versprille, 2020). Recently, researchers have started evaluating novel tools for the enforcement of outstanding payments (Organ et al., 2022; Kessler, 2020; Perez-Truglia and Troiano, 2018; Dusek et al., 2020). Our optimal tax model considers the welfare gains from policies that target delinquency relative to the gains from other tax policies.

In addition, this study contributes to research that uses property taxes to study questions related to taxation and development (e.g., Khan et al., 2016, 2019; Okunogbe, 2019; Weigel, 2020; Balan et al., 2020). Best et al. (2020) study the implications of horizontal inequities for tax morale and compliance. Bergeron et al. (2020) study the effects of tax rates and enforcement on compliance and how these instruments jointly determine the revenue-maximizing rate. Consistent with our results, they find that responses to tax rate changes are likely driven by liquidity constraints. Our paper shows that governments in developing countries can improve the design of the property tax by accounting for both revenue and welfare effects of tax and enforcement policies. ${ }^{9}$

Finally, there is a large body of work on property taxes in the US, reviewed in Agrawal et al. (2020). ${ }^{10}$ While this paper emphasizes aspects of property taxation that are more salient in developing countries, our results may be applicable to developed-country settings. For instance, liquidity constraints are also important in rich countries. ${ }^{11}$ Similarly, several US cities have trouble collecting property taxes and feature noncompliance rates above 10 percent (Chirico et al., 2019).

The rest of the paper is structured as follows. Section 1 presents our model of optimal property taxation. Sections 2 and 3 describe property taxation in Mexico City and our administrative tax data. We study the effect of tax rate changes on tax revenue in Section 4, the effect of enforcement on revenue in Section 5, and the role of liquidity constraints in Section 6. In Section 7, we implement the model using our empirical estimates and discuss policy implications. Section 8 concludes.

\footnotetext{
${ }^{8}$ Relative to the set of papers that focus on the role of information in enforcing taxes (Pomeranz, 2015; Naritomi, 2019), this papers studies compliance in a setting where the government has full information.

${ }^{9}$ Appendix $\mathrm{K}$ estimates the revenue-maximizing tax rate, which is significantly greater than existing tax rates.

${ }^{10} \mathrm{~A}$ concern in this literature is the impact of property taxes on the real estate market. We document that new construction is not designed to target property tax thresholds and that tax increases are not likely to impact investment in existing housing units. Property taxes are unlikely to affect household location decisions, as school funding is not tied to neighborhood-level taxes and internal migration is lower in lower-income countries. This is especially true in our setting, as Mexico City offers unique amenities.

${ }^{11}$ Cabral and Hoxby (2012) show that property taxes are less popular when households lack escrow accounts to smooth tax payments. Wong (2020) also shows that small property tax increases in the US can lead to financial hardship, including mortgage delinquencies and declines in consumption.
} 


\section{Optimal Property Tax Administration with Liquidity Constraints}

This section develops a model of optimal property tax administration that considers both tax rate and enforcement policies building on the work of Keen and Slemrod (2017). To match our empirical setting, the model features an observed and fixed tax liability and focuses on compliance along the extensive margin. ${ }^{12}$ Since the property tax liability is not tied to a cash flow, the model allows for taxpayer liquidity constraints to impact tax compliance and the welfare cost of taxation. The model delivers expressions for the welfare effects of changes in tax rates and enforcement and for the optimal tax rate that are a functions of estimable elasticities.

\subsection{Model Setup}

Households $i$ live two periods. They consume a private good $c$ and a public good $g$ and have uncertain income $y$ in the first period. Households start owning a property of value $H$, pay a tax $t$ in the first period, and use the liquidated value of the asset for consumption in the second period. These assumptions represent an initial state where households have committed to a level of housing consumption and a second period where households re-optimize housing and consumption. ${ }^{13}$

While the government observes the tax liability, households may decide not to pay the property tax. $\mathbb{I}\left[\right.$ Delinquent $\left._{i}\right]$ denotes the event of household $i$ being delinquent. Households face two types of costs when they are delinquent. First, they incur a private or psychological cost of non-payment $M_{i}(\alpha)=m(\alpha)+\varepsilon_{i}$. The idiosyncratic disutility from not paying taxes $\varepsilon_{i} \sim F(\cdot)$ captures variation in tax morale. ${ }^{14}$ The common cost of non-payment, $m(\alpha)$, measures the utility cost taxpayers experience from threats of fines and property seizure and is an increasing function of the enforcement level $\alpha .{ }^{15}$ Second, when households are delinquent, the value of their property depreciates by a factor z. This factor corresponds to back taxes collected by the government. Households solve the problem:

$$
\begin{aligned}
\max _{s, \text { Delinquent }} & u(c)+\beta u\left(c^{\prime}\right)+v(g)-M_{i}(\alpha) \times \mathbb{I}\left[\text { Delinquent }_{i}\right] \\
c & =y-t H\left(1-\mathbb{I}\left[\text { Delinquent }_{i}\right]\right)-s \\
c^{\prime} & =s(1+r)+H\left(1-z \times \mathbb{I}\left[\text { Delinquent }_{i}\right]\right) \quad \text { and } s \geq 0
\end{aligned}
$$

where savings receive an interest rate $r$ and the level of public goods $g$ is set by the government.

\footnotetext{
${ }^{12}$ In contrast, taxpayers in the model of Keen and Slemrod (2017) can take costly actions to "hide" taxable income. Table C.1, Panel B, shows that most taxpayers either pay their tax in full or do not pay; very few pay partially.

${ }^{13}$ We present a simple model for clarity of exposition and discuss extensions in Section 1.5.

${ }^{14}$ Singhal and Luttmer (2014) discuss the importance and drivers of tax morale.

${ }^{15}$ The enforcement letters we study emphasize potential costs and legal actions to non-compliant households. Glaeser (2006) argues that these type of interventions act as emotional taxes - a cost that needs to be taken into account in welfare evaluations (see also Caplin, 2003; Loewenstein and O'Donoghue, 2006). In their taxonomy of the welfare effects of nudges, Allcott and Kessler (2019) also consider information, reminder, and warm glow effects. As we discuss in Appendix A.2, the intervention in our setting does not feature these effects. Meiselman (2018) and Organ et al. (2022) also include such private costs in their welfare analyses of enforcement policies.
} 
Conditional on the decision $j \in\{$ Pay, Delinquent $\}$, optimal consumption is determined by the first-order condition:

$$
u^{\prime}\left(c_{s}^{j}\right) \geq(1+r) \beta u^{\prime}\left(c_{s}^{\prime, j}\right)
$$

where we index consumption by savings, $s$. When $s>0$, this equation holds with equality. When $s=0$, the household is liquidity constrained, and this equation holds with a strict inequality.

Households decide whether to comply with the property tax by comparing indirect utilities from paying and being delinquent. Denoting the mean indirect utility of payment decision $j$ by $V^{j}$, the overall utility for household $i$ is then $V_{i}=\max \left\{V^{\text {Pay }}, V^{\text {Delinquent }}+\varepsilon_{i}\right\}$. Finally, let $V$ denote the population expectation over $V_{i}$.

Let $N^{\text {Pay }}=\operatorname{Pr}\left(V^{\text {Pay }}>V^{\text {Delinquent }}+\varepsilon_{i}\right)$ be the fraction of households that pay the tax. Following Busso et al. (2013), we note that $\frac{d V}{d V^{j}}=N^{j}$. This expression shows that because households have already optimized over being delinquent or paying, the overall effect on welfare from marginal changes to mean utilities does not depend on changes in delinquency status (i.e, $\left.\frac{d N^{\text {Pay }}}{d V^{\text {Pay }}}\right)$.

Consider now the effects of taxes on mean utilities:

$$
\frac{\partial V^{\text {Delinquent }}}{\partial t}=0 \text { and } \frac{\partial V^{\text {Pay }}}{\partial t}=-u^{\prime}\left(c_{s}^{\text {Pay }}\right) H
$$

By the first expression, tax increases do not impact the mean utility of being delinquent. While the second equation applies both when $s=0$ and when $s>0$, the interpretation differs across these cases. When $s>0$, the envelope theorem holds, and households readjust their savings, but the welfare effect of this readjustment cancels out. When $s=0$, there is no such readjustment, as households are constrained from consuming from their future wealth. Because marginal utility is higher when $s=0$, the welfare cost of raising taxes is also higher in this case.

Consider now the effects of increasing enforcement by raising $\alpha$ :

$$
\frac{\partial V^{\text {Delinquent }}}{\partial \alpha}=-m^{\prime}(\alpha) \text { and } \frac{\partial V^{\text {Pay }}}{\partial \alpha}=0
$$

The last expression shows that tax-paying households are not directly affected by changes in enforcement. In contrast, delinquent households experience a drop in their mean utility as the private cost of not paying taxes increases with enforcement.

A welfare-maximizing social planner would incorporate the private costs of non-compliant households when evaluating the welfare effects of different policies. However, as in Hebous and Keen (2021), it is possible deviate from the principle of horizontal equity and allow for the possibility that the welfare costs of non-compliant taxpayers may be less valued by society than other costs of property taxes. To incorporate this "fairness perspective," we multiply the term $\frac{\partial V^{\text {Delinquent }}}{\partial \alpha}$ by $\omega \leq 1$, which potentially down-weights this welfare cost.

Finally, the government uses tax revenue to provide public goods $g$ and enforcement $\alpha$ at a cost 
$a(\alpha)$. Its budget constraint is:

$$
g+a(\alpha)=t H N^{\text {Pay }}+z H\left(1-N^{\text {Pay }}\right)
$$

where $z$ represents the back-taxes that the government will eventually collect from delinquent taxpayers. While the effects of policy changes on welfare do not depend on changes in the decision to pay or be delinquent, the effects of $t$ and $\alpha$ on $N^{\text {Pay }}$ are crucial drivers of tax revenue.

\subsection{Optimal Property Tax}

The government maximizes $V$ subject to its budget constraint. To simplify exposition, we consider the case where income can take two values, one where households are liquidity constrained, $s=0$, and one with positive saving, $s>0$. Substituting the government's constraint for $g$, a tax increase has the following impact on welfare:

$$
-N^{\text {Pay }} H\left[\pi_{s}^{\text {Pay }} u^{\prime}\left(c_{s}^{\text {Pay }}\right)+\pi_{0}^{\text {Pay }} u^{\prime}\left(c_{0}^{\text {Pay }}\right)\right]+v^{\prime}(g) \times\left\{H N^{\text {Pay }}+(t-z) H \frac{\partial N^{\text {Pay }}}{\partial t}\right\},
$$

where $\pi_{s}^{\text {Pay }}$ denotes the share of households who pay taxes with $s=0$ and $s>0$. We simplify this expression by rearranging, defining the tax elasticity of compliance $\varepsilon_{t}^{\text {Pay }}=\frac{\partial N^{\text {Pay }}}{\partial t} \frac{t}{N^{\text {Pay }}}<0$ and approximating the marginal utility of consumption (e.g., as in Chetty, 2006) to obtain:

$$
\operatorname{MVPF} F_{t}=\underbrace{\frac{v^{\prime}(g)}{u^{\prime}(c)}}_{\text {Value of Public Goods }}-\underbrace{\frac{1-\gamma\left(\pi_{0, c}^{\text {Pay }} \Delta c_{0}^{\text {Pay }}+\pi_{s, c}^{\text {Pay }} \Delta c_{s}^{\text {Pay }}\right)}{1+(1-\tilde{z}) \varepsilon_{t}^{\text {Pay }}}}_{\text {Welfare Cost Per Dollar of Revenue }},
$$

where $\gamma=\frac{-u^{\prime \prime}(c) c}{u^{\prime}(c)}$ is the coefficient of relative risk aversion, $\tilde{z} \leq 1$ is the fraction of back-taxes collected in the future, and $\Delta c$ measures the decrease in consumption in response to the property tax increase. ${ }^{16}$

Equation 1 shows that the marginal value of public funds (MVPF) (e.g., Atkinson and Stern, 1974; Slemrod and Yitzhaki, 2001; Hendren, 2016) from raising taxes depends on the value of public goods and the distortions associated with raising revenue. The first term measures the welfare gain of using $\$ 1$ of consumption $c$ to increase the provision of the public good $g$. The second term measures the welfare cost per dollar of revenue. ${ }^{17}$ Absent liquidity constraints, this terms takes the familiar inverse-elasticity form $\frac{1}{1+(1-\tilde{z}) \varepsilon_{t}^{\text {Pay }}}$. The costs of raising tax revenue are larger when taxpayers are less likely to comply with a tax increase (large $\varepsilon_{t}^{\text {Pay }}$ in absolute value) and when the

\footnotetext{
${ }^{16}$ Note that Equation 1 depends on $\pi_{s, c}^{\text {Pay }}$, which represents the share of consumption by households that pay taxes with a given value of $s$. See Appendix A for details.

${ }^{17}$ Equation 1 captures the welfare effect of a budget-balance policy that raises tax revenue to provide public goods. As Hendren and Sprung-Keyser (2020) shows, it can also be valuable to consider the MVPF of policies without taking into account a balanced budget. The MVPF of raising tax revenue through tax hikes is captured in Equation 1 by the welfare cost per dollar of revenue.
} 
government is less able to collect back-taxes in future periods (low value of $\tilde{z}$ ). Since the property tax is a tax on a stock rather than on a flow of income or consumption, the welfare cost per dollar also includes the factor $(1-\gamma \Delta c)$, which incorporates interactions with liquidity constraints. The coefficient $\gamma \geq 0$ captures how costly consumption changes are for taxpayers. The welfare cost of property taxation increases when tax rate increases lead to larger drops in consumption (more negative $\Delta c$ ). A positive $M V P F_{t}$ implies that the welfare gains from increasing the provision of public goods exceed the welfare cost of raising tax rates.

We obtain an expression for the optimal property tax by setting $M V P F_{t}=0$. Writing $\Delta c_{s}^{\text {Pay }}=$ $-\eta_{t, s}^{c} t$, where $\eta_{t, s}^{c}>0$ is the tax semi-elasticity of consumption, the optimal tax rate is:

$$
t=\frac{\left(1+(1-\tilde{z}) \varepsilon_{t}^{\mathrm{Pay}}\right) \frac{v^{\prime}(g)}{u^{\prime}(c)}-1}{\gamma\left(\pi_{s, c}^{\mathrm{Pay}} \eta_{t, s}^{c}+\pi_{0, s}^{\mathrm{Pay}} \eta_{t, 0}^{c}\right)}
$$

The optimal tax is larger when public goods are more valuable (a larger value of $\left.\frac{v^{\prime}(g)}{u^{\prime}(c)}\right)$ and when taxes have a smaller effect on delinquency $\left(\varepsilon_{t}^{\text {Pay }}\right.$ is close to zero). Similarly, because the consumption response is likely to be greater for liquidity-constrained households (i.e., $\eta_{t, 0}^{c}>\eta_{t, s}^{c}$ ), the government can set higher property taxes when the fraction of liquidity-constrained households is smaller.

\subsection{Optimal Enforcement}

Consider now the government's choice to expend resources on enforcement. Increasing $\alpha$ has the following effect on welfare:

$$
-\left(1-N^{\text {Pay }}\right) \omega m^{\prime}(\alpha)+v^{\prime}(g) \times\left\{(t-z) H \frac{\partial N^{\text {Pay }}}{\partial \alpha}-a^{\prime}(\alpha)\right\} .
$$

In contrast to the effect of changing tax rates, the welfare effects of changes in $\alpha$ do not depend on consumption changes. ${ }^{18}$

In our setting, enforcement can be interpreted in terms of the money spent on mailing enforcement letters, so we assume that $a(\alpha)=\alpha$, where $\alpha$ is money spent on enforcement. Defining the enforcement elasticity of compliance $\varepsilon_{\alpha}^{\text {Pay }}=\frac{\partial N^{\text {Pay }}}{\partial \alpha} \frac{\alpha}{N^{\text {Pay }}}>0$, the MVPF from enforcement is then:

$$
M V P F_{\alpha}=\frac{v^{\prime}(g)}{\omega m^{\prime}(\alpha)}-\frac{1-N^{\mathrm{Pay}}}{(1-\tilde{z}) N^{\mathrm{Pay}} \frac{\varepsilon_{\alpha}^{\mathrm{Pay}} H t}{\alpha}-1}
$$

The first term in this expression is the value of public goods relative to the welfare cost of enforcement. This value is higher when the welfare costs of enforcement $m^{\prime}(\alpha)$ are low or when these costs are not valued by society (low $\omega)$. The second term is the welfare cost of raising revenue from a

\footnotetext{
${ }^{18}$ To see this, note that the welfare costs of enforcement are borne by non-compliant households, whose consumption is not affected by taxes. While some households become compliant in response to the enforcement, the welfare effect of this change is second order since these households were indifferent between delinquency and paying taxes.
} 
$1-N^{\text {Pay }}$ fraction of households. The term $(1-\tilde{z}) \frac{\varepsilon_{\alpha}^{\text {Pay }} H t}{\alpha}$ captures the revenue gains from enforcement net of the public cost of enforcement, $\alpha$, and the reduction in future back taxes, $\tilde{z}$. ${ }^{19}$ We can use Equation 3 to evaluate whether an enforcement action improved welfare, i.e., whether $M V P F_{\alpha}>0$.

Importantly, while the welfare costs of enforcement $m^{\prime}(\alpha)$ is unobserved, we can infer it using tax rate and enforcement elasticities. To do so, we consider a simultaneous change in taxes and enforcement that leaves compliance $N^{\text {Pay }}$ unchanged. ${ }^{20}$ This implies that we can write:

$$
m^{\prime}(\alpha)=u^{\prime}(c) \times \frac{\varepsilon_{\alpha}^{\text {Pay }}(H t / \alpha)}{-\varepsilon_{t}^{\text {Pay }}}
$$

Intuitively, the marginal welfare loss from enforcement is equal to the utility cost associated with a tax rate increase that induces the taxpayer to pay as much more tax as the enforcement intervention. For this reason, the marginal welfare loss from enforcement is greater when taxes are more likely to distort compliance behavior (i.e., when $\varepsilon_{t}^{\text {Pay }}$ is more negative). ${ }^{21}$

\subsection{Relative Value of Enforcement and Liquidity Constraints}

To evaluate whether the government should rely on tax hikes or enhanced enforcement to raise revenue, we need to consider a scenario in which both policies have similar effects on tax revenue. Suppose then that the government increased taxes and reduced enforcement to keep spending $g$ constant. In Appendix A.3, we show that such a reform would improve welfare if:

$$
M V P F_{t}-M V P F_{\alpha} \times \omega \frac{m^{\prime}(\alpha)}{u^{\prime}(c)}>0
$$

Using Equations 3 and 4 implies that:

$$
M V P F_{\alpha} \times \omega \frac{m^{\prime}(\alpha)}{u^{\prime}(c)}=\frac{v^{\prime}(g)}{u^{\prime}(c)}-\frac{\omega\left(1-N^{\text {Pay }}\right)}{(1-\tilde{z}) N^{\text {Pay }} \varepsilon_{\alpha}^{\text {Pay }}(H t / \alpha)-1} \times \frac{\varepsilon_{\alpha}^{\text {Pay }}(H t / \alpha)}{-\varepsilon_{t}^{\text {Pay }}} .
$$

As with $M V P F_{t}$, the first term in this expression measures the welfare gain of using $\$ 1$ of consumption $c$ to increase the provision of the public good $g$. The second term measures the welfare cost of tax payments, which, except for $\omega$, is a function of empirical quantities.

Substituting Equations 1 and 6 into Equation 5 shows that the welfare effects of this balancedbudget reform only depends on the welfare costs of raising revenue and does not depend on the

\footnotetext{
${ }^{19}$ Our model assumes that changes in $\alpha$ do not impact $\tilde{z}$. This assumption is supported by Figure C.2, which shows that the share of back-taxes eventually collected by the government is stable over time. Moreover, to the extent that enforcement collects "low-hanging fruit" (such that $\tilde{z}$ on the remaining tax debt is smaller), this assumption errs on the side of making enforcement look more effective. We do not study the effects of policies that directly change $\tilde{z}$ (such as increasing property seizures) since we do not observe such policy variation in the data.

${ }^{20}$ This strategy is similar to that of Bertrand et al. (2010). Allcott and Taubinsky (2015) label this approach the equivalent price metric. See Appendix A.2 for details.

${ }^{21}$ Since enforcement has both private and administrative costs, perfect compliance may not be an optimal outcome for the government. In Appendix A.4, we also characterize the level of enforcement that maximizes social welfare.
} 
value of public goods. Importantly, because $M V P F_{t}$ depends on consumption changes but $M V P F_{\alpha}$ does not, the relative value of taxation over enforcement depends on the degree to which liquidity constraints increase the welfare costs of taxation. By providing liquidity, the government can reduce the fraction of liquidity-constrained taxpayers, which increases $M V P F_{t}$ as well as the relative value of taxation over enforcement.

\subsection{Limitations and Extensions}

Our model simplifies the analysis to focus on the main forces in our empirical setting. We now discuss possible limitations and extensions to our conceptual framework.

1. Uncertainty. Our model assumes a discrete distribution for income shocks. Allowing for a range of possible incomes would not alter the main results. In this case, the average consumption drop across the range of possible incomes would measure the welfare costs from taxation.

2. Dynamics. Our model can also be extended to allow for multiple time periods, and the importance of liquidity constraints carries over to dynamic models with uncertain income. ${ }^{22}$ Moreover, as in other sufficient statistic models (e.g., Chetty and Finkelstein, 2013), consumption changes are robust welfare measures in the presence of dynamic considerations.

3. Consumption commitments and housing choice. We assume housing consumption is initially fixed. Chetty (2004) shows that, when homeowners do not re-optimize their housing choice, the local value of $\gamma$ is larger, such that consumption commitments exacerbate the welfare costs of property-tax-driven consumption drops. Following Chetty (2004), our empirical implementation considers a range of values for $\gamma$, including larger values that account for these forces. ${ }^{23}$

4. Housing market effects. Our model abstracts away from the effects of taxes on the supply of housing or on property values. While property taxes can impact the supply of housing, these effects are likely to be small in our setting. In Appendix F, we show that the complexity of the property tax system implies that increasing the property tax rate does not impact the supply of housing. Moreover, because property taxes are based on outdated cadastral values, the government's budget constraint is not affected by policy-driven changes in market values.

A potential concern is that tax and spending policies can be capitalized into property values and that this will affect inter-temporal consumption decisions. Brueckner (1982) models the capitalization of local taxes and public goods into property values. A key result in this literature is that at the efficient level of provision, increasing local public spending through property taxes leaves the value of housing unaffected. Our assumption of no capitalization effects is therefore correct

\footnotetext{
${ }^{22}$ For example, Deaton (1991) shows that even in periods when households are not constrained, precautionary savings produce behavior similar to that under liquidity constraints. This shows that interactions between property taxes and liquidity constraints continue to be important in dynamic settings.

${ }^{23}$ While the model could endogenize the decision to adjust housing, the ranges of property tax changes that we consider are unlikely to trigger such decisions from homeowners, who represent the vast majority of households.
} 
when $\mathrm{MVPF}_{t}=0$ (e.g., as in Equation 2). ${ }^{24}$ When public goods are under-provided, increasing public good provision by taxing property would increase property values. ${ }^{25}$ Capitalization would increase the wealth of property owners. Unconstrained households would then reduce savings, which would be reflected by a smaller consumption drop in our data. Constrained households would not change their consumption today but would have higher consumption in the future. Ignoring this positive impact on consumption would then lead us to overestimate the welfare cost of taxation. Our assumption of no capitalization effects therefore biases us against finding that $\mathrm{MVPF}_{t}>0$.

5. Location decisions and tax competition. Unlike other models of property taxation (e.g., Agrawal et al., 2020), we do not consider migration or tax competition. These concerns are less important in developing countries where internal migration is generally lower (Bell et al. 2015) and in our specific setting because Mexico City offers unique amenities, which makes the possibility of tax-driven migration less relevant. Moreover, Brueckner (1982) shows that migration decisions are neutral to property tax changes in equilibrium.

6. Redistribution. We assume that the tax rate applies to properties of similar values. This assumption matches our setting, as the government relies on a partially progressive tax schedule with different tax rates for different value bands. If households responded to progressive property taxes by moving to properties of lesser value, our model could be extended by accounting for the resulting fiscal externality. However, as discussed above, we do not believe that this is the primary margin of adjustment in the context of developing countries. Future work can extend our model to consider whether a progressive property tax could be used to redistribute wealth.

7. Enforcement as reminders. It is possible that enforcement raises taxpayers' welfare by acting as a reminder, prompting them to take an action which they were planning to implement (see, e.g., Allcott and Kessler, 2019). This is unlikely to be the case in our setting, as taxpayers who do not pay in full at the beginning of the year receive six additional bimonthly tax bills, which also remind them of their outstanding liabilities. Our data on payment timing show that, while compliant taxpayers' payments are closely linked to the bimonthly deadlines associated with these reminders, we do not observe that these bills have a reminder effect for delinquent taxpayers (see Figure B.5). It is therefore unlikely that our additional enforcement message acts as a reminder.

8. Enforcement and non-pecuniary spillovers. A possibility that is absent in our model is that enforcement actions can have spillovers on the compliance of delinquent households that are not subject to enforcement. While such spillover effects may increase the revenue effects of enforcement actions, they would also carry welfare costs by increasing the private costs of not paying taxes.

Finally, our model does not allow for the rate of noncompliance to impact the utility of taxpayers.

\footnotetext{
${ }^{24}$ Because enforcement actions are directed at delinquent individuals, rather than at the market as a whole, Equations 3-A.1 are unlikely to be affected by capitalization effects.

${ }^{25}$ Bradbury et al. (2001) and Cellini et al. (2010) provide evidence that tax-financed increases in public good provision have positive effects on property values in the US. Gadenne (2017) finds that tax-financed public spending has significant impacts on the quality of public goods in Brazil. Gonzalez-Navarro and Quintana-Domeque (2016) show that randomly assigned street pavement increased property values in Mexico City. We ignore the case when public goods are over-provided, since property taxes reduce welfare when $\mathrm{MVPF}_{t}<0$ regardless of capitalization.
} 
Besley et al. (2019) develop a model with such non-pecuniary spillovers to study the introduction of a poll tax in the UK that increased evasion by 300-500 percent. While we show that tax hikes increase noncompliance, our effects are orders of magnitude smaller than those of the poll tax. These motives are therefore unlikely to play a central role in our context.

The model delivers expressions for the welfare effects of tax and enforcement policies and iden-

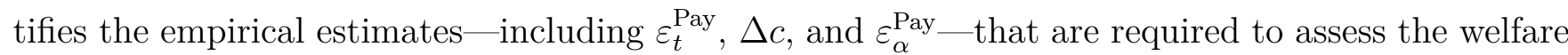
effects of these policies. The following sections describe how we estimate these parameters and Section 7 uses these estimates to provide actionable policy guidance.

\section{Property Taxes in Mexico City}

This section presents the property tax system in Mexico City. ${ }^{26}$ We start by explaining the construction of the tax base and the tax rate schedule. We then discuss the main elements of the tax payment regulation and enforcement. ${ }^{27}$

\subsection{Tax Base}

The base for the property tax is the cadastral value $V_{i t}$ of property $i$ in year $t$, which is determined by the following formula:

$$
V_{i t}=\left(A_{i t} L_{i t}+U_{i t} M_{i t}\right)\left[1-D_{t} \cdot\left(\mathbb{1}_{\left\{t-t_{0} \leq 40\right\}}\left(t-t_{0}\right)+\mathbb{1}_{\left\{t-t_{0}>40\right\}} 40\right)\right]
$$

where $A_{i t}$ is the unit value of land in the neighborhood of property $i, L_{i t}$ is the total land area of the property in square meters, $U_{i t}$ is the unit value of construction in the neighborhood of property $i, M_{i t}$ is the total construction area of the property, $D_{t}$ is a reduction applied per each year of antiquity, and $t_{0}$ is the year of construction of the property. That is, the tax base is the sum of the land and construction value, discounted for antiquity until the property is forty years old,

\footnotetext{
${ }^{26}$ We abstract away from political economy issues for a couple of reasons. First, Mexico City has had leftist governments since 1997. Because these governments have relied on political support from lower-income individuals, it is unlikely that pressure from wealthy individuals limits property taxation. Second, current government officials have expressed a desire to increase tax revenue specifically through property taxation. However, these officials are also sensitive to declining compliance rates and potential hardship for taxpayers. Given that political economy constraints are unlikely to explain the under-reliance on property taxes, we focus our analysis on the importance of compliance and liquidity constraints.

${ }^{27}$ While housing property is also taxed indirectly, these taxes do not interact with our variation. Property buyers pay a 2 percent transfer tax, income from property sales is subject to capital gains tax at a rate between 2 and 35 percent, and inheritances above 10,000,000 MXN (400,000 USD) are taxed at a rate between 10 and 30 percent. In contrast to those in the US, property taxes in Mexico do not determine neighborhood-level public goods.
} 
whereupon the property value remains constant in age. ${ }^{28}$ Assessed property values in the cadaster correlate strongly with commercial values (Figure B.1, Panel B).

The distribution of property values is quite stable during the period of our study. The unit values of land and construction, $A_{i t}$ and $U_{i t}$, are based on commercial values and were updated only once during the period of our study (between 2008 and 2009). This change does not affect our estimations, which exploit variation between 2009 and 2012. In theory, taxpayers can appeal the cadastral valuation proposed by the government and propose their own valuation. In practice, less than 0.2 percent of appeals are approved. ${ }^{29}$ Finally, the age discount makes it possible for properties to change cadastral value bands over time. However, because the discount factor is so small $\left(D_{t}=0.01\right)$, very few properties drop to a lower cadastral value band during the five-year period that we study. We exclude properties with a change in cadastral value band between 2009 and 2012 from our analyses. ${ }^{30}$

\subsection{Tax Rates}

Figure 2 shows that the property tax schedule is partly progressive. The schedule relies on 16 cadastral value bands: A to $\mathrm{P} .{ }^{31}$ For bands $\mathrm{A}-\mathrm{D}$, the tax is a band-specific lump-sum amount that increases over time with inflation. While the lump-sum amounts increase across bands A-D, they increase by less than the property value. For this reason, the average tax rate is decreasing in property values at the lower end of the value distribution. Properties in bands E-P face a progressive schedule, with marginal tax rates ranging from 7.5-16.9 basis points (a percent of a percent), which yield average tax rates that increase with property values. Using household survey data, we calculate that on average, property tax payments correspond to between 0.5 and 1 percent of annual household income, with higher values for poorer households (see Figure B.1, Panel C). ${ }^{32}$

\footnotetext{
${ }^{28}$ The registry of property transactions and the cadaster are held by two different levels of government (states and municipalities, respectively) and are not readily mergeable. For this reason, property transactions cannot be used to update cadastral values. While the tax base may depart from market values, note that this is also often the case in high-income countries as well. For instance, California's Proposition 13 generates large differences between assessed and market values. Similarly, Howard and Avenancio-Leon (2019) show that racial differences in assessment appeals drive large differences between assessments and market values across demographic groups.

${ }^{29}$ In 2010, 319,019 taxpayers filed appeals, but only 379 successfully obtained a reduction in their tax base. In 2011, 249 out of 177,681 taxpayer appeals were successful. In 2012, 162 out of 116,729 appeals were successful.

${ }^{30}$ In total, we exclude 284,686 properties, 87 percent of which registered a cadastral value band change due to an increase in the construction area, for an average cadastral value change of 42 percent. Changes in land area, special amenities (e.g., lifts), and value depreciation over time account for the remaining 13 percent of value-band changes. Our results are robust to including these properties. In addition, exemptions of 30 percent or more of the annual tax liability are available to single mothers with children and seniors with incomes below a specified threshold. Our results are robust to dropping the approximately 7 percent of properties that ever received these exemption (Tables D.4 and E.3).

${ }^{31}$ The thresholds for these bands are constant over time, except between 2008 and 2009, when both the band thresholds and the tax rates were updated for inflation. In later years, only the tax rates are updated for inflation each year. Table B.2 shows the property tax schedule for 2009 as an example.

${ }^{32}$ Panel D in Figure B.1 shows the year-on-year growth rate of property tax payments. Given the small annual inflation adjustments to the liability, there is no anchoring of tax payments at the previous year's liability. Instead, the nominal payment amounts increase slightly each year.
} 
While marginal tax rates change little over the years, the average tax rates in bands E-J are also affected by abatements, which are applied to the gross tax liability. Abatements vary over time and have large impacts on average tax rates: abatements vary between 65 percent (in band E) to 10 percent (in band J). The original purpose of abatements was to ensure that the mean tax liability increased gradually from band E to J. Following the 2008 financial crisis, the government decided to remove the abatements one cadastral value band at a time. ${ }^{33}$

The removal of abatements led to large and unexpected changes in mean tax rates over time and across value bands. Because our data cover the years 2008-2012, our analysis exploits three reform episodes: (1) the 2010 abatement removal for value band I, (2) the 2011 removal for band H, and (3) the 2012 removal for band G. Figure 2 shows that the largest rate changes between 2008 and 2012 were caused by removing these abatements. Among the three reform episodes, properties in band $\mathrm{G}$ saw the largest increase in taxes, and those in band I saw the smallest increase.

The government of Mexico City announced these rate increases every year when it published property tax rates for the following year. It is unlikely that the changes were anticipated by taxpayers, as they were not widely discussed in the media and each reform episode affected only a small subset of properties. We show below that there is no evidence for any behavioral change prior to the reforms. Figure B.4 shows that properties treated with the quasi-exogenous tax rate increases are well distributed across the city. The average share of treated properties within a zipcode is only about 3 percent. The responses to these reforms therefore constitute individual taxpayer responses to tax rate changes rather than responses driven by public debate or general equilibrium changes in policy, attitudes, or perceptions.

\subsection{Tax Payment and Enforcement}

The legal liability for the property tax rests with the property owner. Property tax bills are delivered to the property and are addressed to the owner. At the beginning of the calendar year, taxpayers receive a bill for the yearly liability. To encourage early payment and increase compliance, the government offers early-bird and super-early-bird discounts if taxpayers pay their yearly liability in full before specific dates. The exact deadlines for the discounts and the discount rates vary over time (see Table B.4). While tax bills include the yearly tax liability, they can be paid in six bi-monthly installments. Taxpayers are sent additional bills at the beginning of each bi-monthly period with a reminder that payments are due by the last day of the period. Property tax bills can be paid in

\footnotetext{
${ }^{33}$ Table B.3 lists the abatement rates by value band and year. The government's intention was to remove all abatements but to do so gradually to minimize potential backlash or unrest. Our data do not cover the periods surrounding the abatement removals for bands J, E, and F. Properties in bands A-D never benefited from abatements since their tax liabilities are lump-sum amounts. Removing abatements was the administratively simplest way of raising tax rates. Figure B.1, Panel A, shows that property tax revenues dramatically increased after 2008 in Mexico City.
} 
person at government offices, banks, and convenience stores. ${ }^{34}$

When taxpayers miss a payment, the government automatically updates the unpaid liabilities for monthly inflation and applies a surcharge for every month that a payment is late. Taxpayers who have not paid their yearly liability by April 30th of the following year are catalogued as delinquent taxpayers and face additional penalties and surcharges. ${ }^{35}$

The Ministry of Finance of Mexico City regularly conducts enforcement campaigns to encourage the payment of outstanding property tax debt and to sustain voluntary compliance. Enforcement interventions have varied over time. For instance, enforcement letters have varied in message content over the years (e.g., emphasizing sanctions or public goods provision or simply conveying a reminder). The delivery method for these messages (e.g., letter, phone call, or email) has also varied over time, as has the target group. In some years, all delinquent taxpayers were contacted, while in other years, enforcement has focused on smaller subsets of taxpayers with large debts. We use one of these enforcement interventions to estimate the effects of enforcement in Section 5.

While taxpayers who are unresponsive to administrative enforcement can be prosecuted, the government does not have the capacity to do this in a systematic way. In extreme cases, the government can seize a delinquent taxpayer's property. While this is rare, it does happen (see Table C.1, Panel C). The government can even pursue a jail sentence of up to ten years for tax delinquency.

\section{Administrative Tax Data}

Our empirical analyses exploit three datasets on the universe of tax-liable residential properties in Mexico City from 2008 to 2012. First, the cadaster - or tax register - lists all properties with their unique property tax ID, post code, and property characteristics such as land area, construction area, land and construction value, and total property value.

Second, we use data from annual and bi-monthly property tax bills for all properties. These bills include the property value, tax liability, bill issue date, and due date. Third, we use data from the universe of property tax payments. For each payment, we have data on the relevant tax bill and period, amount, date, and additional variables including inflation adjustments, surcharges, and penalties for late payment. We link the billing and payment data to the cadaster via the unique ID. Our main dataset consists of a balanced panel of 1.42 million properties.

\footnotetext{
${ }^{34}$ Figure B.3 shows a typical property tax bill. While the owner may not receive the tax bill if renters do not notify owners or if the cadaster is out of date, this is a minor concern for enforcement in Mexico City, where renters account for only 15 percent of households. Table B.5 shows descriptive statistics on property owners and renters. While it is possible (though not observable to us) that property tax compliance is lower for rented properties, this can explain only part of the delinquency rate, which is much higher (40 percent) than the rental rate.

${ }^{35}$ While the monthly surcharge varies over time, it is on average 1 percent of the outstanding liability for each month of delay. That is, if a taxpayer makes an overdue payment after 6 months, the government adds a 6 percent surcharge to the inflation-updated liability. Table C.1, Panel C, shows the additional fees paid by delinquent taxpayers who made outstanding tax payments in 2008 and 2009. The table shows that late payment fines are applied to almost all late-payers and that the fines represent a substantial fraction - between 15 and 30 percent - of the tax liability.
} 
The majority of our analyses study outcomes at the property-year level. The main outcome variables are the annual payment amount in current Mexican pesos (MXN, thousand) and the compliance share, defined as the ratio of tax payment to gross liability. Additional outcomes include dummies for zero, partial, and full payment of the net tax liability (net of any early-bird and super-early-bird discounts). Finally, we characterize payment timing with dummies indicating early (all-at-once), bi-monthly (payment in installments), and late payment.

A salient feature of the data is that the distribution of properties is skewed toward low value bands. While the majority of properties fall into bands $\mathrm{A}-\mathrm{E}$, the distribution of cadastral values is slightly less skewed. Because of the progressive tax schedule, tax liabilities are more evenly distributed across value bands. However, because compliance is higher for low value bands, the distribution of tax payments is less evenly distributed (see Figure C.1 for details).

The data reveal interesting trends. While the gradual eliminations of abatements led to a rise in the mean tax liability, average tax payments - in absolute terms and as a share of the yearly liability - have decreased over time. The decrease in tax payments is partly driven by a rise in the share of properties making zero payments and a decline in the share of properties paying in full. These patterns showcase the importance of understanding how households respond to tax rate increases and whether enforcement efforts can influence the decaying compliance rate. ${ }^{36}$

\section{The Elasticity of Tax Revenues to the Tax Rate}

This section estimates the effects of tax rate changes on tax payment and compliance. We study three quasi-experimental reforms: the mean tax increases for properties in value bands I, H, and G in 2010, 2011, and 2012, respectively. We first present results from an RD estimation that exploits the sharp discontinuities in tax rate changes at thresholds between the treated value bands and bands below them. This approach yields estimates of short-term local average treatment effects for properties close to each threshold. We then estimate medium-term effects with a DiD design that uses properties in never-treated value bands as controls.

\subsection{Short-Term Effects: Regression Discontinuity Estimation}

Our RD estimation relies on discontinuous tax rate changes at the lower thresholds of cadastral value bands that experienced large tax rate increases. We focus on rate changes - rather than levelssince tax rate levels differ between value bands and there are small yearly inflation adjustments to rates in all bands. Finally, we use the band below as the counterfactual since properties in the band above the treated band were treated in the previous year.

Consider the properties in a treated band in year $t$ as well as the properties in the band im-

\footnotetext{
${ }^{36}$ Table C.1 describes additional property characteristics. For instance, the average property was built in 1985 and has a land area of 123 square meters and a construction area of 126 square meters.
} 
mediately below it. Let $\hat{V}_{i}=V_{i}-V_{-}$denote the distance between the value of property $i, V_{i}$, and the lower limit of the treated band, $V_{-}$. Let $Y_{i, t}$ denote the outcome of interest for property $i$ in period $t$. We estimate the effect of the tax rate increase on the year-on-year change in the outcome of interest as follows:

$$
\Delta Y_{i, t}=\alpha+\beta T_{i}+f\left(\hat{V}_{i}\right)+g\left(\hat{V}_{i}\right) T_{i}+\epsilon_{i, t}
$$

where $T_{i}$ is an indicator for properties in the treated band, i.e., $T_{i}=\mathbb{1}_{\left\{V_{i} \geq V_{-}\right\}}, f$ and $g$ are continuous functions, and $\epsilon_{i, t}$ is an error term.

The validity of this approach relies on the assumption that taxpayers cannot manipulate their property valuation in response to a change in the tax rate. To validate this assumption, we test for a discontinuity in the distribution of the running variable around the treatment cut-off. We are unable to reject the null hypothesis of no manipulation of property values around the treatment cut-off for all three reforms using either the McCrary (2008) test (see Figure D.1, Column (A)) or the Bugni and Canay (2020) test (see Table D.1). ${ }^{37}$ In addition, we test for discontinuities in property characteristics around the treatment thresholds and find no significant differences in the year of construction, land area, or construction area (see Figure D.1, Columns B-D). Finally, we note that in the unlikely case that taxpayers anticipated the tax rate increase and responded before the change went into effect, our estimates of the tax payment increase would be biased towards zero. We show below that there is no evidence for an anticipatory response.

\section{Estimates}

Figures 3 and 4 show the results for the three different reform episodes (rows) and four different outcomes (columns). Each panel plots the year-on-year (pre- vs post-reform) change for a given outcome in 20 equally spaced cadastral value bins around the lower threshold of the treated band. Each graph reports a third-order polynomial fit along with 95 percent confidence intervals.

Column (A) of Figure 3 shows that the legislated tax rate increases were indeed applied as intended and generated a 9.1 basis point increase in the mean tax rate at the band threshold in 2010 and even larger increases of 12.1 and 18.0 basis points in 2011 and 2012. Column (B) shows that tax payments jumped substantially - between 450 and $600 \mathrm{MXN}$ - in all reform episodes. However, payments increased by less than the mechanically expected increase, as compliance fell. ${ }^{38}$ Figure 4 shows that the share of taxpayers paying their liability in full fell by 5.5 ppt in 2010, by 6.4 ppt in 2011, and by over 10 ppt in 2012. The compliance share also decreased in all reform episodes by

\footnotetext{
${ }^{37}$ The Bugni and Canay (2020) test provides an alternative approach to testing for manipulation of cadastral values. This test examines the balance in the number of observations around the cut-off. Unlike the McCrary (2008) test, it does not rely on local density estimates.

${ }^{38}$ The tax liability for a property at the value band threshold of 2.3 million MXN increased by 2100 MXN in 2010 . Liabilities increased by close to $2350 \mathrm{MXN}$ in 2011 and $2900 \mathrm{MXN}$ in 2012.
} 


\section{$3.2-6.2$ ppt. $^{39}$}

Table 2, Panel A, presents the implied tax rate elasticities for the outcomes considered in Figures $3-4{ }^{40}$ Column (2) lists the elasticities of tax revenue to the tax rate. When the change in the mean tax rate is 9.1 basis points, the elasticity of tax revenues is 0.55 , whereas the estimate is 0.31 when the tax rate increases by 18.0 basis points. While these estimates are consistent with the notion that larger tax rate changes also generate larger compliance responses, we cannot reject the null that these elasticities are equal to each other at conventional significance levels. Table 2 also reports tax compliance elasticities, which we use in our policy analysis in Section 7.

To demonstrate the robustness of our results, we compare our main estimates from the cubic polynomial regression with the results from local polynomial regressions with varying bandwidths and degrees of polynomial in Figure D.2. Table D.2 shows the results from specifying an optimal bandwidth in local linear regressions as in Calonico, Cattaneo and Titiunik (2014). The estimates are statistically indistinguishable from those in Table 2.

As an additional robustness test, we consider an alternative specification for our RD estimates. Because we study the effects of discontinuous tax changes around thresholds, we follow Lalive (2008), Lemieux and Milligan (2008), and Grembi, Nannicini and Troiano (2016) by estimating a differences-in-discontinuities model on our panel data:

$$
\begin{aligned}
\Delta Y_{i, t}= & \alpha_{0}+\beta_{0} T_{i}+f_{0}\left(\hat{V}_{i}\right)+g_{0}\left(\hat{V}_{i}\right) T_{i}+, \\
& {\left[\alpha_{1}+\beta_{1} T_{i}+f_{1}\left(\hat{V}_{i}\right)+g_{1}\left(\hat{V}_{i}\right) T_{i}\right] D_{t}+\epsilon_{i, t}, }
\end{aligned}
$$

where $D_{t}$ is an indicator for the time period when the abatement is removed. The effect of the abatement removal, in excess of the effect of the smaller year-on-year tax rate changes, is given by $\beta_{1}$. The results displayed in Table D.3 show that the $\beta_{1}$ estimate from this equation is very similar to our main estimates, and we can generally reject the null hypothesis that $\beta_{1}=\beta_{0}$.

These results show that while sharp increases in average tax rates have sizable effects on tax payments, taxpayers also respond by decreasing their compliance with the property tax. While the RD approach yields precise and highly credible estimates of the short-term responses to the tax increases, compliance in future years may depend on broader responses by taxpayers. ${ }^{41}$

\subsection{Medium-Term Dynamics: Differences-in-Differences}

An important question for policymakers is whether the effects of tax rate increases persist over time or are temporary. For instance, while liquidity-constrained taxpayers may temporarily decrease

\footnotetext{
${ }^{39}$ Note that these compliance drops are not due to changes in the tax base, as the latter is not updated during the study period and appeals against the tax liability are overwhelmingly unsuccessful, as mentioned in Section 2.1. Because administrative tax data do not record whether properties are occupied by renters or owners, we cannot explore heterogeneity along this margin.

${ }^{40}$ We compute the elasticity $\epsilon_{y, t}=\frac{\partial y}{\partial t} \frac{t}{y}$ using $\frac{\partial y}{\partial t}$ from the RD estimates and $\frac{t}{y}$ from outcome means at baseline.

${ }^{41}$ Because the control bands are treated in $t+1$, we cannot use the RD approach to estimate dynamic responses.
} 
compliance after a tax rate increase, they may also make up for missed payments in later years. In this example, RD estimates would under-estimate the medium-term revenue elasticities.

We estimate medium-term effects using a DiD design that captures the evolution of compliance outcomes over time. This approach compares properties in the treated value band to properties in other high-value bands that never experienced a tax increase. Specifically, for a tax rate increase occurring in year $t_{0}$, we estimate:

$$
Y_{i t}=\alpha+D D_{i t} \beta+\gamma_{i}+\delta_{t}+\epsilon_{i t},
$$

where $Y_{i t}$ denotes the compliance outcome of property $i$ in year $t, \alpha$ is a constant, $D D_{i t}$ is a dummy taking the value of 1 when property $i$ belongs to the treated value band and $t \geq t_{0}, \delta_{t}$ and $\gamma_{i}$ denote year and property fixed effects, and $\epsilon_{i t}$ is the error term. For all years, we use properties in bands $\mathrm{K}$ and $\mathrm{L}$ as controls. ${ }^{42}$ The identifying assumption is that absent the tax hikes, the outcomes for properties in the treatment and control groups would have trended in parallel. Under this assumption, the point estimate for $\beta$ captures the causal effect of the tax rate change on compliance. Given the large share of zeros in our outcome variables, we estimate Equation 7 in levels. To obtain a relative effect, we scale the point estimates and standard errors by the mean outcome in the treatment group in the last pre-reform year. ${ }^{43}$

\section{Estimates}

Figures 5 and 6 capture dynamic responses to tax rate changes. The figures are structured like Figures 3 and 4: the rows pertain to the three different reform episodes, while the columns reflect the different outcome variables. In each graph, the vertical black line indicates the timing of treatment, the red solid line represents the average outcome in the treated band, and the blue dotted line represents the average outcome in control bands $\mathrm{K}$ and L. In all panels, outcomes are scaled by the pre-reform group-specific mean.

The timing of the reforms and the length of our dataset mean that we can observe three postreform periods for the 2010 reform, two post-periods for the 2011 reform, and one post-period for the 2012 reform. On the other hand, we observe the longest pre-reform period (four years) for the 2012 reform and the shortest (two years) for the 2010 reform. We detect no significant difference in pre-trends between the treatment and control groups for any reform episode and no evidence of an anticipated response to the reform. In contrast, we observe a precise and sharp deviation in trends in each of the reform years.

\footnotetext{
${ }^{42}$ Among the properties in bands that are never treated with one of the large quasi-experimental tax rate increases, those in bands $\mathrm{K}$ and $\mathrm{L}$ are the closest in value to the properties in the treated bands. Figures E.2-E.4 show that properties in other untreated bands also exhibit similar pre-reform trends and yield similar results.

${ }^{43}$ The results are very similar when we estimate Equation 7 via pseudo-Poisson maximum likelihood (Santos Silva and Tenreyro 2006), which is suitable when outcome variables are highly skewed or have a large share of zeros (Brockmeyer and Hernandez 2019).
} 
Consistent with the legislative changes, mean tax rates increased significantly after every reform event (Figure 5, Column (A)). As with the RD estimates, we find large increases in tax payments (Column (B)). However, decreases in the share of taxpayers paying in full and in the compliance share (Figure 6) show that compliance also fell significantly. The results are qualitatively similar across the three reform episodes, though the magnitude of the compliance drop is largest for the 2012 reform, which triggered the largest tax rate change. Following the 2012 reform, the full payment share fell by 30 percent, and the compliance share fell by 18 percent. For the 2010 reform, a 17 percent increase in the mean tax rate triggered a 11.6 percent increase in tax payment amounts. The payment response was moderated by a 4 percent reduction in the compliance share. In turn, the drop in the compliance share was partly driven by a 10 percent drop in the share of on-time payments-in-full.

One possible explanation for the smaller estimates for the 2010 and 2011 reforms is that these estimates capture effects over longer post-reform periods (two and three years, respectively), while the estimate of the 2012 tax change only captures the effect for a single post-reform period. However, we obtain similar compliance drops for the 2010 and 2011 tax changes when we estimate DiD effects using a single post-reform period (see Table E.1). These results raise the possibility that larger tax changes can trigger more-than-proportional compliance responses. ${ }^{44}$

Table 2, Panel B, summarizes the treatment effect estimates and the implied elasticities. The elasticity of tax revenues with respect to the tax rate is presented in Column (6). This elasticity ranges from 0.697 in response to the 17 percent increase in the tax rate affecting band $\mathrm{I}$ in 2010 to 0.489 in response to the 40 percent increase in the tax rate affecting band $\mathrm{G}$ in $2012 .{ }^{45}$ While these numbers are very similar to the RD estimates, the DiD estimates are more precisely estimated. Using panel regressions that exploit variation in tax rates across the full range of value bands - and not just for those treated in our quasi-experiments - yields similar results: an average payment elasticity of $0.69(\mathrm{SE}=0.09)$ and a compliance elasticity of -0.29 ( $\mathrm{SE}=0.10)$ (see Table E.5). These results suggest that our main estimates are broadly valid for property taxpayers in Mexico City.

The results of our DiD analysis show that tax rate increases lead to persistent changes in both tax payment and compliance behaviors. By using a different set of control properties than in the RD analysis, the DiD also bolsters the likelihood that we are measuring the causal effects of changes in tax rates. ${ }^{46}$

\footnotetext{
${ }^{44}$ We also find that the tax rate hikes increased taxpayers' likelihood of making an appeal against their tax liability (Figure E.1), even though hardly any appeals lead to a change in the tax liability (see footnote 29).

${ }^{45}$ In Appendix E, we perform robustness tests of our DiD estimations. We confirm that the results are very similar when we use other value bands as the control group (Table E.2 and Figures E.2-E.4), dropping taxpayers benefiting from exemptions (Table E.3) and clustering the standard errors at different levels or bootstrapping them (Table E.4).

${ }^{46} \mathrm{~A}$ potential concern is that tax rate increases might reduce investment in real estate. We discuss this possibility and test for it empirically in Appendix F. We find no evidence of impacts on real estate investment.
} 


\section{The Elasticity of Tax Revenues to Enforcement}

Governments around the world have two options when seeking to raise tax revenue: increasing tax rates on taxpayers who are not delinquent or increasing the number of taxpayers by enforcing existing taxes on delinquent taxpayers. In the context of Mexico City, this trade-off is stark since 40 percent of taxpayers are delinquent. We characterize it by estimating the elasticity of tax payment to enforcement using a field experiment that we designed and evaluated in collaboration with the Ministry of Finance of Mexico City.

\subsection{Field Experiment}

The Ministry of Finance sent out enforcement letters to 80,000 delinquent taxpayers between July 28 and August 11, 2014, requesting that they pay their outstanding tax debt accumulated from bimester 4 of 2009 to bimester 3 of 2014. A control group of 10,000 delinquent taxpayers received no letter. The comparison of taxpayers who received a letter to those who did not identifies the policy-relevant effect of enforcement efforts. ${ }^{47}$ The mode of delivery, sample selection, and information provided in the letters corresponds to the ministry's typical practices. Therefore, our estimates can be viewed roughly as in-equilibrium effects. Our estimates also have general validity, as the cadastral value distribution among delinquent taxpayers is similar to that of the population (Table G.1). Each personalized letter lists the bimester(s) for which the tax payment is overdue, requests payment within 15 working days after receipt of the letter, and lists the institutions accepting payment (tax administration offices, bank branches, convenience stores).

The treatment group in our intervention was divided into eight groups of 10,000 taxpayers, each receiving a slightly different variant of the letter. Figure G.1 illustrates the experimental design, and Figure G.3 shows the text of the letters. The motivation for testing various treatments was to identify the strongest possible enforcement message and hence maximize the potential for enforcement to be effective-both in terms of raising revenue and in terms of improving welfare. Half of the letters put additional emphasis on sanctions used to enforce the tax (referred to below as the sanctions treatment), while the other half emphasized the fact that property tax revenue is used to fund health services, education, and community infrastructure (referred to as the public goods treatment). Within these two main groups, half of the letters were signed by a compliance officer and the other half by a (more senior) fiscal attorney. In addition, the gender of the signatory was varied arbitrarily. Fiscal attorney signatures were either male or gender neutral (the first name was signed only as an initial), while compliance officer signatures were either female or gender neutral.

\footnotetext{
${ }^{47}$ In contrast, studies that examine enforcement design often compare status-quo enforcement messages to alternative designs (e.g., Atinyan and Asatryan, 2019).
} 


\subsection{Empirical Results}

Figure 7 displays the effects of the enforcement intervention. The plots show trends in payment outcomes around the time of the intervention and distinguish the control group, the sanctions treatment, and the public goods treatment. As expected, the three groups exhibit linear trends in all outcomes prior to the intervention. The treatment groups start diverging in early August when the first letters are delivered. ${ }^{48}$ The divergence accelerates sharply by mid-August. This timing coincides with the end of the 15-day deadline to respond to the letter starting after all the letters are delivered. In contrast, we do not see any trend changes for the control group.

The graphs display point estimates for $\beta_{1}$ and $\beta_{2}$ from the regression:

$$
Y_{i}=\alpha+\beta_{1} T 1_{i}+\beta_{2} T 2_{i}+\epsilon_{i}
$$

where $Y_{i}$ is the outcome for property $i$ evaluated 40 days after the sending of all letters, $\alpha$ is a constant, $T 1_{i}$ and $T 2_{i}$ are dummies indicating the two mutually exclusive treatments (the sanctions treatment and the public goods treatment), and $\epsilon_{i}$ is the error term.

The results in Figure 7 show that the sanctions treatment generated a 9.4 ppt increase in the likelihood of making a payment toward outstanding tax debt and a 54 peso increase in the payment amount. Relative to the control group, the intervention close to tripled the payment likelihood and doubled overall payments. The public goods treatment had smaller but statistically significant effects. Comparing Panels B (any payment) and C (payment amount) suggests that the public goods treatment is relatively more regressive, generating payment by taxpayers with disproportionately smaller liabilities. ${ }^{49}$ We find similar results when we control for property characteristics $X_{i}$ (e.g., cadastral value and age of the property) or when we estimate treatment effects using a DiD framework (Table G.2).

Table 3 reports estimates of the treatment effects for all treatments in pair-wise comparisons. Panel A lists the effects on the likelihood of making a payment toward outstanding tax debt, and Panel B shows the effects on the payment amount. In addition to confirming the significant difference between the sanctions and public goods treatments (Column (1)), the table shows that the seniority of the enforcement officer matters: a fiscal attorney signature achieves a larger impact than a compliance officer signature (Column (2)). Furthermore, although one might expect a gender bias in taxpayers' response to male/female signatures, our evidence rejects this idea. In fact, male signatures have a smaller impact than gender-neutral signatures, and female signatures have a slightly larger impact than gender-neutral signatures (Columns (3) and (4)). While we consistently reject the null hypothesis that male signatures have larger effects, we can reject the null hypothesis

\footnotetext{
${ }^{48}$ It takes three to five days for letters to be delivered.

${ }^{49}$ We interpret the public goods treatment effect as being due to enforcement, since we compare the public goods letter to a non-letter control and since any type of letter from the Ministry of Finance is likely to give the impression of increased enforcement. Studies comparing public goods messages to neutral baseline messages from tax administrations mostly find no effect (Atinyan and Asatryan 2019).
} 
that female signatures have smaller effects only when we control for property characteristics (Table G.2).

The size of the enforcement effects in Mexico City compares favorably to that of other compliance interventions. In a meta-analysis of tax compliance experiments, Atinyan and Asatryan (2019) find that deterrence nudges increase extensive-margin compliance on average by only 1.-2.5 percent. When focusing on comparable property tax compliance interventions, we find that our effects are slightly smaller than those in Weigel (2020), who shows that a door-to-door campaign in the Congo increased compliance (likelihood of payment) from 0.05 percent to 11 percent; similar to those in Okunogbe (2019), who finds that a detection and penalty intervention in Liberia increased compliance from 3 percent to 9 percent; and larger than those in Del Carpio (2014), who finds that a social norms intervention in Peru increased compliance from 29 percent to 34.5 percent.

The results of our field experiment show that enforcement actions are a cost-effective means of raising revenue for the government. However, while stricter enforcement may raise tax revenue, the welfare costs of enforcement due to the private costs it generates to delinquent taxpayers may exceed the revenue benefits. Section 7 uses our empirical estimates to implement our model and provides policy guidance on whether it is preferable to raise tax revenue through increased tax rates or through stricter enforcement.

\section{Property Taxes and Liquidity Constraints}

The model in Section 1 shows that the welfare costs of taxing property may be exacerbated by the presence of liquidity constraints. We now implement two empirical strategies that show that household liquidity constraints shape taxpayer behavior. We first show that property tax rates affect taxpayers' choice to pay late or in installments. We then show that tax increases lead to consumption drops for households without access to credit. ${ }^{50}$

\subsection{Evidence from the Choice of Payment Modality}

We examine how taxpayers' choice of payment modality responds to the tax rate. Taxpayers can pay their annual liability in installments or in full at the beginning of the year to take advantage of the early-bird discount. Liquidity constraints may lead households to pay in installments rather than all at once. By giving up the discount, these households effectively take out a loan from the government. Conditional on attempting to pay in installments, liquidity-constrained taxpayers may also be less likely to remain compliant.

We provide two pieces of evidence that taxes impact payment modality. First, we exploit variation generated by the non-monotonous shape of the tax rate schedule in a regression-kink-style

\footnotetext{
${ }^{50}$ Appendix I provides additional evidence that liquidity constraints shape taxpayer behavior by using daily payment data and variation in the deadlines for early-bird discounts to estimate a dynamic discrete choice model of payment timing. The estimated model shows that taxpayers place a very high value on liquidity.
} 
analysis. As discussed above, the mean tax rate as a share of the property value is first decreasing and then increasing with property value. The lines with blue square markers in Panels $\mathrm{A}-\mathrm{C}$ of Figure 8 plot the mean tax rate schedule, which features an inflection point in value band D.

Panel A in Figure 8 also shows that the likelihood of making a tax payment (including a partial payment) is negatively correlated with the mean tax rate. Payment compliance is first increasing and then decreasing in property values, with a peak in band $\mathrm{D}$, where the tax rate is minimized. Panel B shows that conditional on the taxpayer making a payment, the likelihood of paying all at once (as opposed to paying in installments) is also negatively correlated with the mean tax rate, again with an inflection point in band $\mathrm{D}$. Panel $\mathrm{C}$ shows that conditional on the taxpayer attempting to pay in installments, the likelihood of paying all six installments on time (as opposed to paying partially or late) is also negatively correlated with the mean tax rate, again with an inflection point in band D. This evidence is highly consistent with liquidity constraints shaping taxpayer behavior, as the inflection points in these three data series are otherwise hard to explain.

To provide a second piece of evidence that taxes impact payment modality, we now show that the quasi-experimental tax rate increases that we analyze in Section 4.2 are also associated with changes in payment modality. In Panels D-F of Figure 8, we implement the DiD design in Equation 7 using the sample of taxpayers who make at least a partial payment in each year. Consistent with the view that tax rate increases activate liquidity constraints, we find that treated taxpayers become more likely to pay their liability in installments instead of all at once. These taxpayers hence forgo the early-bird discounts. One interpretation of the discounts is that taxpayers who do not pay in full before the deadline take out a loan from the government. The results suggest that taxpayers are more likely to avail themselves of these loans when tax rates increase.

\subsection{Evidence from Consumption Data}

We now study whether property tax increases impact consumption. As we discuss in Section 1, liquidity constraints can increase the welfare cost of taxing property, and the effect of taxes on consumption is a key input for our optimal tax formulas. ${ }^{51}$

Because our administrative tax data do not measure consumption, we use additional data from the Mexican Household Income and Expenditure Survey (Encuesta Nacional de Ingresos y Gastos de los Hogares, ENIGH, collected by INEGI (2019)). To study the impact of taxes on consumption, we estimate the following specification:

$$
\ln C_{i t}=\alpha+\beta_{1} \ln P_{i t}+\delta_{1} \ln I_{i t}+\gamma_{1} X_{i t}+\varepsilon_{i t}
$$

where $P_{i t}$ is the property tax payment of household $i$ in year $t, C_{i t}$ is household per capita consumption, $I_{i t}$ is household per capita income, and the control vector $X_{i t}$ contains year dummies and

\footnotetext{
${ }^{51}$ Appendix H shows that household consumption in Mexico City is not fully insured against income shocks and that property tax payments also respond to income shocks.
} 
delegación (i.e., city district) fixed effects. In this equation, $\beta_{1}$ measures the consumption elasticity with respect to property tax payments. If paying property taxes leads households to decrease their consumption, we would expect to find that $\beta_{1}<0$.

Previous work has estimated regressions similar to Equation 8 to study the impacts of unexpected income shocks (e.g., Attanasio, 1999; Blundell et al., 2008) and unemployment insurance payments (e.g., Gruber, 1997; Kroft and Notowidigdo, 2016) on consumption. An important concern with Equation 8 is that property tax payments are likely correlated with other factors that influence consumption. For instance, households facing unmeasured income shocks may decide to skip a property tax payment and may also decrease everyday consumption. These kind of shocks would lead to upwardly biased estimates of $\beta_{1} .^{52}$

To provide unbiased estimates of $\beta_{1}$, we use the tax increases that we analyze in Section 4 to isolate variation in property tax payments that is unrelated to other drivers of consumption. Consider the following first-stage equation:

$$
\ln P_{i t}=\pi_{1}+\pi_{2} Z_{i t}+\delta_{2} \ln I_{i t}+\gamma_{2} X_{i t}+\epsilon_{i t}
$$

where the instrument $Z_{i t}$ measures the percentage increase in mean property tax rates driven by the removal of abatements. As our RD and DiD estimations show, tax increases have significant effects on tax payments, suggesting that $Z_{i t}$ would be a relevant and statistically strong instrument. The exclusion restriction is that tax rate changes impact consumption through property tax payments only. Our results in Section 4 show that tax changes lead to sharp variation between treated and untreated households and that these households have parallel trends on a number of outcomes prior to the tax increases. These results suggest that the tax-change-driven variation in $Z_{i t}$ is likely unrelated to other determinants of household consumption. ${ }^{53}$

Our instrumental variables strategy requires three key variables: consumption, $C_{i t}$; tax payments, $P_{i t}$; and tax rate changes, $Z_{i t}$. Unfortunately, while the ENIGH data measure consumption and property tax payments, they do not record tax liabilities. We overcome this issue by using a split-sample instrumental variables strategy (e.g., Angrist and Krueger, 1992; Card and McCall, 1996) that combines information from our administrative tax data and our household survey data. Specifically, we use property characteristics that are common in both datasets to construct a proxy for the change in tax liability. As we discuss in Section 2.1, a property's cadastral value - and hence the tax liability - is based on land and construction area, unit values of land and construction that vary across districts (delegaciones), and property age. We therefore use the administrative tax data to calculate $Z_{i t}$ as the average year-to-year change in tax liability for fine bins of land area $\times$ construction area $\times$ property age $\times$ district $\times$ year. We then assign values of $Z_{i t}$ to the ENIGH

\footnotetext{
${ }^{52}$ Indeed, OLS estimations of Equation 8 yield positive estimates of $\beta_{1}$.

${ }^{53}$ Unlike in the US, property tax revenue in Mexico is not used to fund neighborhood schools or other amenities. Any benefits from additional tax revenue would be spread among the more than 20 million residents of Mexico City.
} 
data based on household characteristics. ${ }^{54}$ Finally, to account for the uncertainty in our measures of $Z_{i t}$, we bootstrap this procedure to calculate standard errors.

We obtain an estimate of $\pi_{2}=0.473(S E=0.069)$ when we estimate Equation 9 (see Table J.1). The first-stage regression shows that $Z_{i t}$ is highly predictive of tax payments and yields an $F$-statistic over 40. $\pi_{2}$ has a natural economic interpretation: it is the elasticity of tax payments to changes in mean property tax rates. It is therefore reassuring that our estimate of $\pi_{2}$ has a similar magnitude to our estimated elasticities in Table 2.

Table 4 reports the IV estimates of Equation 8. Column (1) shows that while tax payments have a negative effect on consumption, this relationship is not statistically significant on average. Because we expect tax payments to have larger impacts for lower-income households and for households without access to credit, we augment Equation 8 by including interactions with income and credit access. ${ }^{55}$ Column (2) shows the estimates produced when we interact tax payment with household income, where we normalize log income relative to the cross-sectional mean. This column reveals a statistically significant difference in the effects of tax payments on consumption across different households. Column (3) shows the results from interacting tax payment with credit constraints, as measured by access to a credit card. The interaction of tax payment with credit constraints is statistically significant and is negatively related to consumption. This interaction is particularly important since 80 percent of households do not have access to credit cards. ${ }^{56}$ Finally, Column (4) shows that the interactions with income and credit constraints have the same sign and are statistically significant when we include both interactions in the estimation. ${ }^{57}$

The last specification of Table 4 helps us understand the magnitude and heterogeneity in the effects of property taxes on consumption. According to these parameters, doubling property taxes leads to a decline in consumption of $7.9(=4.1+3.8)$ percent for households without access to credit. ${ }^{58}$ The decline is even larger for low-income households. For a family with income in the 25th percentile of the distribution that does not have access to credit, doubling property taxes leads to

\footnotetext{
${ }^{54}$ Because we compute $Z_{i t}$ using the universe of property tax records, this procedure measures precise changes in tax liability. Appendix J provides additional details.

${ }^{55}$ We also include interactions between the instrument and relevant variables in the first stage.

${ }^{56}$ The fact that we observe a consumption response for households without a credit card but we do not observe a response for those with access to credit or with higher incomes is inconsistent with the idea that the tax change was perceived as permanent. This is because permanent tax changes should impact the consumption of all households regardless of liquidity constraints.

${ }^{57}$ These estimates are robust to using an alternative definition for $Z_{i t}$. Namely, we define $\tilde{Z}_{i t}$ as the predicted probability that a household's property is part of the treated cadastral value band in 2010 (band I). As with our previous formulation, this instrument isolates reform-driven variation in the tax liability. Tables J.2 and J.3 show that we find similar estimates when we use this instrument or when we use both instruments.

${ }^{58}$ This magnitude is reasonable since as mentioned above, household survey data report that average property tax payments can be close to 1 percent of annual income. Moreover, Chetty (2004) notes that income shocks can lead to larger changes in consumption when households face consumption commitments, such as with housing.
} 
Table 1: Parameters for Welfare Calculations

A. Welfare Effects of Tax Increases

\begin{tabular}{ccccc}
\hline$M V P F_{t}$ & $\varepsilon_{t}^{\text {Pay }}$ & $\Delta c^{\text {Pay }}$ & $\gamma$ & $\tilde{z}$ \\
\hline$\frac{v^{\prime}(g)}{u^{\prime}(c)}-\frac{1-\gamma \Delta c^{\text {Pay }}}{1+(1-\tilde{z}) \varepsilon_{t}^{\text {Pay }}}$ & $\{-0.24,-0.46\}$ & $\{0.00,-0.07\}$ & $\{1,3\}$ & 0.10 \\
\hline
\end{tabular}

B. Welfare Effects of Enforcement

\begin{tabular}{ccccc}
\hline$M V P F_{\alpha} \times \frac{m^{\prime}(\alpha)}{u^{\prime}(c)}$ & $\varepsilon_{\alpha}^{\text {Pay }}(H t / \alpha)$ & $\varepsilon_{t}^{\text {Pay }}$ & $N^{\text {Pay }}$ & $\omega$ \\
\hline$\frac{v^{\prime}(g)}{u^{\prime}(c)}-\frac{\omega\left(1-N^{\text {Pay }}\right)}{(1-\tilde{z}) N^{\text {Pay }} \varepsilon_{\alpha}^{\text {Pay }}(H t / \alpha)-1} \times \frac{\varepsilon_{\alpha}^{\text {Pay }}(H t / \alpha)}{-\varepsilon_{t}^{\text {Pay }}}$ & $\{16,54\}$ & $\{-0.24,-0.46\}$ & $\{0.60,0.75\}$ & $\{0.5,1\}$ \\
\hline
\end{tabular}

Notes: This table displays the parameters that we use for the policy simulations: empirically estimated parameters (blue) and the calibrated or calculated parameters (red).

a 12.1 percent decrease in consumption. ${ }^{59}$

While doubling property taxes might seem extreme, recall that the sanctions treatment in our field experiment in Section 5 led to a doubling of tax payments relative to payments made by the control group. To put these estimates in the perspective of our tax changes, recall that property taxes increased by 20 percent in 2010, by 27 percent in 2011, and by 47 percent in 2012. According to our estimates, these tax changes led to consumption drops of 2.4-5.7 percent for the most affected households.

These estimates show that policy makers are right to be concerned about the potential of property taxes to exacerbate liquidity constraints. In the next section, we quantify the extent to which liquidity constraints increase the welfare cost of taxes, using a range of estimates that includes our IV estimates.

\section{Welfare Effects of Taxes and Enforcement}

We now connect our empirical results with our conceptual framework to quantify the welfare effects of the policies most commonly used to raise property tax revenue. ${ }^{60}$ Table 1 collects the ingredients needed to perform these calculations.

\footnotetext{
${ }^{59}$ Table J.4 reports the details of these marginal effects. To gauge the magnitude of these effects, note that Gruber (1997); Kroft and Notowidigdo (2016) estimate that losing a job without unemployment insurance (UI) would lead to a 23 percent drop in consumption in the US and that increasing the UI replacement rate by 10 ppt would reduce this drop by 2.7 percent.

${ }^{60}$ Following the model in Section 1, we assume that the government aims to set tax and enforcement policies to maximize the well-being of its residents. In Appendix K, we alternatively assume that the government aims to maximize revenue, and we show that the current tax rates are far below the revenue-maximizing rates.
} 


\subsection{Tax Rates}

Consider first the effects of raising tax rates on welfare. The formula for the $M V P F_{t}$ in Panel A of Table 1 shows that, absent liquidity constraints $\left(\Delta c^{\text {Pay }}=0\right)$, the welfare cost of raising tax rates is given by $\frac{1}{1+(1-\tilde{z}) \varepsilon_{t}^{\text {Pay }}}$. To implement this formula, we use data to calibrate that the share of back-taxes that the government eventually collects in future years, $\tilde{z}$, equals $10 \% .{ }^{61}$ In the model, the elasticity $\varepsilon_{t}^{\text {Pay }}$ captures the decrease in compliance following a tax increase. This concept is best approximated by the compliance share elasticity, which weights drops in compliance by revenue. Our central estimate of this elasticity is $\varepsilon_{t}^{\text {Pay }}=-0.29$. For illustrative purposes, we consider the smallest and largest estimates of this elasticity: $\varepsilon_{t}^{\text {Pay }} \in\{-0.24,-0.46\}$. Assuming that $\varepsilon_{t}^{\text {Pay }}=-0.24$ implies that the welfare cost of an additional peso of tax revenue equals $1.28{ }^{62}$ The welfare effect of using this tax revenue to provide public goods depends on the value of $\frac{v^{\prime}(g)}{u^{\prime}(c)}$. The blue line in Panel A of Figure 9 plots the $M V P F_{t}$ for values of $\frac{v^{\prime}(g)}{u^{\prime}(c)} \in[1,3] .{ }^{63}$ The $M V P F_{t}$ is increasing in the marginal value of public goods and, in this initial parameterization, indicates that tax hikes raise welfare as long as $\frac{v^{\prime}(g)}{u^{\prime}(c)}>1.28$.

We now consider how liquidity constraints alter the welfare cost of raising tax rates. The formula for the $M V P F_{t}$ shows that when tax hikes lead to consumption drops, i.e., $\Delta c^{\text {Pay }}<0$, the welfare cost of raising an additional peso of tax revenue is multiplied by $\left(1-\gamma \Delta c^{\text {Pay }}\right)$. To capture this effect, we use our IV estimates of the consumption elasticity with respect to tax payments to set $\Delta c^{\text {Pay }}=-0.07 .{ }^{64}$ The red-dotted line in Panel A of Figure 9 adjusts our $M V P F_{t}$ calculation using this consumption drop along with the assumption that $\gamma=1$. Since the welfare cost of raising taxes increased by $-\gamma \Delta c^{\text {Pay }}=7 \%$, this line lies slightly below the solid blue line. In this scenario, raising taxes to provide public goods raises welfare as long as $\frac{v^{\prime}(g)}{u^{\prime}(c)}$ is greater than 1.37. The dashed orange line shows the effect of instead assuming that $\gamma=3 .{ }^{65}$ In this case, liquidity constraints increase the welfare cost of tax hikes by $21 \%$, and the break-even value of $\frac{v^{\prime}(g)}{u^{\prime}(c)}$ rises to 1.55 . For illustrative purposes, the green dot-dashed line plots the $M V P F_{t}$ assuming that $\varepsilon_{t}^{\text {Pay }}=-0.46$. This line shows that increasing taxes only raises welfare if the value of public goods is greater than 2.06. Overall, this figure shows that under our central estimates of $\varepsilon_{t}^{\text {Pay }}$, the government can increase welfare by raising property tax rates to provide public goods and that this conclusion is robust to accounting for liquidity constraints as well as a range of other parameter values.

${ }^{61}$ Figure C.2 shows that the government recovered 10 percent of the outstanding debt between 2008 and 2012 .

${ }^{62}$ This cost rises to 1.35 when $\varepsilon_{t}^{\text {Pay }}=-0.29$ and to 1.59 when $\varepsilon_{t}^{\text {Pay }}=-0.46$.

${ }^{63}$ While estimates of the value of public goods from the United States imply $\frac{v^{\prime}(g)}{u^{\prime}(c)} \approx 1.5$ (Cellini et al., 2010 ; Suárez Serrato and Wingender, 2014), this value is likely larger in countries with a lower provision of public goods.

${ }^{64}$ We compute this value using the estimates from column (4) of Table 4 and the fraction of households without access to a credit card in our survey data to set the fraction of liquidity-constrained households $\pi_{0, c}^{\text {Pay }}=80 \%$. We therefore have that $\Delta c=-0.038 \times 0.2-0.079 \times 0.8=-0.07$.

${ }^{65}$ Chetty and Looney (2006) offer a similar calibration in a developing country context. The larger value captures the possibility that consumption commitments amplify welfare costs (Chetty, 2004). 
Panel B of Figure 9 implements the optimal property tax from Equation 2. ${ }^{66}$ For ease of interpretation, we plot only positive tax rates, and we top-code optimal tax rates at 250 basis points. We also plot the average tax rate (solid grey line) and the maximum tax rate (dashed grey line) for reference. Assuming no liquidity constraints and that $\varepsilon_{t}^{\text {Pay }}=-0.24$, the blue solid line shows that as long as the value of public goods exceeds 1.5, the optimal tax rate is greater than 250 basis points. Liquidity constraints (red dotted line), higher welfare costs of consumption declines (yellow dashed line), and larger compliance drops (green dot-dashed line) all work to reduce the optimal tax rate. While these lines illustrate how different forces influence optimal tax rates, the red dotted line is a reasonable case for practical purposes. This line shows optimal tax rates greater than 45 basis points whenever the value of public goods is greater than or equal to 1.5. This suggests that while liquidity constraints generally work to lower optimal tax rates, current property tax rates are likely below the optimal rates. ${ }^{67}$

\subsection{Enforcement}

Consider now the welfare effects of enforcement. To make these effects comparable to those of rate hikes, we multiply the $M V P F_{\alpha}$ by the change in tax liability that would be equivalent in its effect on compliance to a given enforcement treatment. Panel B of Table 1 shows that this equivalent tax liability is given by $\frac{\varepsilon_{\alpha}^{\text {Pay }}(H t / \alpha)}{-\varepsilon_{t}^{\text {Pay }}} .{ }^{68}$ Assuming that $\varepsilon_{t}^{\text {Pay }}=-0.24$, the equivalent increases in tax liability are 66.67 MXN for the public goods treatment (i.e., $\varepsilon_{\alpha}^{\mathrm{Pay}}(H t / \alpha)=16$ ) and $225 \mathrm{MXN}$ for the sanctions treatment (i.e., $\varepsilon_{\alpha}^{\text {Pay }}(H t / \alpha)=54$ ). Using the observed share of compliers $N^{\text {Pay }}=60 \%$ and assuming that society places an equal weight on the welfare of all households (i.e., $\omega=1$ ), our calculation implies that an additional peso of tax revenue that is raised by the public goods treatment has a welfare cost of 3.49. In the case of the sanctions treatment, this welfare cost is slightly smaller and equals 3.20.69 The blue and red dotted lines in Panel C of Figure 9 plot the $M V P F_{\alpha}$ under these two scenarios and show that raising tax revenue through these enforcement messages does not raise welfare for values of public goods smaller than 3 . These lines show that, in our setting, even though enforcement interventions are effective in raising revenue, they are not a desirable policy tool for a welfare-maximizing government.

We now discuss alternative settings under which enhanced enforcement may increase welfare. First, consider a situation where rate hikes are not effective in raising revenue. Setting $\varepsilon_{t}^{\text {Pay }}=-0.46$ lowers the welfare cost of raising revenue through enforcement to 1.66 in the case of our sanctions treatment. The orange line in Panel $\mathrm{C}$ of Figure 9 plots the $M V P F_{\alpha}$ in this case. Enforcement

\footnotetext{
${ }^{66}$ As with most sufficient statistic formulas (Chetty, 2009), we assume constant elasticities to implement Equations 2 and A.1. Equations 1 and 3 do not rely on this assumption, as they measure marginal effects of policy changes.

${ }^{67}$ As we note in Section 1, allowing for the capitalization of taxes and spending on property values would result in higher optimal tax rates.

${ }^{68}$ As we discuss in Section 1.4, this term results by expressing $m^{\prime}(\alpha)$ as the utility cost of a tax that raises the same revenue as an increase in enforcement.

${ }^{69}$ If $\varepsilon_{t}^{\text {Pay }}=-0.29$, these values equal 2.90 and 2.65 , respectively for the public goods and sanctions treatments.
} 
can therefore be more effective in settings where rate hikes yield little additional revenue (e.g., Bergeron et al., 2020). Second, consider a setting where compliance is more widespread. The orange line in Panel $\mathrm{C}$ of Figure 9 plots the $M V P F_{\alpha}$ further assuming that $N^{\text {Pay }}$ equals a hypothetical value of $75 \%$. The $M V P F_{\alpha}$ is now higher, indicating that enforcement raises welfare. This result is due to the fact that when compliance is higher, fewer households incur the private costs of enforcement. Finally, consider the case where the government violates the principle of horizontal equity by under-valuing the welfare cost to delinquent taxpayers by a factor of $\omega<1$. In our baseline where $N^{\text {Pay }}=60 \%$ and $\varepsilon_{t}^{\text {Pay }}=-0.24$, the welfare cost of the sanctions treatment decreases from 3.2 to 1.6 when the government values the welfare cost of non-compliance half as much as the utility derived by taxpayers from public goods and private consumption. This assumption may be problematic in our setting since our results suggest that liquidity constraints may contribute to the observed non-compliance. Assuming that $\omega<1$ may therefore penalize households that are simply unable to pay their taxes.

\subsection{Comparison of Tax Rates and Enforcement}

We now use our model to evaluate whether it is preferable to increase tax rates or tighten enforcement. We use Equation 5 to compute the welfare effect of a balanced-budget policy that increases taxes and reduces enforcement. Panel D of Figure 9 shows how the welfare effect of this policy varies with the tax elasticity $\varepsilon_{t}^{\text {Pay }}$. Since taxes are less distortionary when $\varepsilon_{t}^{\text {Pay }}$ is closer to zero, the welfare gains from this policy increase with $\varepsilon_{t}^{\text {Pay }}$. The dashed lines report the range of our estimates of $\varepsilon_{t}^{\text {Pay }}$ as well as the DiD estimate that pools data from all tax-rate changes. The blue solid line in Panel D shows that increasing tax rates and reducing the reliance on the public goods enforcement treatment raises welfare as long as $\varepsilon_{t}^{\text {Pay }}$ is greater than our smallest estimate of -0.46. The relative desirability of taxes over enforcement diminishes only slightly when we consider the sanctions treatment (red dotted line), when we allow for liquidity constraints (yellow dashed line), or when we allow for larger utility costs of consumption changes (green dashed line). Panel D also shows the effect of under-valuing the welfare of delinquent households by varying $\omega$. Lower values of $\omega$ mechanically lower the desirability of taxes over enforcement. At our central value of $\varepsilon_{t}^{\text {Pay }}$, assuming $\omega=0.5$ (emerald dash-dot line) equalizes the welfare effects of both policy instruments in our setting. ${ }^{70}$

The results in this section show that the welfare costs of raising property tax rates are smaller than plausible magnitudes of the value of public goods. While liquidity constraints raise the welfare cost of taxation moderately, incorporating this force does not change the conclusion that tax hikes likely increase both revenue and welfare. In contrast, the private costs associated with enforcement likely exceed the value of public goods, so that enhanced enforcement is likely welfare reducing.

\footnotetext{
${ }^{70}$ This line can also be interpreted as a robustness check on our estimation of the private cost of not paying taxes. At our central value of $\varepsilon_{t}^{\text {Pay }}$, taxes are more desirable than enforcement even if we over-estimated this cost by $100 \%$ of its true value. Figure A.3 plots the relative desirability of taxes over enforcement for additional values of $\omega$.
} 
While enforcement may be more effective in settings where tax hikes do not increase revenue or where the government does not value the welfare cost of non-compliance, we conclude that in our setting, a welfare-maximizing government would rather increase tax rates than enhance enforcement.

\section{Conclusion}

This paper studies the design of property taxes in developing countries in a holistic and detailed manner. Our work draws on administrative tax data from the universe of residential properties in Mexico City and various quasi-experimental and experimental identification strategies. We examine traditional policy tools featured in optimal tax theory - i.e., the tax rate - in addition to tax system features such as enforcement, payment schedules, and payment modality as well as interactions among these different tools.

We show that it is possible to raise property tax revenue through higher tax rates or through enforcement. Collectively, the variation that we study contributed to a 36 percent increase in total property tax revenue. However, we also find that taxpayer behavior is sensitive to liquidity constraints. Tax rate increases lead to drops in compliance, an increased likelihood of paying in installments, and reductions in consumption. Liquidity constraints thus need to be taken into account in the design of property tax systems in developing countries. Because our study is based in Mexico City, a setting that is similar to other developing countries in terms of the prevalence of household liquidity constraints and the level of administrative capacity, our findings carry broad relevance.

Our optimal tax model combines our empirical estimates of tax, enforcement, and consumption elasticities to quantify the optimal tax rate and compliance level. The model illuminates when a welfare-maximizing government would prefer to increase tax rates or enhance enforcement. Since we calculate that our field experiment generated welfare losses, we conclude that it is not desirable to increase enforcement. In contrast, while liquidity constraints increase the welfare cost of raising tax rates, we find that current tax rates are still below their optimal level. Because optimal tax rates depend on the share of liquidity-constrained taxpayers, we identify provision of liquidity as an important policy tool that can lessen the welfare costs of property taxation.

Overall, our results reveal that details of property tax systems can have important impacts on taxpayer welfare and revenue collection. In particular, the optimal design and administration of loans for liquidity-constrained taxpayers - including terms of eligibility, interest rates, and payment schedules - is an important avenue for future research. Future work continuing to build on the tax systems paradigm is likely to yield important insights in other settings (e.g., Okunogbe, 2019; Bergeron et al., 2020) and to illuminate the roles of tax fairness and equity (e.g., Best et al., 2020). 


\section{References}

Agrawal, David R., William H. Hoyt, and John D. Wilson, "Local Policy Choice: Theory and Empirics," 2020. Working Paper. 5, 12

Allcott, Hunt and Dmitry Taubinsky, "Evaluating Behaviorally Motivated Policy: Experimental Evidence from the Lightbulb Market," American Economic Review, August 2015, 105 (8), 2501-38. 10, 47

_ and Judd B. Kessler, "The Welfare Effects of Nudges: A Case Study of Energy Use Social Comparisons," American Economic Journal: Applied Economics, January 2019, 11 (1), 236-76. 3, 6, 12, 48

Andreoni, James, "IRS as loan shark tax compliance with borrowing constraints," Journal of Public Economics, 1992, 49 (1), $35-46.50$

Angrist, Joshua D. and Alan B. Krueger, "The Effect of Age at School Entry on Educational Attainment: An Application of Instrumental Variables with Moments from Two Samples," Journal of the American Statistical Association, 1992, 87 (418), 328-336. 26

Atinyan, Armenak and Zareh Asatryan, "Nudging for Tax Compliance: A Meta Analysis," 2019. Working Paper. 22, 23, 24

Atkinson, A. B. and N. H. Stern, "Pigou, Taxation and Public Goods12," The Review of Economic Studies, 01 1974, 41 (1), 119-128. 8

Attanasio, Orazio and Steven Davis, "Relative Wage Movements and the Distribution of Consumption," Journal of Political Economy, 1996, 104 (6), 1227-62. 1

Attanasio, Orazio P, "Consumption," Handbook of Macroeconomics, 1999, 1, 741-812. 26, 84

_ and Miguel Székely, "Wage shocks and consumption variability in Mexico during the 1990s," Journal of Development Economics, 2004, 73 (1), 1-25. 1, 84

Attanasio, Orazio P. and Tullio Jappelli, "Intertemporal Choice and the Cross-Sectional Variance of Marginal Utility," The Review of Economics and Statistics, 2001, 83 (1), 13-27. 1

Balan, Pablo, Augustin Bergeron, Gabriel Tourek, and Jonathan Weigel, "Local Elites as Tax Collectors: Experimental Evidence from the DRC," 2020. Mimeo. 5

Basri, Chatib M., , Mayara Felix, Rema Hanna, and Ben Olken, "Tax Administration vs. Tax Rates: Evidence from Corporate Taxation in Indonesia," 2019. NBER Working Paper 26150. 4

Bell, Martin, Elin Charles-Edwards, Philipp Ueffing, John Stillwell, Marek Kupiszewski, and Dorota Kupiszewska, "Internal migration and development: comparing migration intensities around the world," Population and Development Review, 2015, 41 (1), 33-58. 12

Bergeron, Augustin, Gabriel Tourek, and Jonathan Weigel, "Shifting the Laffer Rate in Developing Countries: Evidence from Randomized Tax Rates in the DRC," 2020. Mimeo. 5, 31, 32

Bertrand, Marianne, Dean Karlan, Sendhil Mullainathan, Eldar Shafir, and Jonathan Zinman, "What's Advertising Content Worth? Evidence from a Consumer Credit Marketing Field Experiment*," The Quarterly Journal of Economics, 02 2010, 125 (1), 263-306. 10, 47

Besley, Timothy and Torsten Persson, "Taxation and Development," in Alan J Auerbach, Raj Chetty, Martin Feldstein, and Emmanuel Saez, eds., Handbook of Public Economics, Vol. 5 2013. 4

_ , Anders Jensen, and Torsten Persson, "Norms, Enforcement, and Tax Evasion," Working Paper 25575, National Bureau of Economic Research February 2019. 13

Best, Michael, Anne Brockmeyer, Henrik Kleven, Johannes Spinnewijn, and Mazhar Waseem, "Production vs Revenue Efficiency with Low Tax Compliance: Theory and Evidence from Pakistan," Journal of Political Economy, 2015, 123 (6), 1311-1355. 4

_ , Francois Gerard, Evan Kresch, and Joana Naritomi, "Greener on the Other Side? Spatial Discontinuities in Property Tax Rates and their Effects on Tax Morale," 2020. Working Paper. 5, 32

Blundell, Richard, Luigi Pistaferri, and Ian Preston, "Consumption Inequality and Partial Insurance," American Economic Review, December 2008, 98 (5), 1887-1921. 26

Bradbury, Katharine L., Christopher J. Mayer, and Karl E. Case, "Property tax limits, local fiscal behavior, and property values: evidence from Massachusetts under Proposition 212," Journal of Public Economics, $2001,80(2), 287-311.12$ 
Brockmeyer, Anne and Marco Hernandez, "Taxation, Information and Withholding: Evidence from Costa Rica," 2019. Working Paper. 20

_ , Spencer Smith, Marco Hernandez, and Stewart Kettle, "Casting a Wider Tax Net: Experimental Evidence from Costa Rica," American Economic Journal: Economic Policy, 2019, 11 (3), 55-87. 4

Brueckner, Jan K., "A test for allocative efficiency in the local public sector," Journal of Public Economics, 1982, 19 (3), 311 - 331. 11, 12

Bugni, Federico A and Ivan A Canay, "Testing Continuity of a Density via g-order statistics in the Regression Discontinuity Design," Journal of Econometrics, 2020. 18, 64

Busso, Matias, Jesse Gregory, and Patrick Kline, "Assessing the Incidence and Efficiency of a Prominent Place Based Policy," American Economic Review, April 2013, 103 (2), 897-947. 7

Cabral, Marika and Caroline Hoxby, "The Hated Property Tax: Salience, Tax Rates, and Tax Revolts," Working Paper 18514, National Bureau of Economic Research November 2012. 5

Calonico, Sebastian, Matias D Cattaneo, and Rocio Titiunik, "Robust nonparametric confidence intervals for regression-discontinuity designs," Econometrica, 2014, 82 (6), 2295-2326. 19, 64

Caplin, Andrew, Fear as a Policy Instrument, Russell Sage, 2003. 6, 48

Card, David and Brian P. McCall, "Is Workers' Compensation Covering Uninsured Medical Costs? Evidence from the "Monday Effect"," Industrial and Labor Relations Review, 1996, 49 (4), 690-706. 26

Carpio, Lucia Del, "Are the Neighbors Cheating? Evidence from Social Norm Experiment on Property Taxes in Peru," 2014. Mimeo. 24

Cellini, Stephanie Riegg, Fernando Ferreira, and Jesse Rothstein, "The Value of School Facility Investments: Evidence from a Dynamic Regression Discontinuity Design*," The Quarterly Journal of Economics, 02 2010, 125 (1), 215-261. 12, 29

Chamberlain, Gary, "Chapter 22 Panel data," in "in," Vol. 2 of Handbook of Econometrics, Elsevier, 1984, pp. 1247 - 1318. 93

Chetty, Raj, "Consumption Commitments, Unemployment Durations, and Local Risk Aversion," Working Paper 10211, National Bureau of Economic Research January 2004. 11, 27, 29

_ , "A general formula for the optimal level of social insurance," Journal of Public Economics, 2006, 90, 1879-1901. 8

_ , "Sufficient Statistics for Welfare Analysis: A Bridge Between Structural and Reduced-Form Methods," Annual Review of Economics, 2009, 1 (1), 451-488. 30

- and Adam Looney, "Consumption smoothing and the welfare consequences of social insurance in developing economies," Journal of Public Economics, December 2006, 90 (12), 2351-2356. 29

- and Amy Finkelstein, "Chapter 3 - Social Insurance: Connecting Theory to Data," in Alan J. Auerbach, Raj Chetty, Martin Feldstein, and Emmanuel Saez, eds., handbook of public economics, vol. 5, Vol. 5 of Handbook of Public Economics, Elsevier, 2013, pp. 111 - 193. 11

Chirico, Michael, Robert Inman, Charles Loeffler, John MacDonald, and Holger Sieg, "Deterring Property Tax Delinquency in Philadelphia: An Experimental Evaluation of Nudge Strategies," National Tax Journal, 2019, 72 (3), 479-506. 5

Clausing, Kimberly A., "Corporate tax revenues in OECD countries," International Tax and Public Finance, 2007, 14(2), 115â133. 93

Deaton, Angus, "Saving and Liquidity Constraints," Econometrica, 1991, 59 (5), 1221-1248. 11

Demirguc-Kunt, Asli, Leora Klapper, Singer Dorothee, Saniya Ansar, and Jake Hess, "The Global Findex Database: Measuring Financial Inclusion and the Fintech Revolution," Technical Report, World Bank 2017. 4

Devereux, Michael, "Developments in the Taxation of Corporate Profit in the OECD Since 1965: Rates, Bases, and Revenues," Oxford University Centre of Business Taxation Working Paper No. 07/04, 2007. 93

Dusek, Libor, Nicolas Pardo, and Christian Traxler, "Salience, Incentives, and Timely Compliance: Evidence from Speeding Tickets," 2020. Working Paper. 5 
Fang, Hanming and Dan Silverman, "On the compassion of time-limited welfare programs," Journal of Public Economics, 2004, 88 (7), 1445 - 1470. 86

Gadenne, Lucie, "Tax me, but spend wisely? Sources of public finance and government accountability," American Economic Journal: Applied Economics, 2017, pp. 274-314. 12

Glaeser, Edward L., "Paternalism and Psychology," University of Chicago Law Review, 2006, 73 (1), 133156. 6, 48

Gonzalez-Navarro, Marco and Climent Quintana-Domeque, "Paving Streets for the Poor: Experimental Analysis of Infrastructure Effects," The Review of Economics and Statistics, 2016, 98 (2), 254-267. 12

Grembi, Veronica, Tommaso Nannicini, and Ugo Troiano, "Do fiscal rules matter?," American Economic Journal: Applied Economics, 2016, pp. 1-30. 19

Gruber, Jonathan, "The Consumption Smoothing Benefits of Unemployment Insurance," The American Economic Review, 1997, 87 (1), 192-205. 26, 28

Haughwout, Andrew, Robert Inman, Steven Craig, and Thomas Luce, "Local revenue hills: evidence from four US cities," Review of Economics and Statistics, 2004, 86 (2), 570-585. 94

Hebous, Shafik and Michael Keen, "Pareto-Improving Minimum Corporate Taxation," IMF Working Papers, 2021, 2021 (250). 7

Hendren, Nathaniel, "The Policy Elasticity," Tax Policy and the Economy, 2016, 30 (1), 51-89. 8

_ and Ben Sprung-Keyser, "A Unified Welfare Analysis of Government Policies*," The Quarterly Journal of Economics, 03 2020, 135 (3), 1209-1318. 8

Hotz, V. Joseph and Robert A. Miller, "Conditional Choice Probabilities and the Estimation of Dynamic Models," The Review of Economic Studies, 1993, 60 (3), 497-529. 86

Howard, Troup and Carlos Avenancio-Leon, "The Assessment Gap: Racial Inequalities in Property Taxation," 2019. Mimeo. 14

INEGI, "Encuesta Nacional de Ingresos y Gastosde los Hogares," 2019. 25

International Monetary Fund, "World Revenue Longitudinal Data," 2019. 39

Jack, William and Tavneet Suri, "Risk Sharing and Transactions Costs: Evidence from Kenya's Mobile Money Revolution," American Economic Review, January 2014, 104 (1), 183-223. 4

Kawano, Laura and Joel Slemrod, "How do corporate tax bases change when corporate tax rates change? With implications for the tax rate elasticity of corporate tax revenues," International Tax and Public Finance, 2015, 23(3), 401â433. 93

Keen, Michael and Joel Slemrod, "Optimal Tax Administration," Journal of Public Economics, July 2017, 152, 133-142. 2, 4, 6, 49

Kessler, Ryan, "Does Punishment Compel Payment? Driverâs License Suspensions and Fine Delinquency," 2020. Working Paper. 5

Khan, Adnan Q., Asim I Khwaja, and Benjamin A. Olken, "Tax farming redux: Experimental evidence on performance pay for tax collectors," The Quarterly Journal of Economics, 2016, 131 (1), 219-271. 5

_ , _, and _, "Making Moves Matter: Experimental Evidence on Incentivizing Bureaucrats through Performance-Based Postings," American Economic Review, January 2019, 109 (1), 237-70. 5

Kroft, Kory and Matthew J. Notowidigdo, "Should Unemployment Insurance Vary with the Unemployment Rate? Theory and Evidence," The Review of Economic Studies, 02 2016, 83 (3), 1092-1124. 26, 28

Lalive, Rafael, "How do extended benefits affect unemployment duration? A regression discontinuity approach," Journal of econometrics, 2008, 142 (2), 785-806. 19

Lemieux, Thomas and Kevin Milligan, "Incentive effects of social assistance: A regression discontinuity approach," Journal of Econometrics, 2008, 142 (2), 807-828. 19

Loewenstein, George and Ted O'Donoghue, "" We can do this the easy way or the hard way": Negative emotions, self-regulation, and the law," The University of Chicago Law Review, 2006, 73 (1), 183-206. 6,48

McCrary, Justin, "Manipulation of the running variable in the regression discontinuity design: A density test," Journal of Econometrics, 2008, 142 (2), 698-714. 18, 66 
Meiselman, Ben S., "Ghostbusting in Detroit: Evidence on nonfilers from a controlled field experiment," Journal of Public Economics, 2018, 158, 180 - 193. 3, 4, 6

Morduch, Jonathan, "Income Smoothing and Consumption Smoothing," Journal of Economic Perspectives, September 1995, 9 (3), 103-114. 4

— and Dean Karlan, "Access to Finance," Handbook of Development Economics, 06 2009, 5. 4

Mullainathan, Sendhil, Joshua Schwartzstein, and William J. Congdon, "A Reduced-Form Approach to Behavioral Public Finance," Annual Review of Economics, 2012, 4 (1), 511-540. 47

Naritomi, Joana, "Consumers as Tax Auditors," American Economic Review, 2019, 109 (9), 3031-72. 5

Okunogbe, Oyebola, "State Capacity and Taxation: The Role of Detection and Enforcement Capacity on Property Tax Compliance in Liberia," 2019. Mimeo. 5, 24, 32

Organ, Paul R., Alex Ruda, Joel Slemrod, and Alex Turk, "Incentive effects of the IRSâ passport certification and revocation process," Journal of Public Economics, 2022, 208, 104625. 3, 5, 6

Perez-Truglia, Ricardo and Ugo Troiano, "Shaming tax delinquents," Journal of Public Economics, 2018, $167,120-137.5$

Pomeranz, Dina, "No Taxation without Information: Deterrence and Self-Enforcement in the Value Added Tax," American Economic Review, 2015, 105 (8), 2539-2569. 5

_ and José Vila-Belda, "Taking State-Capacity Research to the Field: Insights from Collaborations with Tax Authorities," Annual Review of Economics, 2019, 11 (1), 755-781. 4

Silva, Joao Santos and Silvana Tenreyro, "The Log of Gravity," The Review of Economics and Statistics, 2006, 88 (4), 641-658. 20

Singh, Divya, "Do Property Tax Incentives for New Construction Spur Gentrification? Evidence from New York City," 2020. Working Paper. 78

Singhal, Monica and Erzo Luttmer, "Tax Morale," Journal of Economic Perspectives, 2014, 28 (4), 149168. 6

Slemrod, Joel, "Buenas notches: lines and notches in tax system design," eJTR, 2013, 11, 259. 85

_ , "Tax Compliance and Enforcement," NBER Working Paper 24799, 2018. 5

_ and Christian Gillitzer, Tax Systems, MIT Press, 2013. Zeuthen Lecture Series. 4

- and Shlomo Yitzhaki, "Integrating Expenditure and Tax Decisions:The Marginal Cost of Funds and the Marginal Benefit of Projects," National Tax Journal, June 2001, 54 (2), 189-202. 8

Suárez Serrato, Juan Carlos and Owen Zidar, "Who Benefits from State Corporate Tax Cuts? A Local Labor Markets Approach with Heterogeneous Firms," American Economic Review, 2016, 106 (9), 25822624. 93

_ and _, "The structure of state corporate taxation and its impact on state tax revenues and economic activity," Journal of Public Economics, 2018, 167, 158 - 176. 93

— and Philippe Wingender, "Estimating the Incidence of Government Spending," December 2014. Mimeo. 29

Townsend, Robert M., "Consumption Insurance: An Evaluation of Risk-Bearing Systems in Low-Income Economies," Journal of Economic Perspectives, September 1995, 9 (3), 83-102. 4

Train, Kenneth, Discrete Choice Methods with Simulation 2009. 87

Versprille, Allyson, "Growing Collection Woes May Haunt IRS Years After Pandemic Ends," Bloomberg, May 2020. 5

Weigel, Jonathan, "The Participation Dividend of Taxation: How Citizens in Congo Engage More with the State When it Tries to Tax Them," Quarterly Journal of Economics, 2020, Forthcoming. 5, 24

Wong, Francis, "Mad as Hell: Property Taxes and Financial Distress," Working Paper 2020. 5

World Bank, "World Development Indicators," 2019. 39 


\section{Tables}

Table 2: The Effect of Tax Rates on Tax Payment

\begin{tabular}{|c|c|c|c|c|c|c|c|c|}
\hline & \multicolumn{4}{|c|}{ A. Regression Discontinuity } & \multicolumn{4}{|c|}{ B. Difference-in-Differences } \\
\hline & $\begin{array}{c}\text { Mean Tax } \\
\text { Rate } \\
(1)\end{array}$ & $\begin{array}{c}\text { Payment } \\
\text { Amount } \\
\quad(2)\end{array}$ & $\begin{array}{c}\text { Payment } \\
\text { in Full } \\
(3)\end{array}$ & $\begin{array}{c}\text { Compliance } \\
\text { Share } \\
(4)\end{array}$ & $\begin{array}{c}\text { Mean Tax } \\
\text { Rate } \\
(5)\end{array}$ & $\begin{array}{c}\text { Payment } \\
\text { Amount } \\
(6)\end{array}$ & $\begin{array}{c}\text { Payment } \\
\text { in Full } \\
(7)\end{array}$ & $\begin{array}{c}\text { Compliance } \\
\text { Share } \\
(8)\end{array}$ \\
\hline & \multicolumn{8}{|c|}{ I. Estimates for the 2009-2010 Treatment } \\
\hline Level Effect & $\begin{array}{c}9.127^{* * *} \\
(.059)\end{array}$ & $\begin{array}{l}.584^{* *} \\
(.240)\end{array}$ & $\begin{array}{c}-5.483^{* * *} \\
(2.122)\end{array}$ & $\begin{array}{l}-3.208 \\
(2.043)\end{array}$ & $\begin{array}{c}8.319^{* * *} \\
(.000)\end{array}$ & $\begin{array}{c}.677^{* * *} \\
(.099)\end{array}$ & $\begin{array}{c}-3.772^{* * *} \\
\quad(.623)\end{array}$ & $\begin{array}{c}-1.963^{* * *} \\
(.527))\end{array}$ \\
\hline $\begin{array}{l}\text { Mean at Baseline } \\
\text { (Treated) }\end{array}$ & 50.112 & 5.836 & 36.626 & 47.881 & 50.112 & 5.836 & 36.626 & 47.881 \\
\hline Relative Effect & $\begin{array}{l}.182 \\
(.001)\end{array}$ & $\begin{array}{l}.100 \\
(.041)\end{array}$ & $\begin{array}{l}-.150 \\
(.058)\end{array}$ & $\begin{array}{l}-.067 \\
(.043)\end{array}$ & $\begin{array}{l}.166 \\
(.000)\end{array}$ & $\begin{array}{l}.116 \\
(.017)\end{array}$ & $\begin{array}{l}-.103 \\
(.017)\end{array}$ & $\begin{array}{l}-041 \\
(.011)\end{array}$ \\
\hline \multirow[t]{2}{*}{ Implied Elasticity } & & $\begin{array}{l}.55 \\
(.226)\end{array}$ & $\begin{array}{l}-.822 \\
(.318)\end{array}$ & $\begin{array}{l}-.368 \\
(.234)\end{array}$ & & $\begin{array}{c}.697 \\
(.101)\end{array}$ & $\begin{array}{l}-.617 \\
(.104)\end{array}$ & $\begin{array}{l}-.244 \\
(.067)\end{array}$ \\
\hline & \multicolumn{8}{|c|}{ II. Estimates for the 2010-2011 Treatment } \\
\hline Level Effect & $\begin{array}{c}12.147^{* * *} \\
(.031)\end{array}$ & $\begin{array}{c}.575^{* * *} \\
(.131)\end{array}$ & $\begin{array}{c}-6.433^{* * *} \\
(1.523)\end{array}$ & $\begin{array}{c}-4.939^{* * *} \\
(1.296)\end{array}$ & $\begin{array}{l}11.011^{* * *} \\
(.000)\end{array}$ & $\begin{array}{c}.800^{* * *} \\
(.095)\end{array}$ & $\begin{array}{c}-5.226^{* * *} \\
\quad(.526)\end{array}$ & $\begin{array}{c}-3.323^{* * *} \\
(.475)\end{array}$ \\
\hline $\begin{array}{l}\text { Mean at Baseline } \\
\text { (Treated) }\end{array}$ & 47.461 & 4.734 & 35.072 & 47.478 & 47.461 & 4.734 & 35.072 & 47.478 \\
\hline Relative Effect & $\begin{array}{l}.256 \\
(.000)\end{array}$ & $\begin{array}{l}.121 \\
(.027)\end{array}$ & $\begin{array}{l}-.183 \\
(.043)\end{array}$ & $\begin{array}{l}-.104 \\
(.027)\end{array}$ & $\begin{array}{l}.232 \\
(.000)\end{array}$ & $\begin{array}{l}.169 \\
(.017)\end{array}$ & $\begin{array}{l}-.149 \\
(.017)\end{array}$ & $\begin{array}{l}-.070 \\
(.011)\end{array}$ \\
\hline \multirow[t]{2}{*}{ Implied Elasticity } & & $\begin{array}{c}.475 \\
(.108)\end{array}$ & $\begin{array}{l}-.717 \\
(.170)\end{array}$ & $\begin{array}{l}-.407 \\
(.107)\end{array}$ & & $\begin{array}{c}.728 \\
(.085)\end{array}$ & $\begin{array}{l}-.642 \\
(.064)\end{array}$ & $\begin{array}{l}-.300 \\
(.043)\end{array}$ \\
\hline & \multicolumn{8}{|c|}{ III. Estimates for the 2011-2012 Treatment } \\
\hline Level Effect & $\begin{array}{c}18.002^{* * *} \\
(.024)\end{array}$ & $\begin{array}{c}.452^{* * *} \\
(.085)\end{array}$ & $\begin{array}{c}-10.949^{* * *} \\
(1.387)\end{array}$ & $\begin{array}{c}-6.228^{* * *} \\
(1.185)\end{array}$ & $\begin{array}{c}16.465^{* * *} \\
(.000)\end{array}$ & $\begin{array}{c}.644^{* * *} \\
(.095)\end{array}$ & $\begin{array}{c}-11.391^{* * *} \\
(.532)\end{array}$ & $\begin{array}{c}-8.169^{* * *} \\
(.449)\end{array}$ \\
\hline $\begin{array}{l}\text { Mean at Baseline } \\
\text { (Treated) }\end{array}$ & 41.06 & 3.287 & 37.969 & 44.885 & 41.06 & 3.287 & 37.969 & 44.885 \\
\hline Relative Effect & $\begin{array}{l}.438 \\
(.000)\end{array}$ & $\begin{array}{l}.137 \\
(.025)\end{array}$ & $\begin{array}{l}-.288 \\
(.036)\end{array}$ & $\begin{array}{l}-.138 \\
(.026)\end{array}$ & $\begin{array}{l}.401 \\
(.000)\end{array}$ & $\begin{array}{l}.196 \\
(.029)\end{array}$ & $\begin{array}{l}-.300 \\
(.014)\end{array}$ & $\begin{array}{l}-.182 \\
(.010)\end{array}$ \\
\hline Implied Elasticity & & $\begin{array}{l}.314 \\
(.059)\end{array}$ & $\begin{array}{l}-.658 \\
(.083)\end{array}$ & $\begin{array}{l}-.316 \\
(.060)\end{array}$ & & $\begin{array}{l}.489 \\
(.073)\end{array}$ & $\begin{array}{l}-.747 \\
(.035)\end{array}$ & $\begin{array}{l}-.455 \\
(.025)\end{array}$ \\
\hline
\end{tabular}

Notes: This table reports results from the RD and DiD estimations discussed in Section 4. Each year, properties in a specific value band are treated with a large tax rate increase. The treated value bands are $\mathrm{I}, \mathrm{H}$, and $\mathrm{G}$ in the years 2010, 2011, and 2012, respectively. In the RD, we compare these properties to properties just below the lower threshold of the treated value band. The estimating equation is $\Delta Y_{i, t}=\alpha+\beta T_{i}+f\left(\hat{V}_{i}\right)+g\left(\hat{V}_{i}\right) T_{i}+\epsilon_{i, t}$, where $\hat{V}_{i}$ denotes the distance between the value of property $i$ and the lower limit of the treated band, $T_{i}$ indicates properties in the treated band, and $f$ and $g$ are third-order polynomial functions. Standard errors are robust to heteroskedasticity and clustered at the postcode level. In the DiD, we compare treated properties to properties in value bands $\mathrm{K}$ and $\mathrm{L}$. The estimating equation is $Y_{i t}=\alpha+D D_{i t} \beta+\gamma_{i}+\delta_{t}+\epsilon_{i t}$, where $D D_{i t}$ indicates treated properties in post-reform years and $\delta_{t}$ and $\gamma_{i}$ denote year and property fixed effects. We estimate this equation in levels and transform the point estimates into relative effects, scaling them by the treatment group mean in the last pre-reform year. Standard errors are robust to heteroskedasticity and clustered at the property level. The number of $\{$ treated properties, control properties $\}$ in the $\mathrm{RD}$ is $\{6763,11101\}$ in $2010,\{11039,17055\}$ in 2011, and $\{16890$, $31948\}$ in 2012; in the DiD (which uses a balanced sample) it is $\{5747,6510\}$ in 2010, $\{9661,6510\}$ in 2011, and \{15227, 6510\} in 2012. Outcomes: payment amount is in MXN thousands, full payment is in percentage points, compliance share is tax payment over liability X 100. Figures 3-6 present the RD and DiD estimations graphically. Appendices D and E present various identification and robustness tests. ${ }^{*} p<.1,{ }^{* *} p<.05,{ }^{* * *} p<.01$. 
Table 3: The Effect of Enforcement Letters on Tax Payment - Experimental Estimates

\begin{tabular}{|c|c|c|c|c|c|c|c|}
\hline \multicolumn{2}{|c|}{ 1: Letter Content } & \multicolumn{2}{|c|}{ 2: Sender Position } & \multicolumn{2}{|c|}{ 3: Male Sender } & \multicolumn{2}{|c|}{ 4: Female Sender } \\
\hline Sanctions & $\begin{array}{l}\text { Public } \\
\text { Good }\end{array}$ & $\begin{array}{c}\text { Fiscal } \\
\text { Attorney }\end{array}$ & $\begin{array}{c}\text { Compliance } \\
\text { Officer }\end{array}$ & Male & Neutral & Female & Neutral \\
\hline \multicolumn{8}{|c|}{ Outcome A: Any Payment } \\
\hline $\begin{array}{c}9.364^{* * * *} \\
(.29)\end{array}$ & $\begin{array}{c}4.858^{* * *} \\
(.274)\end{array}$ & $\begin{array}{c}7.598^{* * *} \\
(.284)\end{array}$ & $\begin{array}{c}6.624^{* * *} \\
(.281)\end{array}$ & $\begin{array}{c}7.038^{* * *} \\
(.332)\end{array}$ & $\begin{array}{c}8.15^{* * * *} \\
(.337)\end{array}$ & $\begin{array}{c}6.772^{* * *} \\
(.329)\end{array}$ & $\begin{array}{c}6.477^{* * * *} \\
(.329)\end{array}$ \\
\hline \multicolumn{2}{|c|}{.000} & \multicolumn{2}{|c|}{.000} & \multicolumn{2}{|c|}{.002} & \multicolumn{2}{|c|}{.390} \\
\hline \multicolumn{8}{|c|}{ Outcome B: Payment Amount (MX Pesos) } \\
\hline $\begin{array}{c}54.226^{* * * *} \\
(2.593)\end{array}$ & $\begin{array}{c}16.051^{* * *} \\
(2.297)\end{array}$ & $\begin{array}{c}42.416^{* * *} \\
(2.496)\end{array}$ & $\begin{array}{c}27.861^{* * *} \\
(2.407)\end{array}$ & \begin{tabular}{|c|}
$39.707^{* * *}$ \\
$(2.979)$
\end{tabular} & $\begin{array}{c}45.124^{* * *} \\
(2.942)\end{array}$ & \begin{tabular}{|c|}
$29.025^{* * *}$ \\
$(2.807)$
\end{tabular} & $\begin{array}{c}26.698^{* * * *} \\
(2.811)\end{array}$ \\
\hline \multicolumn{2}{|c|}{.000} & \multicolumn{2}{|c|}{.000} & \multicolumn{2}{|c|}{.089} & \multicolumn{2}{|c|}{.422} \\
\hline
\end{tabular}

Notes: This table evaluates the effect of enforcement letters, as discussed in Section 5, on payment of outstanding tax debt, contrasting the different treatments summarized in Figure G.1. Each of Columns (1)-(4) and each panel corresponds to one regression. We estimate $Y_{i}=\alpha+\beta_{1} T 1_{i}+\beta_{2} T 2_{i}+\epsilon_{i}$, where $Y_{i}$ is the outcome for property $i$ evaluated 40 days after all letters were sent, $\alpha$ is a constant, $T 1_{i}$ and $T 2_{i}$ are dummies indicating the two mutually exclusive treatments (i.e., the sanctions treatment and the public goods treatment), and $\epsilon_{i}$ is the error term. The outcome is any payment in Panel A and the payment amount in Panel B. The outcomes are cumulative over time for each property. The bottom line of each panel reports the p-values from a Wald test of significant differences between each pair of treatment estimates. Figure 7 presents accompanying non-parametric evidence for the effect of the sanctions treatment and public goods treatment. Since the treatment and control groups exhibit slightly different trends prior to the intervention, as shown in Figure G.2, we display the data and run our estimations on detrended data. To do so, we estimate the following regression on the pre-intervention data: $Y_{i g t}=\mu_{g} \cdot t+\alpha_{i}+\lambda_{t}+\epsilon_{i g t}$, where $t$ indicates days and $g$ treatment groups. We then subtract the trend $\mu_{g} \cdot t$ from each treatment group. In all estimations, weekends are excluded from the sample. Payment amounts are winsorized at the 99th percentile. Standard errors in parentheses are robust to heteroskedasticity and are clustered at the property level. Table G.2 shows that the results are robust to including property characteristics as controls and estimating the treatment effects via difference-in-differences. ${ }^{*} p<.1,{ }^{* *} p<.05,{ }^{* * *} p<.01$.

Table 4: The Effect of Property Taxes on Consumption - Instrumental Variable Estimates

\begin{tabular}{lcccc}
\hline & $(1)$ & $(2)$ & $(3)$ & $(4)$ \\
\hline $\log ($ Pay $)$ & -.028 & -.049 & -.021 & -.038 \\
& $(.05)$ & $(.053)$ & $(.049)$ & $(.052)$ \\
$\log ($ Pay $) \times \log$ (pc income $)$ & & $.098 * * *$ & & $.075^{* *}$ \\
& & $(.037)$ & & $(.037)$ \\
$\log ($ Pay $) \times$ Lack of credit & & & $-.05 * * *$ & $-.041 * * *$ \\
$\log ($ pc income $)$ & $.829 * * *$ & .262 & $. .008)$ & $(.007)$ \\
& $(.033)$ & $(.205)$ & $(.031)$ & $.36 * *$ \\
& & & $.206)$ \\
\hline
\end{tabular}

Notes: This table reports the second-stage results from the IV estimation discussed in Section 6.2. N=2,649. All regressions include delegación fixed effects and year dummies. Bootstrapped standard errors based on 1,000 replications are in parentheses. The outcome is $\log (\mathrm{pc}$ consumption). $\log (\mathrm{pc}$ income $)$ is centered at the mean. The first-stage results are shown in Table J.1. Robustness tests using alternative instruments are shown in Tables J.2 and J.3. ${ }^{*} p<0.1,{ }^{* *} p<0.05,{ }^{* * *} p<0.01$. 


\section{Figures}

Figure 1: Ratio of Tax Revenue to GDP in High-Income vs Lower-Income Countries

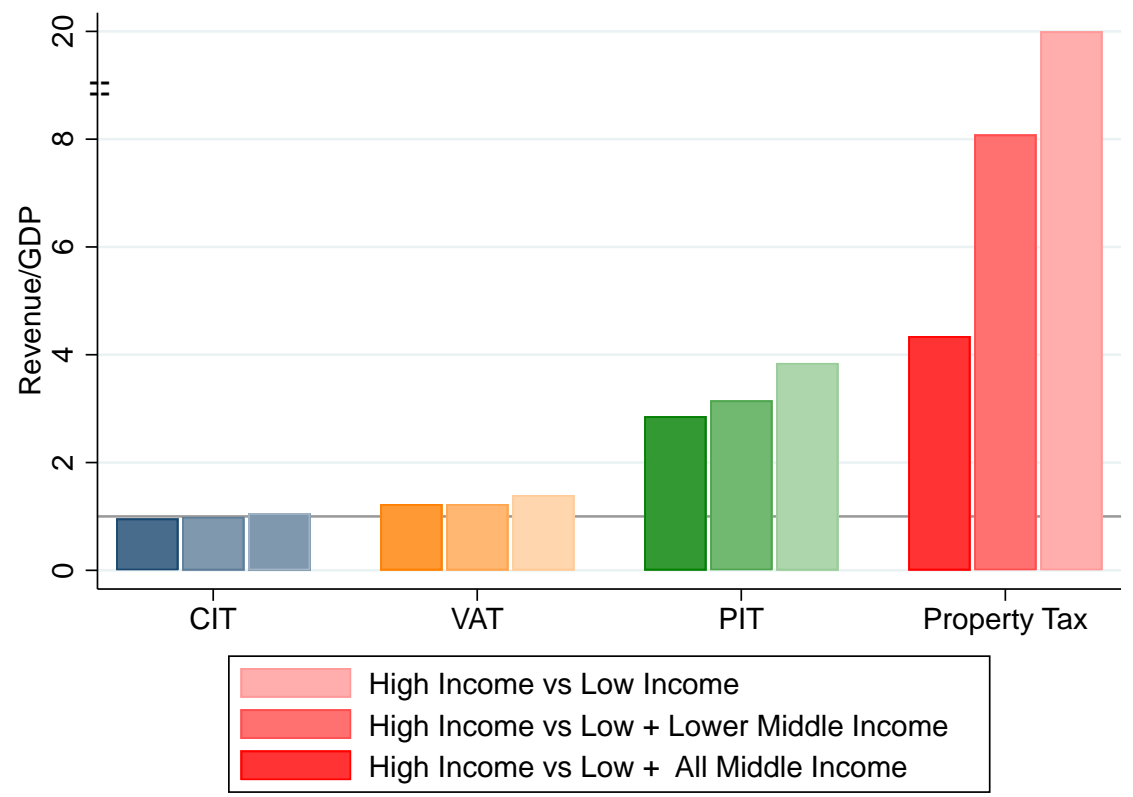

Notes: This figure shows the ratio of tax revenue as a share of GDP in high-income versus lower-income countries, as discussed in the introduction, for corporate income tax (CIT), value-added tax (VAT), personal income tax (PIT), and property taxes in 2017. The data are from the International Monetary Fund (2019) World Revenue Data and the World Bank (2019) World Development Indicators. The country income classification follows that of the World Bank Atlas methodology.

Figure 2: Variation in Tax Rates over Time and across Cadastral Value Bands, 2008-2012

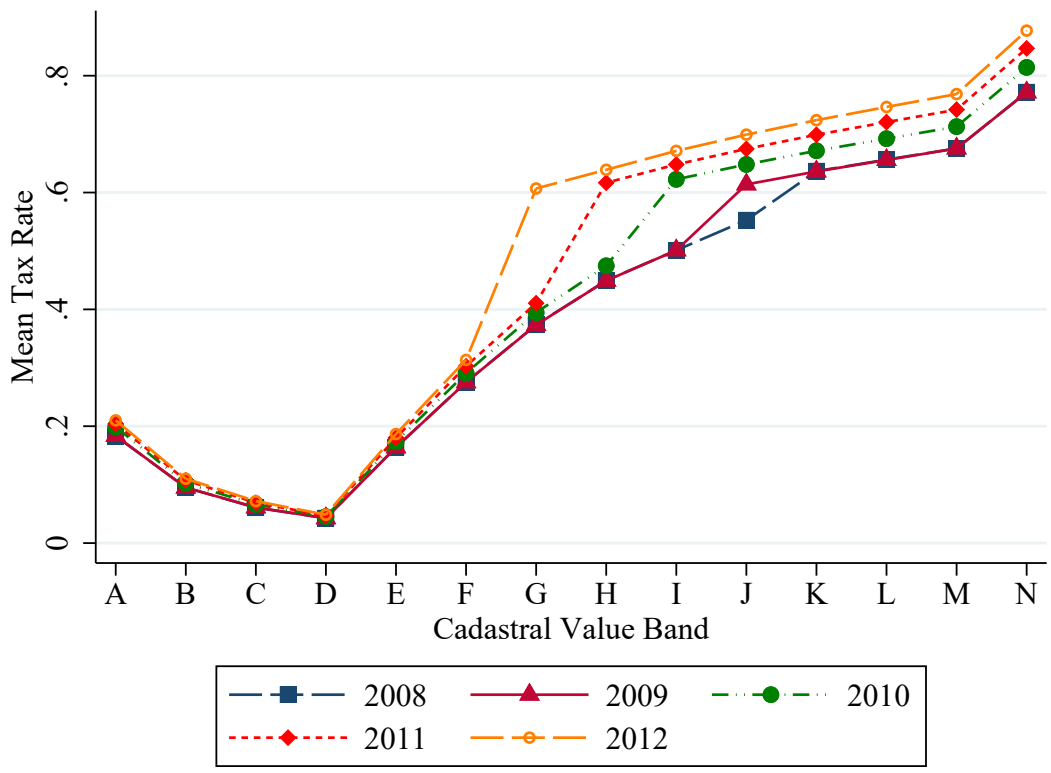

Notes: This figure, discussed in the introduction, shows the mean tax rate in percentage points by cadastral value band and year. We construct this figure using administrative tax bills. 
Figure 3: The Effect of Tax Rates on Tax Payment - Regression Discontinuity Estimates
A. Mean Tax Rate
B. Payment Amount

\section{Estimates for the 2009-2010 Treatment}
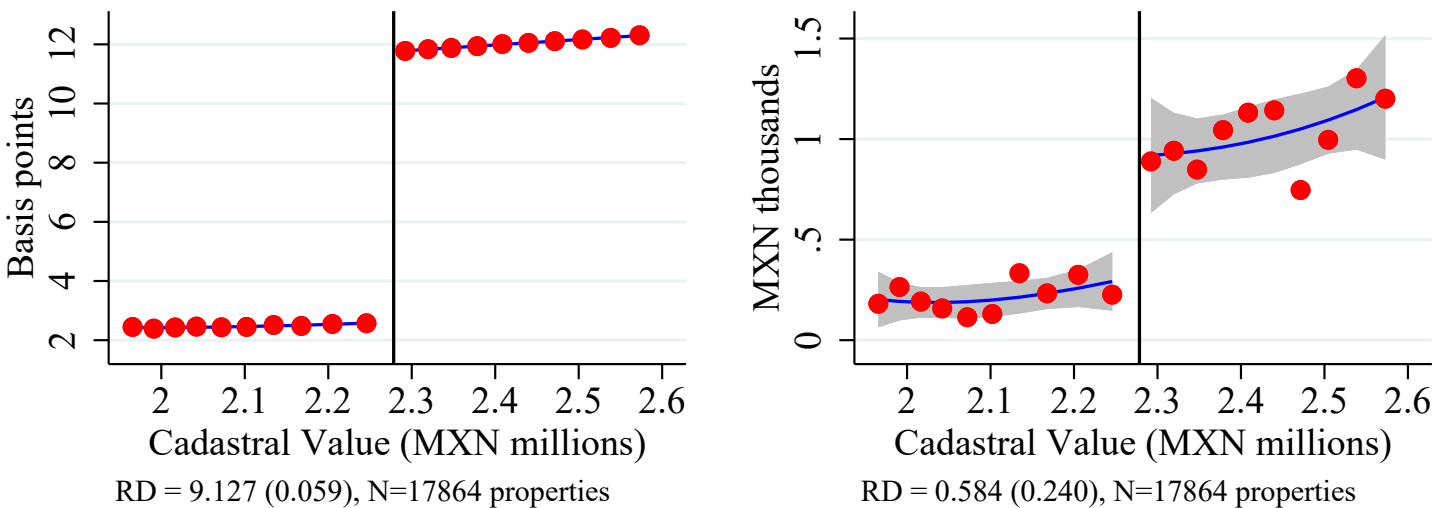

II. Estimates for the 2010-2011 Treatment
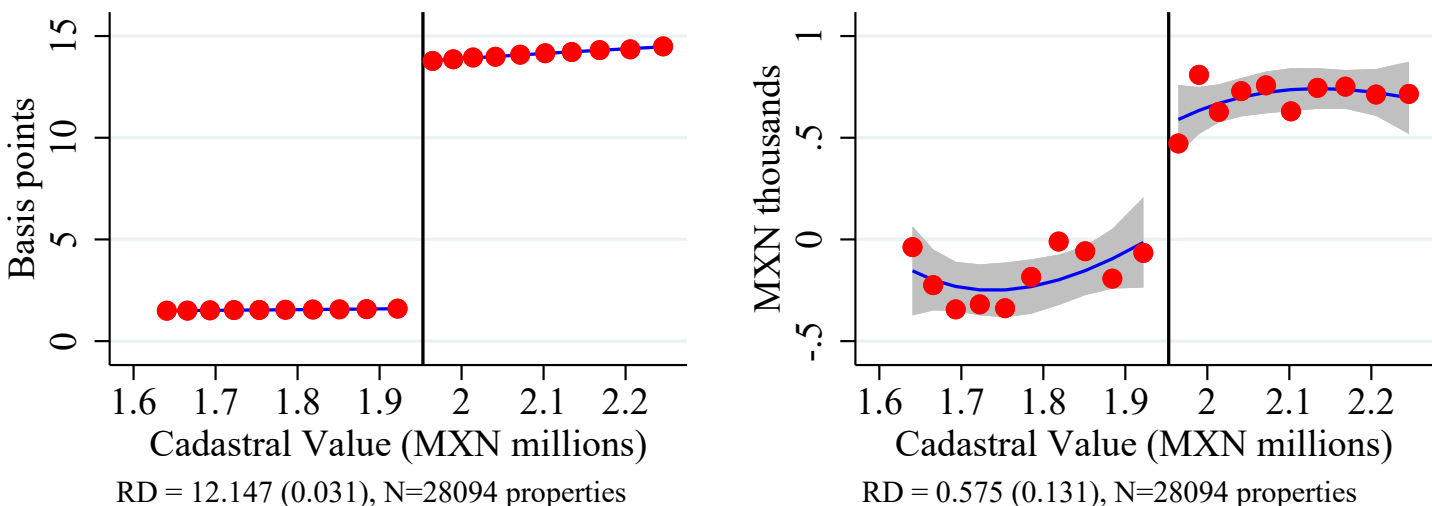

III. Estimates for the 2011-2012 Treatment
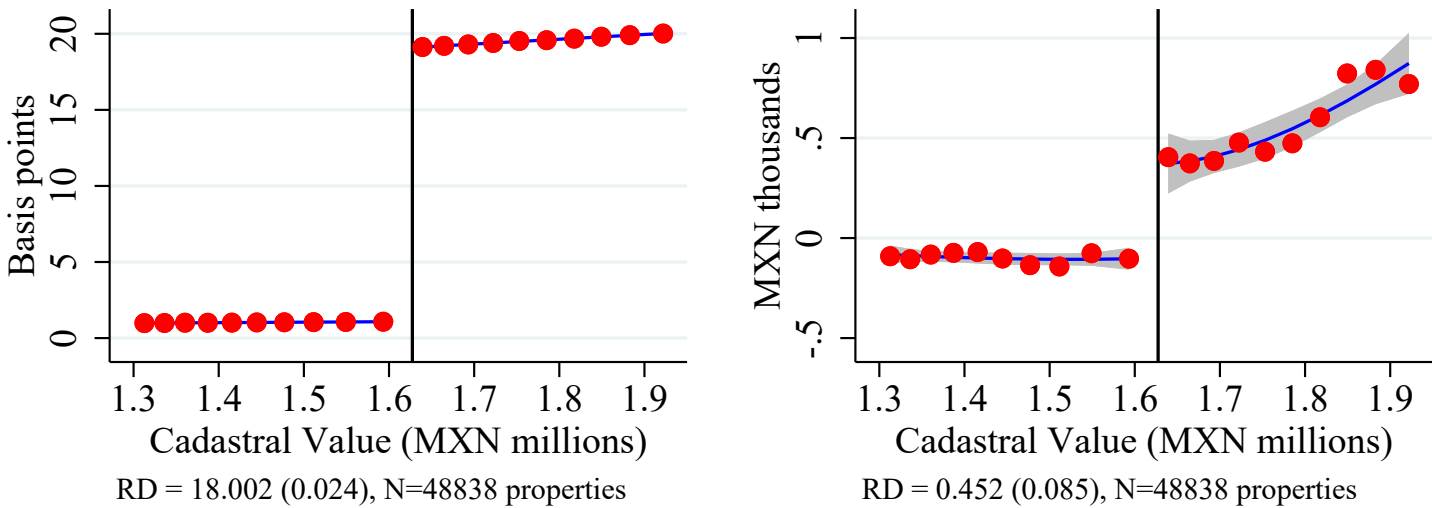

Notes: These graphs implement the RD estimation from Section 4.1. The red dots represent the mean outcome in equally spaced cadastral value bins. The solid blue lines (gray areas) depict a fitted third-order polynomial (the corresponding 95 percent confidence intervals). The vertical black lines mark the thresholds between the control and treatment bands. Properties to the right of the threshold are treated with a tax rate increase. We use the band below as the counterfactual since properties in the band above the treated band are treated in the previous year. The treated value bands are I, H and G in the years 2010, 2011 and 2012, respectively. The notes display the estimate for $\beta$ from $\Delta Y_{i, t}=\alpha+\beta T_{i}+f\left(\hat{V}_{i}\right)+g\left(\hat{V}_{i}\right) T_{i}+\epsilon_{i, t}$, where $\hat{V}_{i}$ denotes the distance between the value of property $i$ and the lower limit of the treated band, $T_{i}$ indicates properties in the treated band, and $f$ and $g$ are third-order polynomial functions. Standard errors are robust to heteroskedasticity and clustered at the postcode level. Table 2 summarizes the estimates and implied elasticities. Table D.2 shows the robustness to local linear regressions with optimal bandwidth. Figure D.2 shows the robustness to varying bandwidths and degrees of polynomial. 
Figure 4: The Effect of Tax Rates on Compliance - Regression Discontinuity Estimates

A. Full Payment Dummy

B. Compliance Share

I. Estimates for the 2009-2010 Treatment
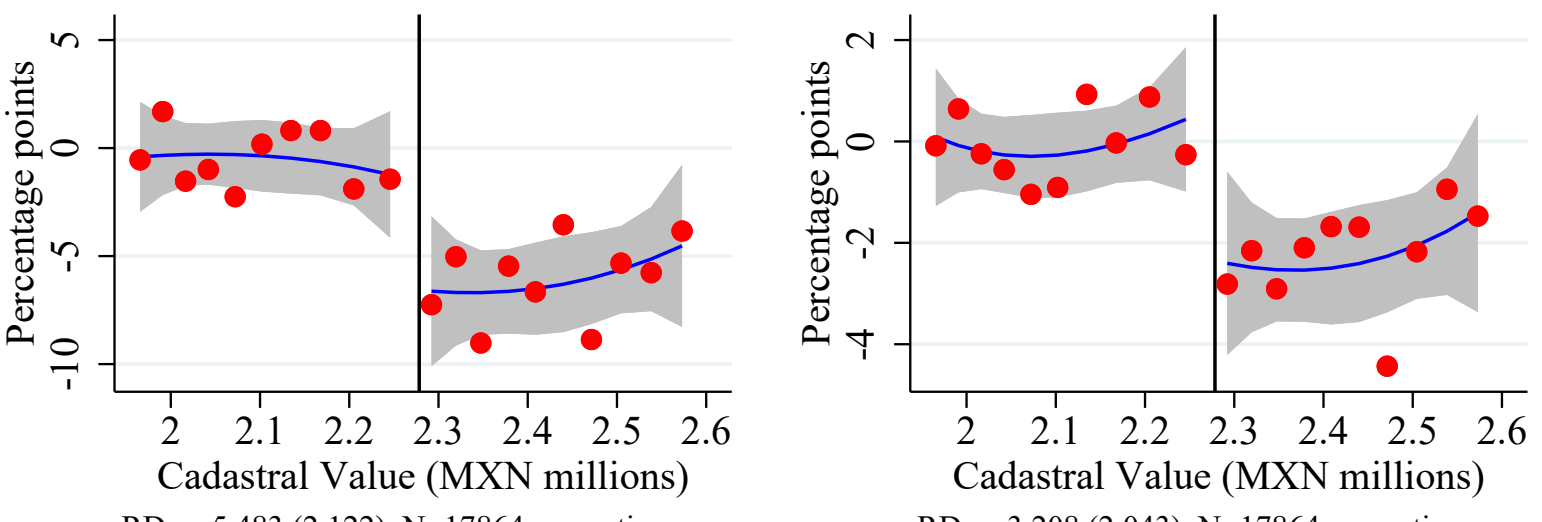

$\mathrm{RD}=-5.483$ (2.122), $\mathrm{N}=17864$ properties

$\mathrm{RD}=-3.208$ (2.043), $\mathrm{N}=17864$ properties

II. Estimates for the 2010-2011 Treatment
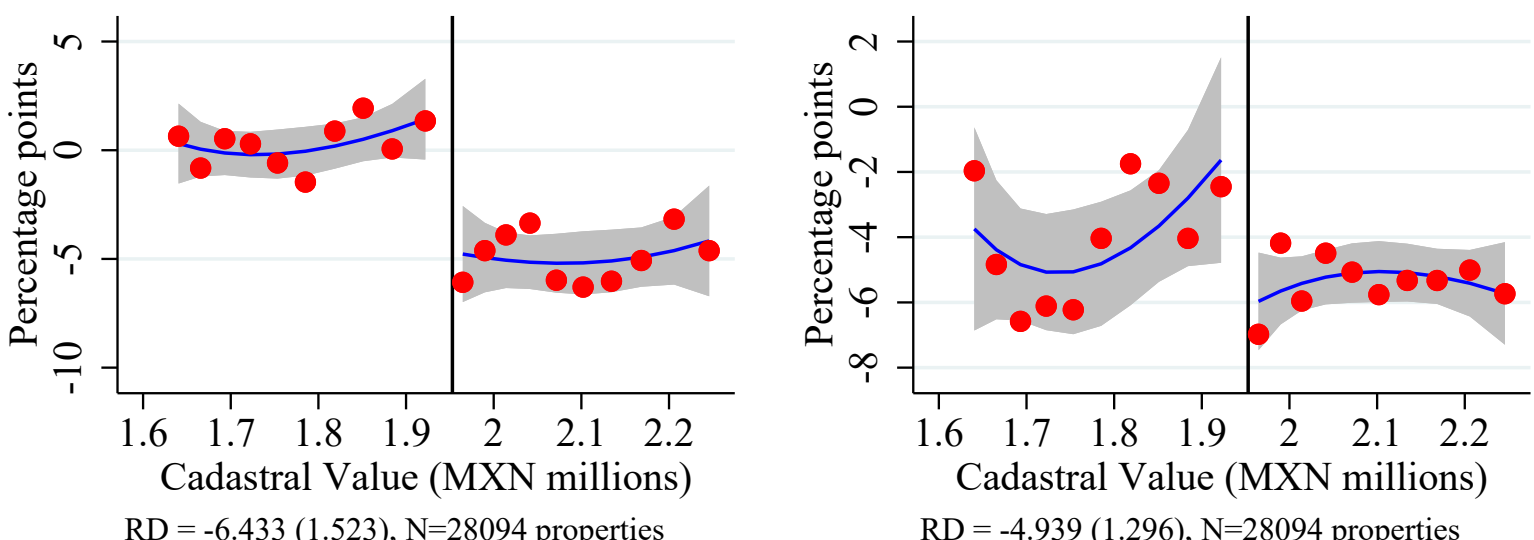

III. Estimates for the 2011-2012 Treatment
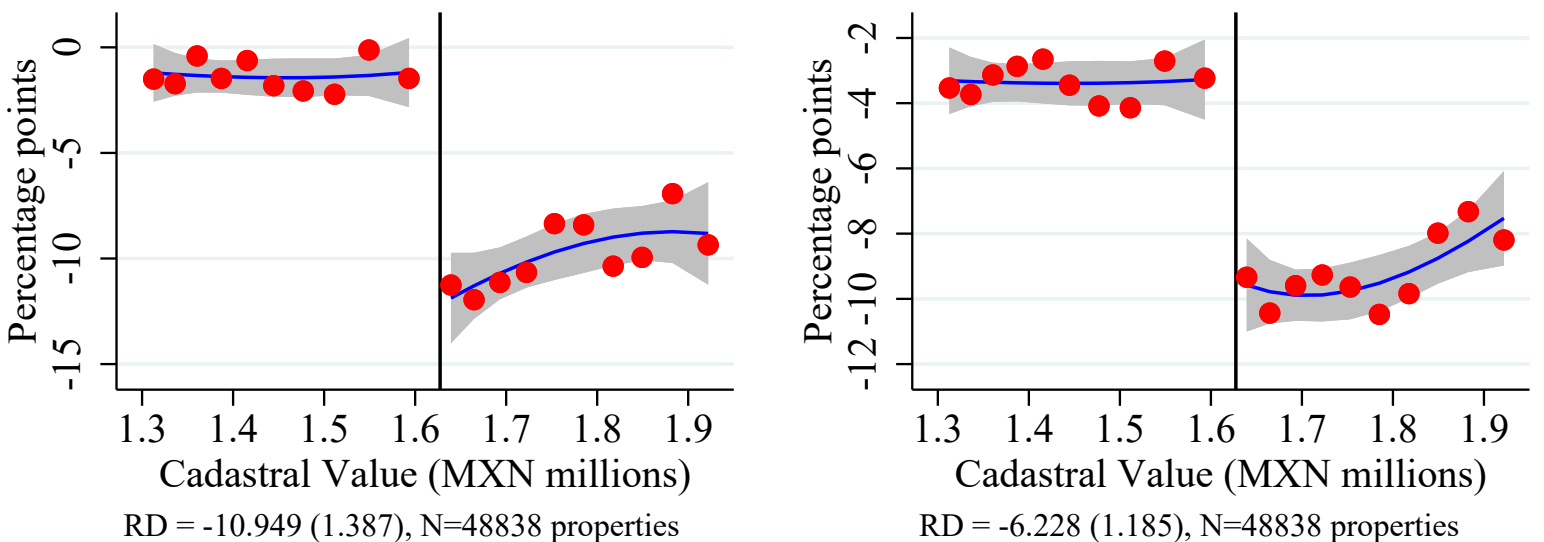

Notes: This figure is identical to Figure 3 but displays the results for different outcomes: a dummy indicating that taxpayers paid their liability fully and on time and the compliance share, defined as the tax payment divided by the liability. 
Figure 5: The Effect of Tax Rates on Tax Payment - Difference-in-Difference Estimates
A. Mean Tax Rate
B. Payment Amount

I. Estimates for the 2009-2010 Treatment
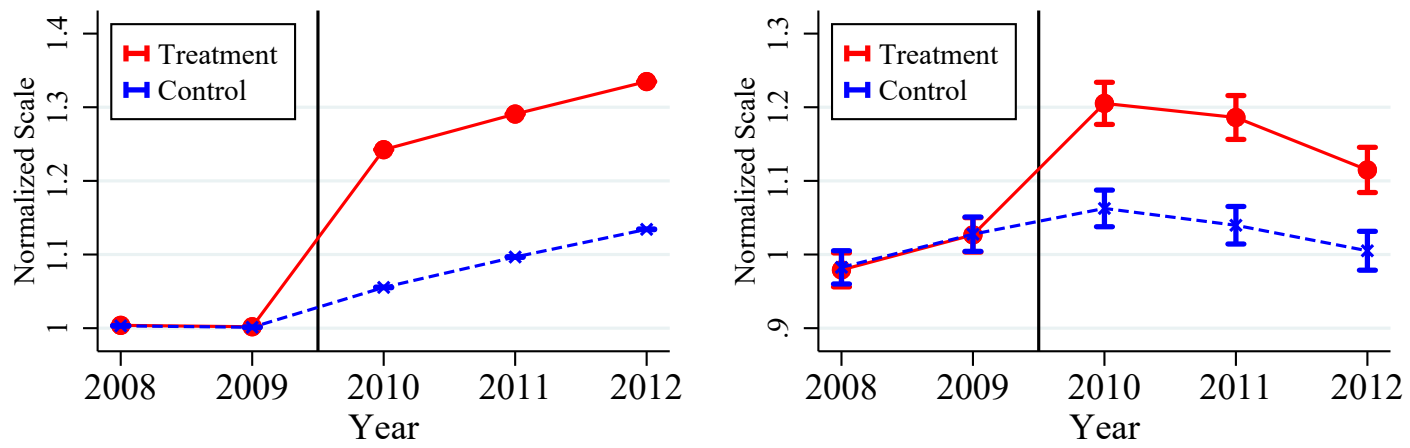

$\mathrm{DD}=.166(.000), \mathrm{N}=12257$ properties per year

$\mathrm{DD}=.116(.017), \mathrm{N}=12257$ properties per year

II. Estimates for the 2010-2011 Treatment

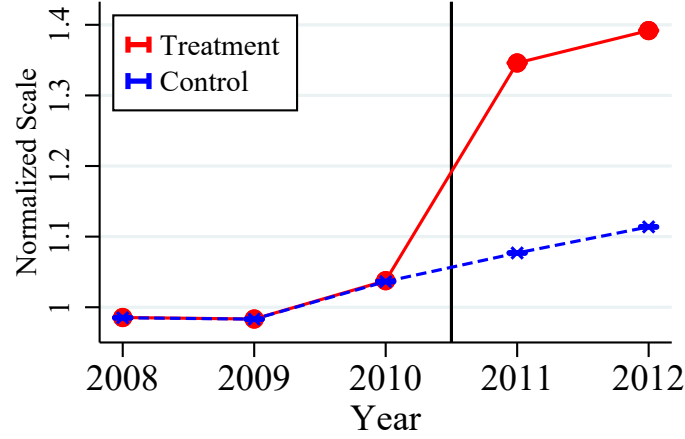

$\mathrm{DD}=.232(.000), \mathrm{N}=16172$ properties per year

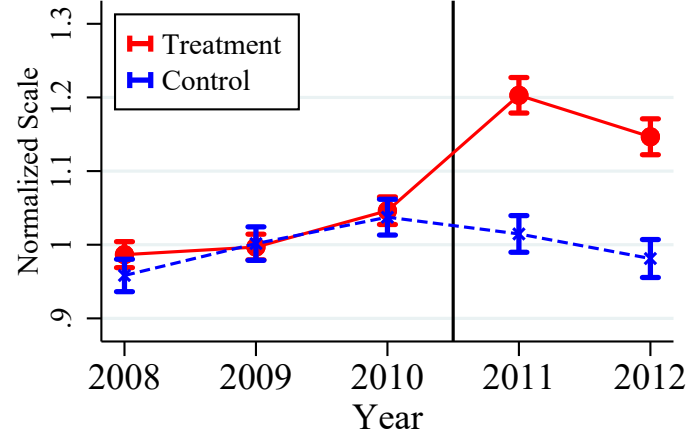

$\mathrm{DD}=.169(.020), \mathrm{N}=16172$ properties per year

III. Estimates for the 2011-2012 Treatment

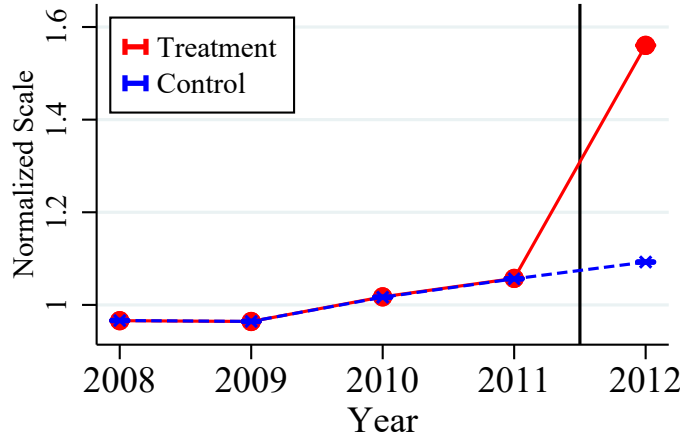

$\mathrm{DD}=.401(000), \mathrm{N}=21735$ properties per year

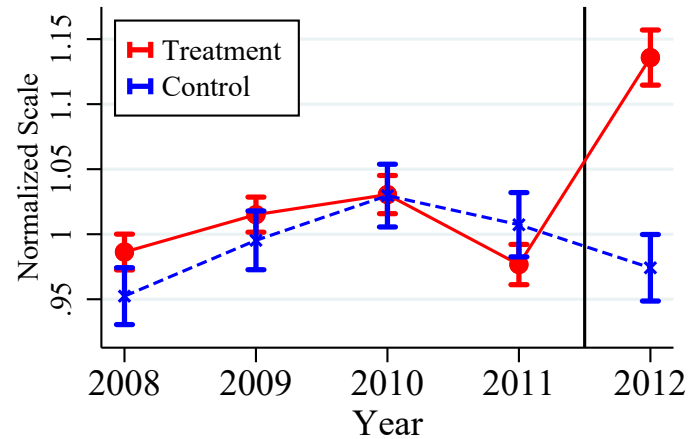

$\mathrm{DD}=.196(.029), \mathrm{N}=21735$ properties per year

Notes: These graphs implement the DiD estimation from Section 4.2. Treatment and control group outcomes are normalized by their pre-reform mean. The vertical black lines mark the treatment timing. The notes display the estimate for $\beta$ from $Y_{i t}=\alpha+D D_{i t} \beta+\gamma_{i}+\delta_{t}+\epsilon_{i t}$, where $D D_{i t}$ indicates treated properties in post-reform years and $\delta_{t}$ and $\gamma_{i}$ denote year and property fixed effects. We estimate this equation in levels and transform the point estimates into relative effects, scaling them by the treatment group mean in the last pre-reform year. Standard errors are robust to heteroskedasticity and clustered at the property level. The treated value bands are I, H and G in the years 2010, 2011 and 2012, respectively. The control group is composed of properties in bands K and L. Table 2 summarizes the estimates and implied elasticities. Appendix E presents various robustness tests. 
Figure 6: The Effect of Tax Rates on Compliance - Difference-in-Difference Estimates
A. Full Payment Dummy
B. Compliance Share

I. Estimates for the 2009-2010 Treatment
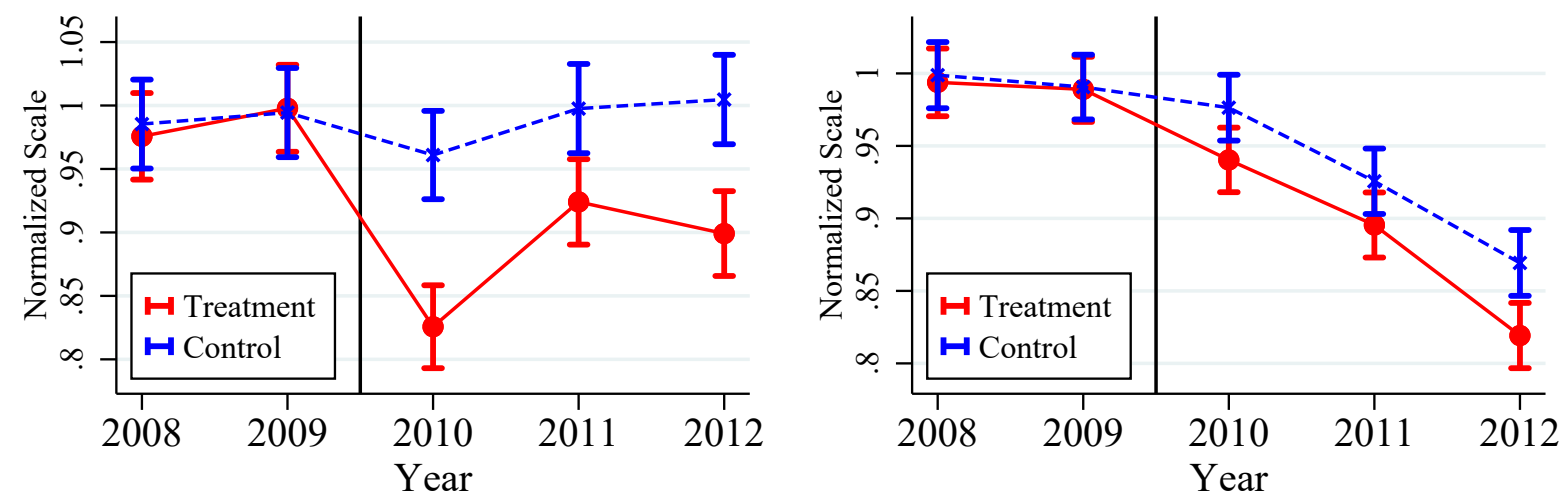

$\mathrm{DD}=-.103(.017), \mathrm{N}=12257$ properties per year

$\mathrm{DD}=-.041(.011), \mathrm{N}=12257$ properties per year

II. Estimates for the 2010-2011 Treatment
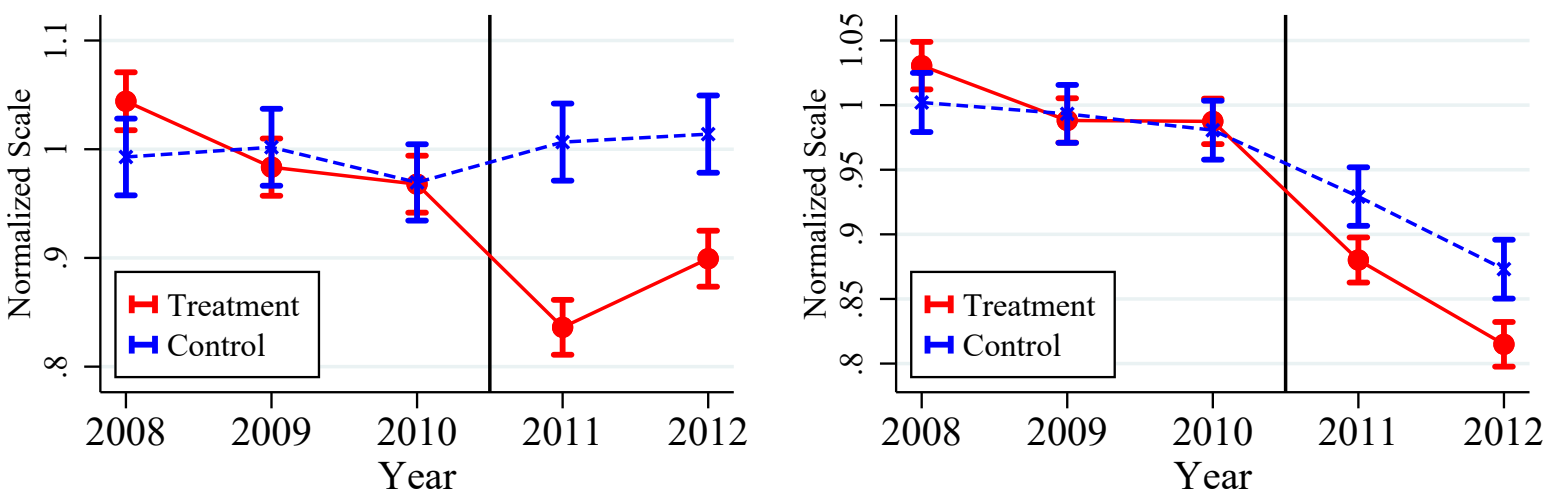

$\mathrm{DD}=-.149(.015), \mathrm{N}=16172$ properties per year

$\mathrm{DD}=-.070(.010), \mathrm{N}=16172$ properties per year

III. Estimates for the 2011-2012 Treatment

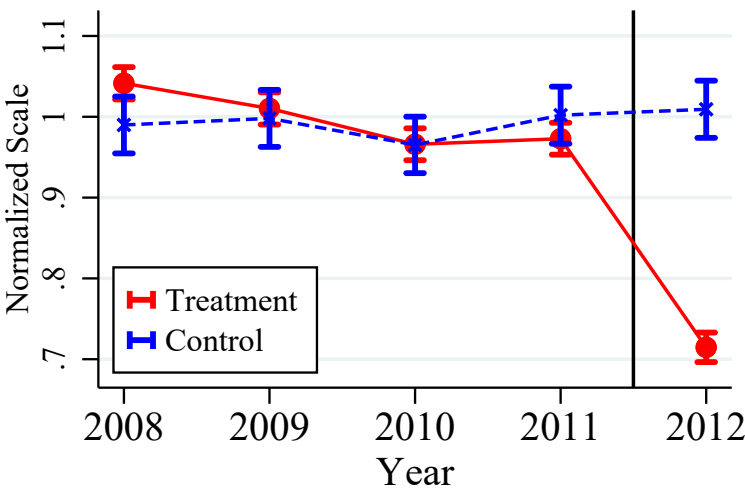

$\mathrm{DD}=-.300(.014), \mathrm{N}=21735$ properties per year

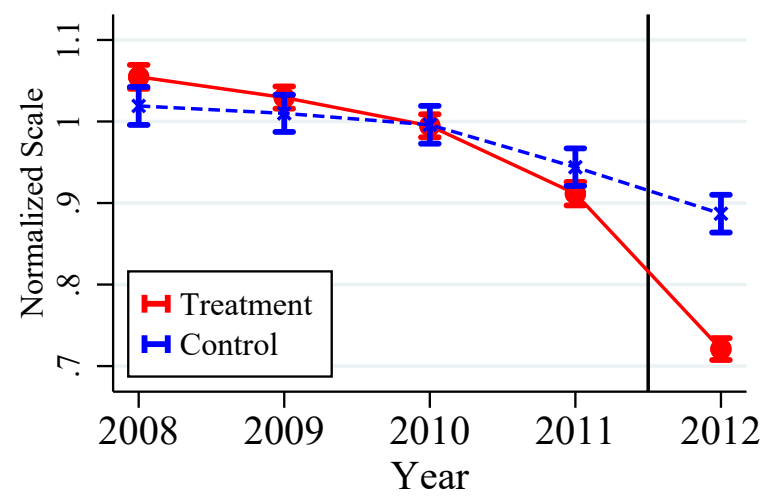

$\mathrm{DD}=-.182(.010), \mathrm{N}=21735$ properties per year

Notes: This figure is identical to Figure 5 but displays the results for different outcomes: a dummy indicating that taxpayers paid their liability fully and on time and the compliance share, defined as the tax payment divided by the liability. 
A. Any Payment

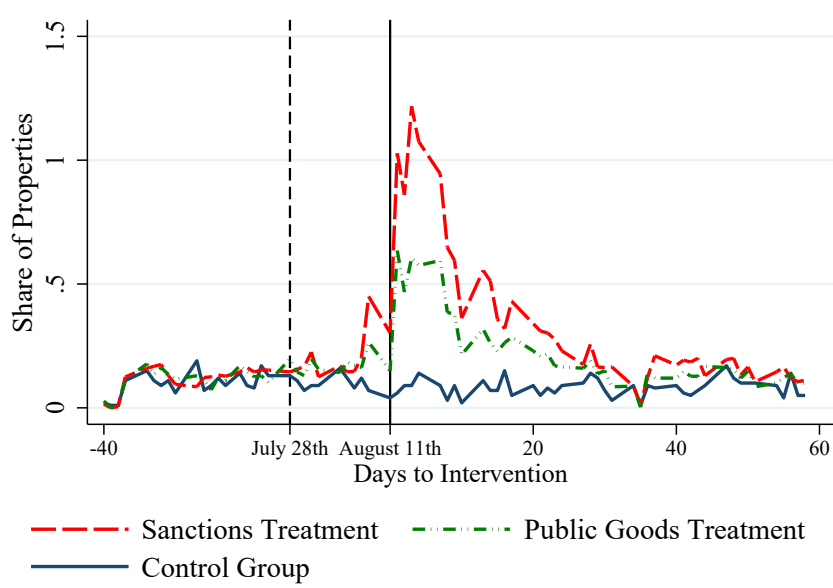

C. Cumulative Payment Amount

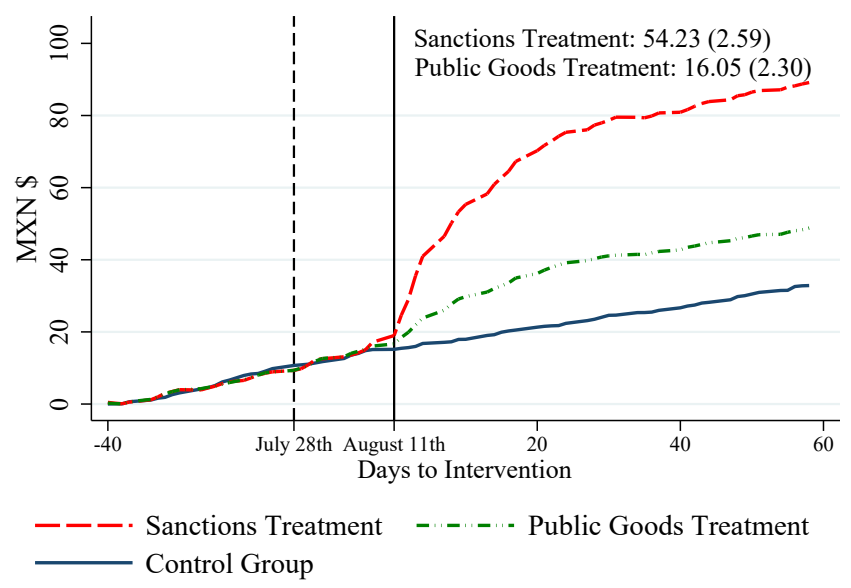

B. Cumulative Payments (Any Amount)

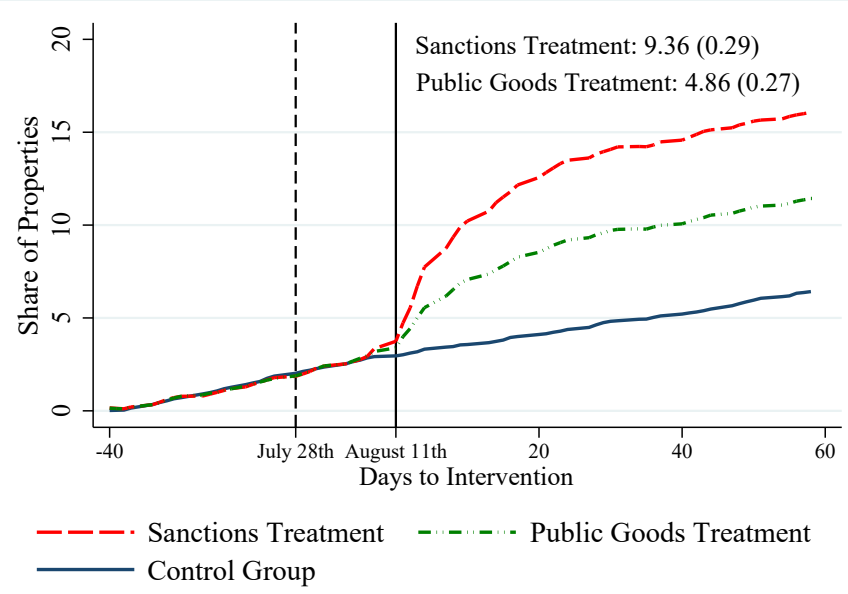

D. Cumulative Share of Liability Paid

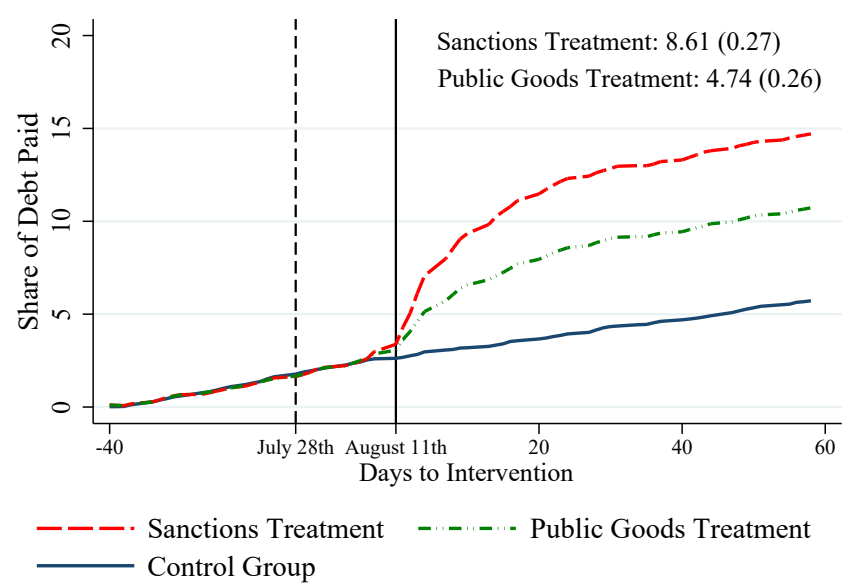

Notes: This figure displays taxpayers' response to enforcement letters, as discussed in Section 5. Panel A shows the share of properties for which a payment was made on any given day around the time of the enforcement intervention. Panel B shows the cumulative share of properties for which a payment was made, Panel C shows the average cumulative payment amount, and Panel D displays the share of the outstanding liability paid. We consider payments made between July and November 2014 against outstanding debt for the period from bimester 4 of 2009 to bimester 3 of 2014. The period during which the letters were sent-July 28 to August 11, 2014 - is represented by the vertical lines. Panels B-D display the point estimates $\beta_{1}$ and $\beta_{2}$ from the OLS regression $Y_{i}=\alpha+\beta_{1} T 1_{i}+\beta_{2} T 2_{i}+\epsilon_{i}$, where $Y_{i}$ is the outcome for property $i$ evaluated 40 days after all letters were sent and $T 1_{i}$ and $T 2_{i}$ are dummies for the sanctions treatment and the public goods treatment, respectively. Since the treatment and control groups exhibit slightly different trends prior to the intervention, as shown in Figure G.2, we display here and run our estimations on detrended data. To do that, we run the following regression on the pre-intervention data: $Y_{i g t}=\mu_{g} \cdot t+\alpha_{i}+\lambda_{t}+\epsilon_{i g t}$, where $t$ indicates days and $g$ treatment groups. We then subtract the trend $\mu_{g} \cdot t$ from each treatment group. This is reasonable because the pre-intervention trend is indeed almost perfectly linear and the control group trend continues linearly after the intervention. In all estimations, weekends are excluded from the sample. Payment amounts are winzorized at the 99th percentile. Standard errors are robust to heteroskedasticity and are clustered at the property level. Table 3 presents regression estimates evaluating all treatment arms of the intervention, and Table G.2 shows the robustness of these results to controlling for property characteristics in the estimation and to estimation via difference-in-difference. 

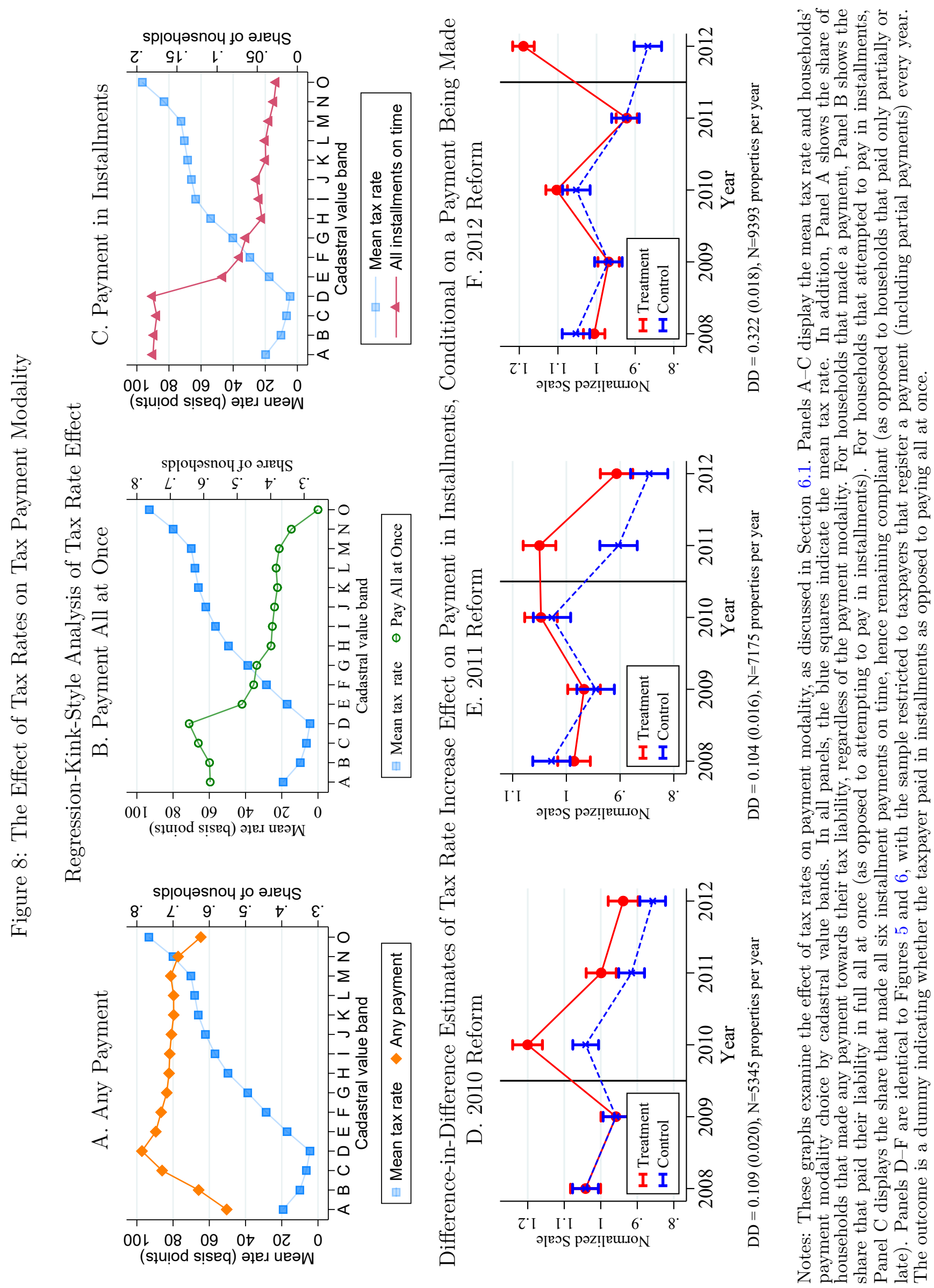

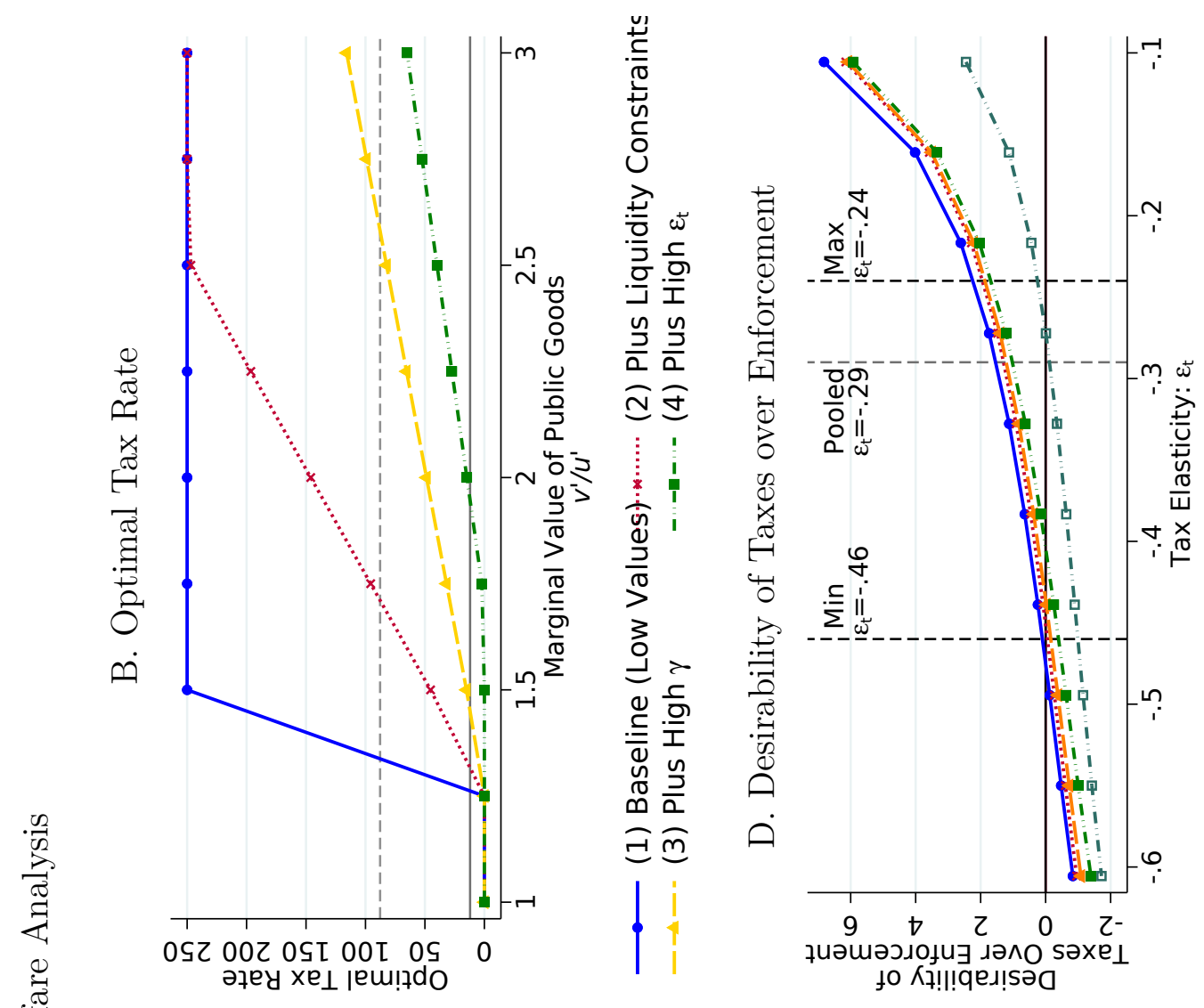

:

w $>$

.

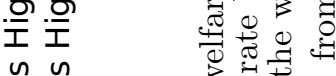

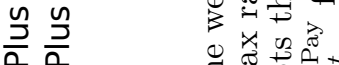

ป正

;

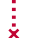

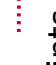

ง $\cdot \frac{\sigma}{0}$

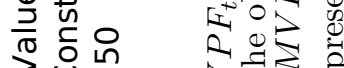

उ 0 झाई है

文

ข

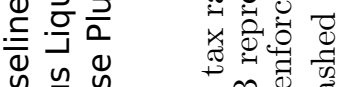

ก๊

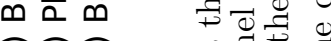

드르

| 1 1

$\varangle \circlearrowright \circlearrowright$

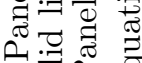

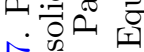

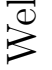

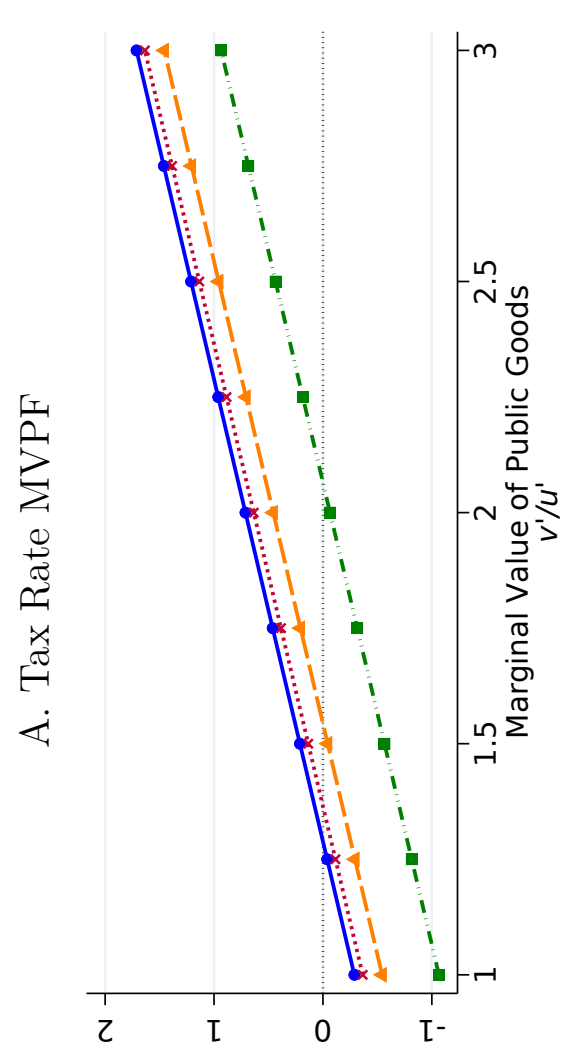

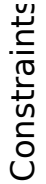

$\pm$

흠듬

음

$\frac{n}{\frac{2}{2}} \frac{n}{\frac{1}{2}}$

$\widehat{\simeq}$

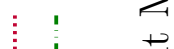

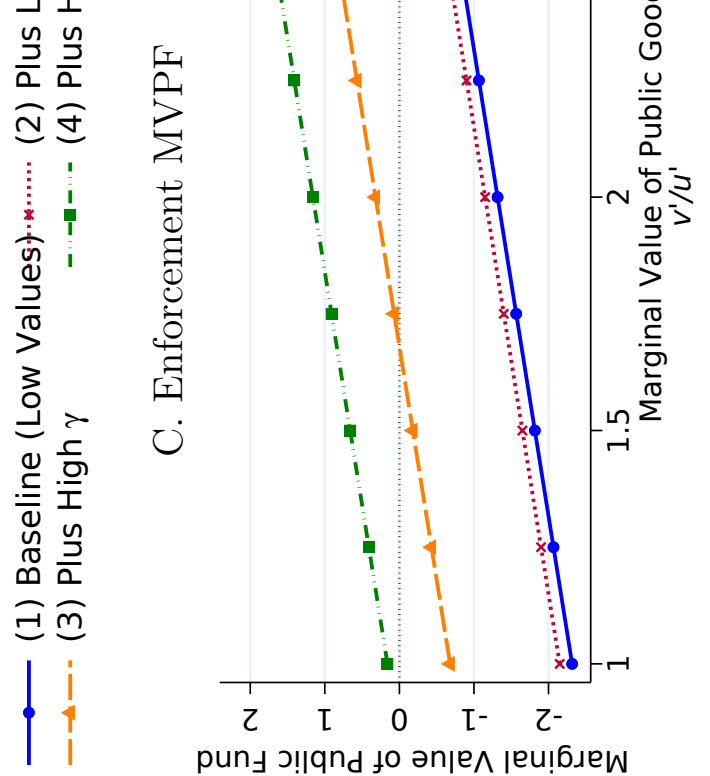

$\omega^{\infty} z$

퓸ำ.

प्त

证

.

드 चु क

오 오

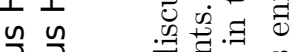

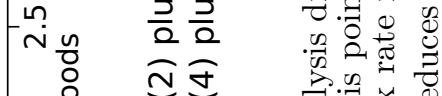

! $\quad$ ส

ช요

สำ

एँ⿱

$\frac{1}{\sqrt{0}}$

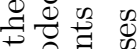

$3 \quad$ वृ 000

包

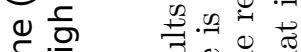

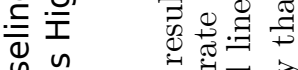

ஸ⿱一兀)

กิ

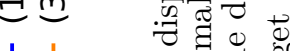

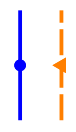

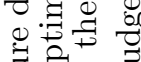

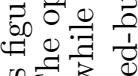

包些焉

F ก ส

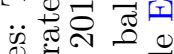

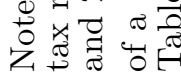




\section{Online Appendix: Not for Publication}

This appendix contains additional information and analyses. Appendix A provides additional model results. Appendix B includes additional contextual information on property taxes in Mexico City. Appendix $\mathrm{C}$ presents summary statistics on the data that we use. We present additional details for the regression discontinuity analysis in Appendix D, for the difference-in-difference analysis in Appendix E, for the real response estimations in Appendix F, for the field experiment in Appendix $\mathrm{G}$, for the analysis of liquidity constraints in Appendix H, for the analysis of payment modality and timing in Appendix I, for the instrumental variable estimation in Appendix J, and for the calculation of the revenue-maximizing rate in Appendix K.

\section{A Model Appendix}

This section expands on Section 1 by presenting additional derivations and results.

\section{A.1 Approximating Marginal Utility}

For a given individual, we approximate marginal utility with a first-order Taylor expansion:

$$
u^{\prime}(c) \approx u^{\prime}(\bar{c})+u^{\prime \prime}(\bar{c}) \times(c-\bar{c})=u^{\prime}(\bar{c})[1-\gamma \times \Delta c]
$$

where $\Delta c$ is the percentage change in consumption (i.e., $\Delta c \leq 0)$ and $\gamma=-\frac{u^{\prime \prime}(\bar{c}) \bar{c}}{u^{\prime}(\bar{c})}$ is the coefficient of relative risk aversion and captures the curvature of utility.

We now approximate the average marginal utility. Letting $\bar{c}=\bar{c}_{0}^{\mathrm{Pay}} \pi_{0}^{\mathrm{Pay}}+\bar{c}_{s}^{\mathrm{Pay}} \pi_{s}^{\mathrm{Pay}}$ be the average consumption across the two types of households, we express the average marginal utility as:

$$
\begin{aligned}
\pi_{s}^{\text {Pay }} u^{\prime}\left(c_{s}^{\text {Pay }}\right)+\pi_{0}^{\text {Pay }} u^{\prime}\left(c_{0}^{\text {Pay }}\right) & \approx \pi_{0}^{\text {Pay }}\left[u^{\prime}(\bar{c})+u^{\prime \prime}(\bar{c})\left(c_{0}^{\text {Pay }}-\bar{c}\right)\right]+\pi_{s}^{\text {Pay }}\left[u^{\prime}(\bar{c})+u^{\prime \prime}(\bar{c})\left(c_{s}^{\text {Pay }}-\bar{c}\right)\right] \\
& =u^{\prime}(\bar{c})+u^{\prime \prime}(\bar{c})\left(\pi_{0}^{\text {Pay }} c_{0}^{\text {Pay }}+\pi_{s}^{\text {Pay }} c_{s}^{\text {Pay }}-\bar{c}\right) \\
& =u^{\prime}(\bar{c})\left[1-\gamma\left(\pi_{0, c}^{\text {Pay }} \Delta c_{0}^{\text {Pay }}+\pi_{s, c}^{\text {Pay }} \Delta c_{s}^{\text {Pay }}\right)\right]
\end{aligned}
$$

where $\pi_{0, c}^{\text {Pay }}=\frac{\bar{c}_{0} \pi_{0}^{\text {Pay }}}{\bar{c}_{0} \pi_{0}^{\text {Pay }}+\bar{c}_{s} \pi_{s}^{\text {Pay }}}$ is the consumption share of liquidity-constrained households. Assuming $c_{0}^{\text {Pay }}=c_{s}^{\text {Pay }}$, then $\pi_{0, c}^{\text {Pay }}=\pi_{0}^{\text {Pay }}$.

\section{A.2 Measuring $m^{\prime}(\alpha)$}

One drawback of Equation 3 is that we do not directly observe the welfare cost of additional enforcement, $m^{\prime}(\alpha)$. Building on previous approaches (e.g., Bertrand et al., 2010; Mullainathan et al., 2012; Allcott and Taubinsky, 2015), we express $m^{\prime}(\alpha)$ as the utility cost of a tax with the same impact on $N^{\text {Pay }}$. First, note that because $N^{\text {Pay }}=\operatorname{Pr}\left(V^{\text {Pay }}>V^{\text {Delinquent }}+\varepsilon_{i}\right)$, it follows that

$$
\frac{\partial N^{\text {Pay }}}{\partial V^{\text {Pay }}}=-\frac{\partial N^{\text {Pay }}}{\partial V^{\text {Delinquent }}} .
$$


Let $\Delta t$ be a tax increase such that the combined effect of the tax and the marginal enforcement action leaves $N^{\text {Pay }}$ unaffected. We then have:

$$
\begin{aligned}
0 & =d N^{\text {Pay }}=\frac{\partial N^{\text {Pay }}}{\partial V^{\text {Pay }}} \frac{\partial V^{\text {Pay }}}{\partial t} \Delta t+\frac{\partial N^{\text {Pay }}}{\partial V^{\text {Delinquent }}} \frac{\partial V^{\text {Delinquent }}}{\partial \alpha} \\
& =\underbrace{\frac{\partial N^{\text {Pay }}}{\partial V^{\text {Pay }}}}_{>0} \underbrace{\left(\frac{\partial V^{\text {Pay }}}{\partial t} \Delta t-\frac{\partial V^{\text {Delinquent }}}{\partial \alpha}\right)}_{=0} .
\end{aligned}
$$

Because the first term is non-zero, the second term being equal to zero implies that:

$$
\Delta t=\frac{\frac{\partial V^{\text {Delinquent }}}{\partial \alpha}}{\frac{\partial V^{\text {Pay }}}{\partial t}}=\frac{-m^{\prime}(\alpha)}{-u^{\prime}(c) H}=\frac{m^{\prime}(\alpha)}{u^{\prime}(c) H} .
$$

Because this joint tax and enforcement change is such that $N^{\text {Pay }}$ is unaffected, we can write:

$$
\begin{aligned}
0 & =\Delta t \frac{\partial N^{\text {Pay }}}{\partial t}+\frac{\partial N^{\text {Pay }}}{\partial \alpha} \\
0 & =\frac{m^{\prime}(\alpha)}{u^{\prime}(c) H} \frac{\varepsilon_{t}^{\text {Pay }}}{t}+\frac{\varepsilon_{\alpha}^{\text {Pay }}}{\alpha} \\
m^{\prime}(\alpha) & =u^{\prime}(c)\left(\frac{H t}{\alpha}\right)\left(\frac{\varepsilon_{\alpha}^{\text {Pay }}}{-\varepsilon_{t}^{\text {Pay }}}\right),
\end{aligned}
$$

where the second line substitutes for $\Delta t$ and transforms the expression into terms of elasticities and the third line solves for $m^{\prime}(\alpha)$. This expression shows that we can measure $m^{\prime}(\alpha)$ as a multiple of marginal utility that depends on the relative effects of taxes and enforcement on compliance.

This expression also shows that the welfare cost of enforcement is increasing in $\varepsilon_{\alpha}^{\text {Pay }}$. This makes sense. If a given enforcement action has a large effect on payment, the equivalent tax increase would have to be greater to result in the same effect on compliance. However, while a larger value of

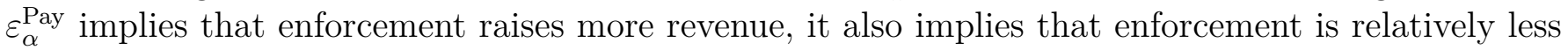
attractive from a welfare perspective.

It is worth pointing out that our approach to measuring $m^{\prime}(\alpha)$ relies on the assumption that our enforcement treatment takes the form of a psychological tax (e.g., as in Caplin, 2003; Loewenstein and O'Donoghue, 2006; Glaeser, 2006). In addition to the case of the psychological tax, Allcott and Kessler (2019) consider that nudges may provide information that impacts decision-making of households, as well as the case where nudges provide a moral subsidy. Since taxpayers received six reminder bills prior to receiving the enforcement message, it is unlikely that the enforcement message provided any new information about the tax liability. Alternatively, the message may be interpreted as providing information that may impact beliefs about $\tilde{z}$. However, since stronger enforcement actions apply only to a small subset of delinquent taxpayers, it is unlikely that the treatment improved beliefs about $\tilde{z}$. In fact, even if taxpayers updated their beliefs, they might have updated to a $\tilde{z}$ that was higher than its actual value. If this were the case, household responses to the enforcement letter would carry further welfare losses arising from acting sub-optimally based on these erroneous beliefs. Accounting for this possibility would further reduce the desirability of enforcement messages as a policy tool. Finally, while other types of nudges may activate a "warm glow" effect from paying taxes, even our public goods treatment was primarily an enforcement message. For this 
reason, we do not believe that the enforcement actions that we study are likely to generate a moral subsidy.

\section{A.3 Comparing $M V P F_{\alpha}$ and $M V P F_{t}$}

We now consider the welfare effect of increasing taxes and reducing enforcement while keeping government expenditure constant. The welfare impact of this policy experiment is given by:

$$
d W=W_{t}+\left.W_{\alpha} \cdot \frac{d \alpha}{d t}\right|_{d g=0}
$$

From the government budget constraint, we have that:

$$
\left.\frac{d \alpha}{d t}\right|_{d g=0}=-\frac{H N\left(1+(1-\tilde{z}) \varepsilon_{t}^{\mathrm{Pay}}\right)}{\frac{t H N}{\alpha}(1-\tilde{z}) \varepsilon_{\alpha}^{\mathrm{Pay}}-1} .
$$

From Equations 1 and 3, we can write:

$$
\begin{aligned}
W_{t} & =M V P F_{t} \times u^{\prime}(c)\left(H N\left(1+(1-\tilde{z}) \varepsilon_{t}^{\mathrm{Pay}}\right)\right) \text { and } \\
W_{\alpha} & =M V P F_{\alpha} \times \omega m^{\prime}(\alpha)\left(\frac{t H N}{\alpha}(1-\tilde{z}) \varepsilon_{\alpha}^{\mathrm{Pay}}-1\right) .
\end{aligned}
$$

Combining these four expressions, we then have that:

$$
d W=u^{\prime}(c)\left(H N\left(1+(1-\tilde{z}) \varepsilon_{t}^{\mathrm{Pay}}\right)\right) \times\left[M V P F_{t}-M V P F_{\alpha} \times \frac{\omega m^{\prime}(\alpha)}{u^{\prime}(c)}\right]
$$

Recalling from above that $\frac{m^{\prime}(\alpha)}{u^{\prime}(c)}=\left(\frac{H t}{\alpha}\right)\left(\frac{\varepsilon_{\alpha}^{\text {Pay }}}{-\varepsilon_{t}^{\text {Pay }}}\right)$, we have:

$$
d W \propto M V P F_{t}-M V P F_{\alpha} \times \omega\left(\frac{H t}{\alpha}\right)\left(\frac{\varepsilon_{\alpha}^{\text {Pay }}}{-\varepsilon_{t}^{\text {Pay }}}\right) .
$$

We use this expression to plot Panel C of Figure 9.

\section{A.4 Optimal Enforcement}

Setting $M V P F_{\alpha}=0$ yields the following condition for the optimal enforcement level $\alpha$ :

$$
\varepsilon_{\alpha}^{\text {Pay }}=\frac{\left(1-N^{\text {Pay }}\right) \frac{\alpha \omega m^{\prime}(\alpha)}{v^{\prime}(g)}+\alpha}{(1-\tilde{z}) N^{\text {Pay }} H t} .
$$

At the optimum $\alpha$, the government equates the enforcement elasticity $\varepsilon_{\alpha}^{\text {Pay }}$ to the ratio of enforcement costs to tax revenue. Importantly, this ratio accounts for both public enforcement expenditures $\alpha$ and the private disutility from enforcement $m(\alpha)$ that is incurred by the $1-N^{\text {Pay }}$ delinquent taxpayers. ${ }^{71}$

\footnotetext{
${ }^{71}$ Keen and Slemrod (2017) call this term the adjusted marginal cost-revenue ratio. The term $\alpha m^{\prime}(\alpha)$ can be viewed as a first-order approximation of $m(\alpha)$. Private enforcement costs are discounted by the value of public goods $v^{\prime}(g)$ since an increase in $\alpha$ requires lowering $g$.
} 
From a full fairness perspective that ignores the welfare costs to non-compliant taxpayers, i.e., $\omega=0$, this equation simplifies to a cost-benefit analysis that compares the effect of enforcement on revenue to the administrative cost of enforcement.

For a given enforcement level $\alpha$, this expression defines the equilibrium compliance rate that equates the marginal costs and benefits of enforcement:

$$
N_{\alpha}^{\text {Pay }}=\frac{1+\frac{\omega m^{\prime}(\alpha)}{v^{\prime}(g)}}{(1-\tilde{z}) \frac{\varepsilon_{\alpha}^{\text {Pay }} H t}{\alpha}+\frac{\omega m^{\prime}(\alpha)}{v^{\prime}(g)}} .
$$

This expression is useful from a policy perspective, as it tells the government whether the marginal benefit exceeds the marginal cost of enforcement. This is the case when $N_{\alpha}^{\text {Pay }}$ - which combines the administrative costs, private costs, and effectiveness of enforcement - is smaller than the observed compliance rate $N^{\text {Pay }}$. In this situation, the government can raise welfare by increasing enforcement (Figure A.1 provides a graphical intuition of this result).

Figure A.2 plots the compliance rate that equates the marginal cost and benefit of enforcement. As we discuss in Section 1, the government can increase welfare by increasing enforcement when $N_{\alpha}^{\text {Pay }}<$ $N^{\text {Pay }}$. Conversely, it would be preferable to reduce enforcement when $N_{\alpha}^{\text {Pay }}>N^{\text {Pay }}$. Regardless of the value of public goods, the observed compliance rate of $N^{\text {Pay }}=60 \%$ lies below $N_{\alpha}^{\text {Pay }}$ in both our baseline parameterization and the case with higher $\varepsilon_{\alpha}^{\text {Pay }}$. This result implies that the government is over-relying on enforcement as a means to raise tax revenue. While the equilibrium compliance rate is not very sensitive to the enforcement elasticity, a larger tax elasticity shifts the curve $N_{\alpha}^{\text {Pay }}$ down.

The green dot-dashed line shows that, under the assumptions that $\varepsilon_{t}^{\text {Pay }}=-0.46$ and $\frac{v^{\prime}(g)}{u^{\prime}(c)}=1.75$, current compliance rates are close to optimal. Current enforcement levels could then be rationalized by a government that assumed that tax hikes have small effects on tax revenue (i.e., that $\varepsilon_{t}^{\text {Pay }}$ is large and negative). This insight showcases the importance of studying the welfare effects of enforcement by taking into account the efficiency of alternative policies available to the government.

\section{A.5 Government Provision of Liquidity}

Assume now that the government allows households that pay property taxes to borrow up to the amount of the property taxes at interest rate $r .{ }^{72}$ We can interpret this rate of return as incorporating a risk adjustment for the possibility that households do not pay back the loan. Because the government can eventually seize the asset, this collateral implies that this adjustment is low.

The provision of liquidity to constrained taxpayers lowers the welfare cost of taxation since consumption would be less affected. Specifically, the change in consumption for constrained households is now $\eta_{t, l}^{c} \times t$, where it is plausible to assume that $\eta_{t, l}^{c} \approx \eta_{t, s}^{c}<\eta_{t, 0}^{c}$. Therefore, when the government provides liquidity, $M V P F_{t}$ is greater, since the effect on consumption is smaller. The provision of liquidity to constrained taxpayers also means that enforcement becomes relatively less desirable since liquidity increases the value of $M V P F_{t}$.

The assumption that the government charges a risk-adjusted interest rate implies that the government's budget constraint is not affected by providing liquidity. Departing from this assumption, it is also possible to study the optimal provision of liquidity. As in Andreoni (1992), the government

\footnotetext{
${ }^{72}$ We assume that only households that pay property taxes and have no savings may decide to take out a loan.
} 
may have incentives to act as a "loan shark." The government's budget constraint is now:

$$
g+a(\alpha)=t H N^{\text {pay }}+z H\left(1-N^{\text {pay }}\right)+(\rho-r) \times \pi_{l}^{\text {Pay }} N^{\text {pay }} t H,
$$

where the last term is the revenue from charging interest $\rho$ on the taxes of the share of taxpayers $\pi_{l}^{\text {Pay }}$ who obtain a loan from the government. then:

This implies $\frac{d V^{\text {Pay }}}{d \rho}=-u^{\prime}\left(c^{\text {Pay }}\right) H \pi_{l}^{\text {Pay }}$ and $\frac{d V_{l}^{\text {Delinquent }}}{d \rho}=0$. The effect of increasing $\rho$ on welfare is

$$
-N^{\text {Pay }} \pi_{l}^{\text {Pay }} u^{\prime}\left(c_{l}^{\text {Pay }}\right) H+v^{\prime}(g) \times\left\{(t-z) H \frac{\partial N^{\text {Pay }}}{\partial \rho}+\pi_{l}^{\text {Pay }} N^{\text {pay }} t H+(\rho-r) \times t H\left[\pi_{l}^{\text {Pay }} \frac{\partial N^{\text {Pay }}}{\partial \rho}+\frac{\partial \pi_{l}^{\text {Pay }}}{\partial \rho} N^{\text {pay }}\right]\right\} .
$$

The MVPF for $\rho$ is then:

$$
M V P F_{\rho}=\frac{v^{\prime}(g)}{u^{\prime}(\bar{c})}-\frac{\rho\left(1-\gamma \pi_{l, \rho}^{\text {Pay }} \Delta c_{l, \rho}^{\text {Pay }}\right)}{\frac{t-z}{\pi_{l}^{\text {Pay }}} \varepsilon_{\rho}^{\text {Pay }}+t \rho+(\rho-r) \times t\left[\varepsilon_{\rho}^{\text {Pay }}+\varepsilon_{\rho}^{\pi_{l}}\right]} .
$$

The optimal value of $\rho$ solves this expression when set equal to zero. From this expression, it follows that the government might set $\rho>r$ and therefore act as a loan shark if the value of providing public goods through loans exceeds the welfare cost of raising revenue in this way. 
Figure A.1: $N_{\alpha}$ Equates the Marginal Cost (MC) and Benefit (MB) From Enforcement

A: $N_{\alpha}>N:$ MC of Enforcement Exceeds MB

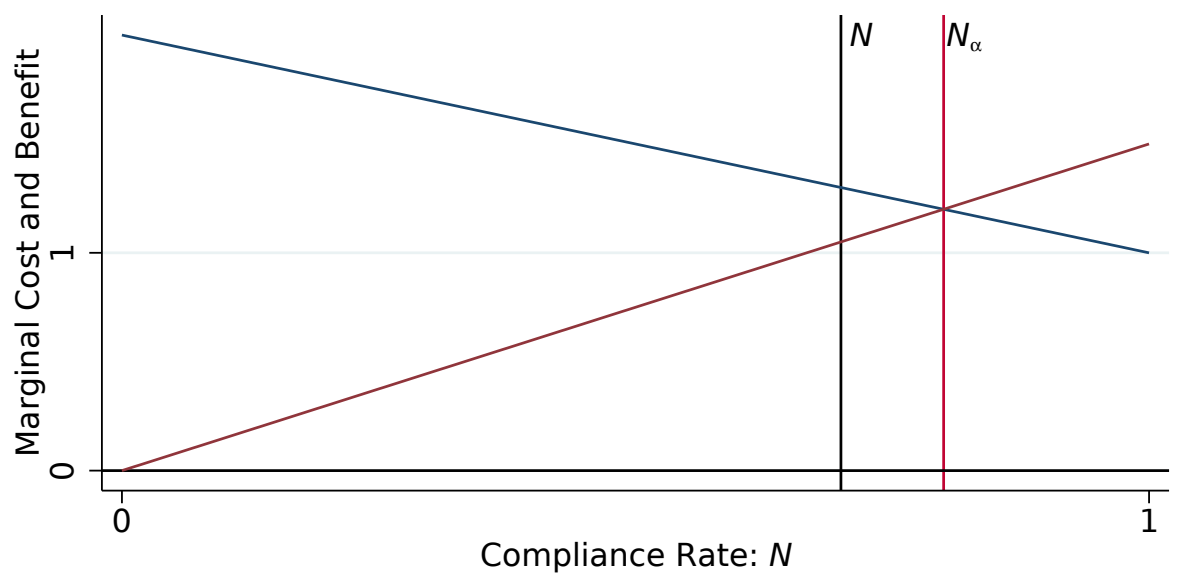

(1) MC (High $\alpha)-(2)$ MB (High $\alpha)$

B: Effect of Lowering $\alpha$

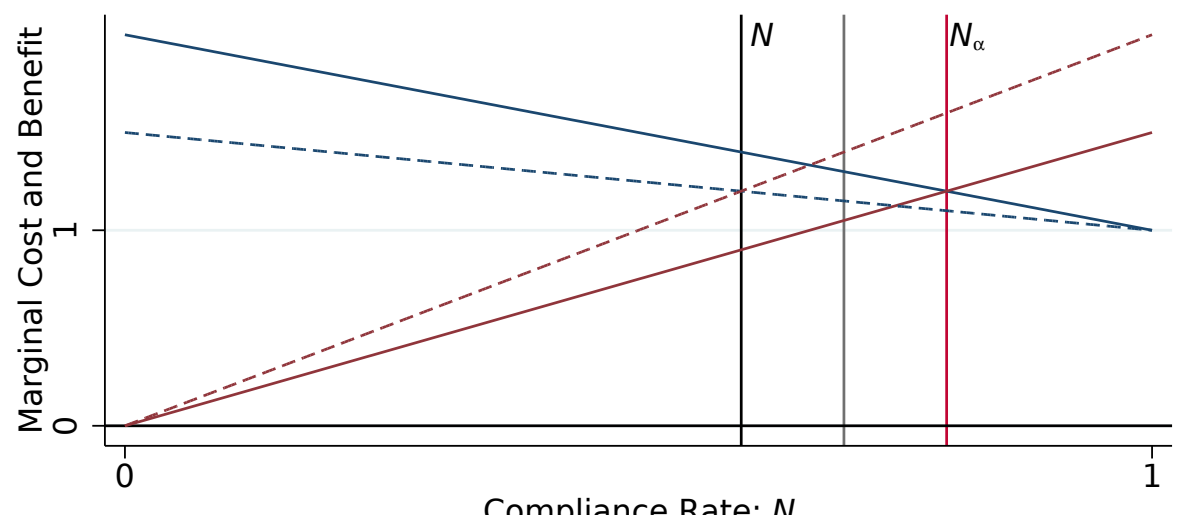

Compliance Rate: $N$

(1) MC (High $\alpha)-(2)$ MB (High $\alpha)$

(3) MC (Low $\alpha)----$ (4) MB (Low $\alpha)$

Notes: This figure plots the marginal cost and benefit of enforcement as well as the implied $N_{\alpha}$. To simplify exposition, we present the case when $\omega=1$. The marginal cost of enforcement (plotted in blue) is given by $(1-N) \frac{m^{\prime}(\alpha)}{v^{\prime}(g)}+1$, which includes the private and public costs of enforcement. The MC of enforcement is a decreasing function of $N$ and equals 1 when $N=1$ (this is because we assume $a(\alpha)=\alpha$, so that $\frac{\partial a(\alpha)}{\partial \alpha}=1$ ). The marginal benefit of enforcement (plotted in red) is given by $(1-\tilde{z}) \frac{H t}{\alpha} \varepsilon_{\alpha}^{\text {Pay }} N$, which starts at the origin and increases with $N$. In Panel A, the MC equals the MB at $N_{\alpha}$. This figure assumes that the observed compliance rate $N<N_{\alpha}$. At the observed compliance rate $N$, the $\mathrm{MC}$ of enforcement exceeds the $\mathrm{MB}$, such that welfare would be increased by lowering $\alpha$. Panel B shows the effect of lowering $\alpha$. For lower values of $\alpha$, the term $m^{\prime}(\alpha)$ is smaller, resulting in a flatter MC curve (shown with the dashed line). For lower values of $\alpha$, the elasticity $\varepsilon_{\alpha}^{\text {Pay }}$ is higher (i.e., initial enforcement efforts are more effective), resulting in a steeper MB curve (shown with the dashed line). In Panel $\mathrm{B}, \mathrm{MB}$ equals $\mathrm{MC}$ at the new $N$, which is lower than $N$ in Panel A. 
Figure A.2: Equilibrium Enforcement
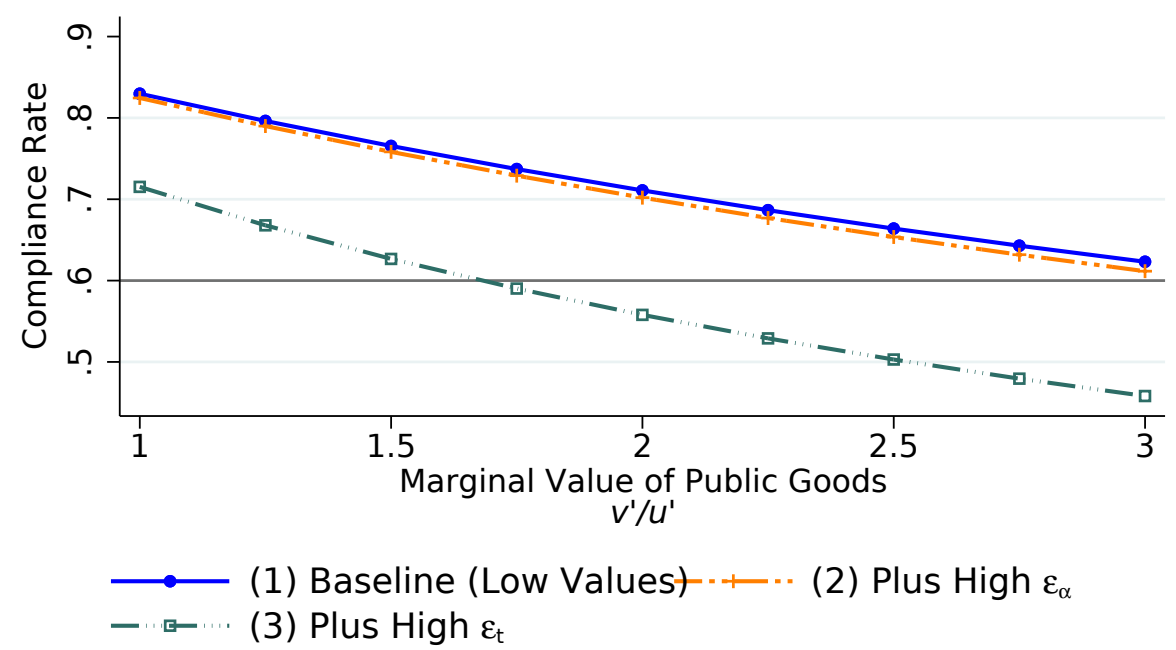

Notes: This figure displays the equilibrium compliance rate discussed in Appendix A.4. The horizontal line represents the observed average compliance rate between 2008 and 2012.

Figure A.3: Role of $\omega$ in Relative Desirability of Taxes over Enforcement

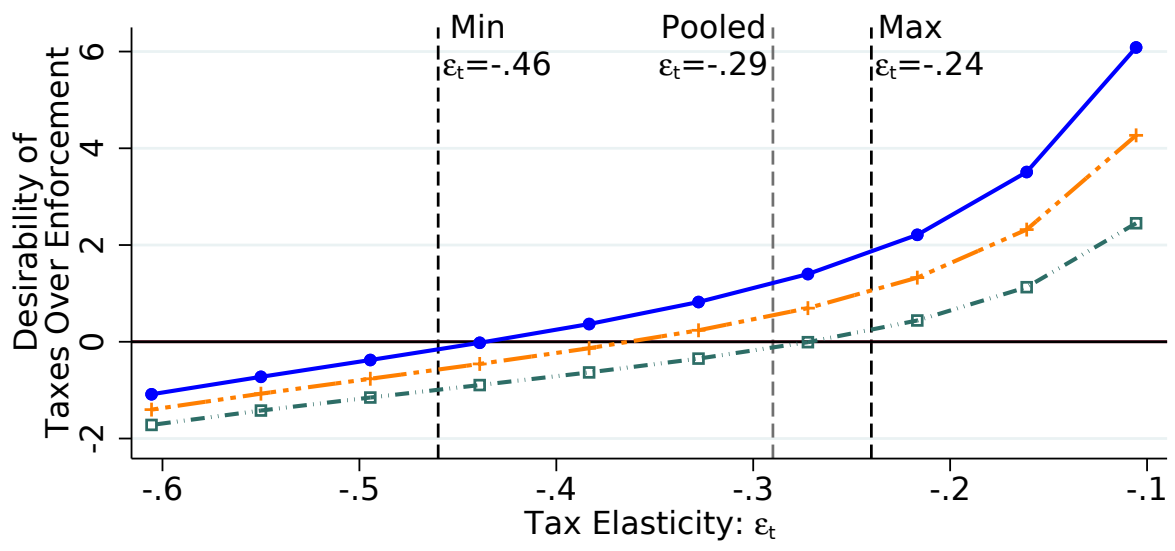

$\longrightarrow$ (1) Baseline (High $\left.\varepsilon_{\alpha} \& \Delta \mathrm{C}\right)=\ldots$ (2) Base Plus $\omega=0.75$

- (3) Base Plus $\omega=0.50$

Notes: This figure plots the welfare impact of a balanced-budget policy that increases taxes and reduces enforcement. The figure varies the parameter $\omega$, which under-weights the private cost of enforcement. 


\section{B Context Appendix}

Table B.1: Consumer Debt in Mexico City

\begin{tabular}{lc}
\hline \hline Variable & Mean \\
& $(1)$ \\
\hline Credit take-up & .345 \\
Informal & .302 \\
Formal & .084 \\
Both & .437 \\
None & \\
Informal borrower shares by type of lender (not exclusive) & .135 \\
Pawnshop & .32 \\
Friends & .729 \\
Family & .013 \\
Other & .578 \\
Reasons for informality & .288 \\
Voluntary & .125 \\
Non-eligibility (lack of access) & .009 \\
Initial costs & \\
Other & .834 \\
Formal borrower shares by credit source (not exclusive) & .113 \\
Credit card & .189 \\
Bank loan & .079 \\
Mortgage & \\
Car/Other & .839 \\
Number of mortgages (liquidity constraints) & 161 \\
One & .87 \\
Two or more & \\
Us formal credit & \\
Paying a bill & \\
Other & \\
\hline Observations & \\
\hline
\end{tabular}

Notes: The table examines consumer debt in Mexico City in 2018, using data from the National Financial Inclusion Survey (Encuesta Nacional de Inclusión Financiera, ENIF). This is discussed in the Introduction. 
Table B.2: Tax Schedule, 2009

\begin{tabular}{cccccc}
\hline \hline Band & $\begin{array}{c}\text { Cadastral } \\
\text { Value Lower } \\
\text { Limit (MXN) }\end{array}$ & $\begin{array}{c}\text { Cadastral } \\
\text { Value Upper } \\
\text { Limit (MXN) }\end{array}$ & $\begin{array}{c}\text { Lump-Sum } \\
\text { Liability } \\
\text { (MXN) }\end{array}$ & $\begin{array}{c}\text { Tax Rate on } \\
\text { Excess from } \\
\text { Lower Limit } \\
\text { (percent) }\end{array}$ & $\begin{array}{c}\text { Percent } \\
\text { Abatement } \\
\text { on Liability }\end{array}$ \\
& $(1)$ & $(2)$ & $(3)$ & $(4)$ & $(5)$ \\
\hline A & 0.11 & $162,740.82$ & 32 & 0 & 0 \\
B & $162,740.83$ & $325,481.16$ & 37 & 0 & 0 \\
C & $325,481.17$ & $650,963.56$ & 45 & 0 & 0 \\
D & $650,963.57$ & $976,444.70$ & 55 & 0 & 0 \\
E & $976,444.71$ & $1,301,927.10$ & 737.28 & 0.09542 & 65 \\
F & $1,301,927.11$ & $1,627,408.26$ & $1,047.86$ & 0.11091 & 45 \\
G & $1,627,408.27$ & $1,952,889.39$ & $1,408.85$ & 0.11461 & 30 \\
H & $1,952,889.40$ & $2,278,371.81$ & $1,781.88$ & 0.12522 & 20 \\
I & $2,278,371.82$ & $2,603,852.96$ & $2,189.45$ & 0.13097 & 15 \\
J & $2,603,852.97$ & $2,929,335.38$ & $2,615.73$ & 0.13478 & 10 \\
K & $2,929,335.39$ & $3,254,816.51$ & $3,054.42$ & 0.13892 & 0 \\
L & $3,254,816.52$ & $3,580,297.67$ & $3,506.58$ & 0.1427 & 0 \\
M & $3,580,297.68$ & $3,906,090.04$ & $3,971.04$ & 0.15075 & 0 \\
N & $3,906,090.05$ & $11,718,268.85$ & $4,462.17$ & 0.16278 & 0 \\
O & $11,718,268.86$ & $24,663,843.29$ & $17,178.84$ & 0.16286 & 0 \\
P & $24,663,843.30$ & & $38,262.00$ & 0.16902 & 0 \\
\hline
\end{tabular}

Notes: This table presents an example of the annual tax schedule discussed in Section 2.2, focusing on the year 2009.

Table B.3: Abatements on Gross Tax Liability

\begin{tabular}{ccccccc}
\hline \hline Band & 2008 & 2009 & 2010 & 2011 & 2012 & 2013 \\
& $(1)$ & $(2)$ & $(3)$ & $(4)$ & $(5)$ & $(6)$ \\
\hline G & 30 & 30 & 30 & 30 & 20 & 20 \\
H & 20 & 20 & 20 & 0 & 0 & 0 \\
I & 15 & 15 & 0 & 0 & 0 & 0 \\
J & 10 & 0 & 0 & 0 & 0 & 0 \\
\hline
\end{tabular}

Notes: This table displays the abatement rates discussed in Section 2.2.

Table B.4: Early-Bird Discounts and Payment Deadlines

\begin{tabular}{|c|c|c|c|c|c|c|c|}
\hline \multirow[t]{4}{*}{ Year } & \multicolumn{2}{|c|}{ Super Early Bird } & \multicolumn{2}{|c|}{ Early Bird } & \multicolumn{3}{|c|}{ Reference Rates } \\
\hline & Deadline & Discount & Deadline & Discount & Central & Treasury & Mortgages \\
\hline & & & & & Bank & Bonds & \\
\hline & (1) & $(2)$ & $(3)$ & (4) & $(5)$ & (6) & (7) \\
\hline 2008 & Jan 31 & $7 \%$ & Feb 28 & $4 \%$ & $7.5 \%$ & $7.42 \%$ & $12.22 \%$ \\
\hline 2009 & Jan 31 & $8 \%$ & Feb 28 & $4 \%$ & $8.25 \%$ & $7.59 \%$ & $12.78 \%$ \\
\hline 2010 & Jan 31 & $5 \%$ & Feb 28 & $0 \%$ & $4.5 \%$ & $4.49 \%$ & $12.79 \%$ \\
\hline 2011 & Jan 10 & $7 \%$ & Jan 31 & $3 \%$ & $4.5 \%$ & $4.14 \%$ & $12.22 \%$ \\
\hline 2012 & Jan 17 & $7 \%$ & Jan 31 & $4 \%$ & $4.5 \%$ & $4.27 \%$ & $12.53 \%$ \\
\hline 2013 & Jan 31 & $7 \%$ & Feb 28 & $6 \%$ & $4.5 \%$ & $4.15 \%$ & $12.13 \%$ \\
\hline
\end{tabular}

Notes: This table displays the early-bird discount schedules discussed in Section 2.3 and Appendix I. Discounts are applied to the annual tax liability. All interest rates are annualized. 
Table B.5: Home Ownership in Mexico

Panel A: Renting vs Owning

\begin{tabular}{lcccc}
\hline \hline & Homeowners & Renters & Others & P value \\
& $(1)$ & $(2)$ & $(3)$ & $(4)$ \\
\hline Share of the population & 62.1 & 14.2 & 23.6 & \\
Average Monthly Labor Income (MXN) & 3966.1 & 5394.7 & 3785.7 & 0.017 \\
& $(263.893)$ & $(473.894)$ & $(363.832)$ & \\
Number of Rooms & 2.2 & 1.7 & 1.8 & 0.000 \\
& $(.048)$ & $(.075)$ & $(.064)$ & \\
Number of Household Members & 4 & 3.5 & 3.7 & 0.127 \\
& $(.092)$ & $(.166)$ & $(.141)$ & \\
Age Head of Household & 55.5 & 37 & 44.8 & 0.000 \\
& $(.748)$ & $(1.466)$ & $(1.348)$ & \\
\hline
\end{tabular}

Panel B: Homeowner Characteristics

\begin{tabular}{ccccc}
\hline \hline Home Financing & Current Mortgage & Pays Property & Property Tax & Own a Second \\
& & Tax & Payment Amount & Home \\
$(1)$ & $(2)$ & $(3)$ & $(4)$ & $(5)$ \\
\hline 14.3 & 9.9 & 56.6 & 300.3 & 5.4 \\
$(1.627)$ & $(1.392)$ & $(2.306)$ & $(20.009)$ & $(1.051)$ \\
\hline
\end{tabular}

Panel C: Home Financing

\begin{tabular}{cccccccc}
\hline \hline & \multicolumn{2}{c}{ Gender } & \multicolumn{3}{c}{ Income Quintiles } \\
Total & Male & Female & Poorest & 2nd & 3rd & 4 th & Richest \\
$(1)$ & $(2)$ & $(3)$ & $(1)$ & $(2)$ & $(3)$ & $(4)$ & $(5)$ \\
\hline 4.3 & 4.8 & 3.9 & 0.0 & 2.3 & 8.0 & 5.0 & 6.1 \\
$(0.643)$ & $(1.080)$ & $(0.785)$ & $(0.00)$ & $(1.171)$ & $(1.877)$ & $(1.558)$ & $(1.510)$ \\
\hline
\end{tabular}

Notes: The table examines home ownership in Mexico, as discussed in Section 2.3. Panels A and B displays summary statistics of Mexican households by ownership status, based on the 2014 ENVI (Encuesta Nacional de Vivienda) from the National Institute of Statistics. In Panel A, the home status "Others" includes loaned properties and properties under litigation. The p-values in Panel A evaluate the differences between homeowners and renters. In Panel B, "Home Financing" indicates the share of owners who have received any kind of loan to finance their home purchase. Panel C displays the share of households with a mortgage in the country and its demographic correlates, based on data from the 2017 World Bank Findex database. Standard errors are in parentheses. The difference in the share of observations with a mortgage in Panels B and $\mathrm{C}$ is driven by differences in the sample. Panels A and B are for Mexico City, while Panel C is for the whole country. 
Figure B.1: Property Taxes in Mexico City

A: Property Tax Revenue

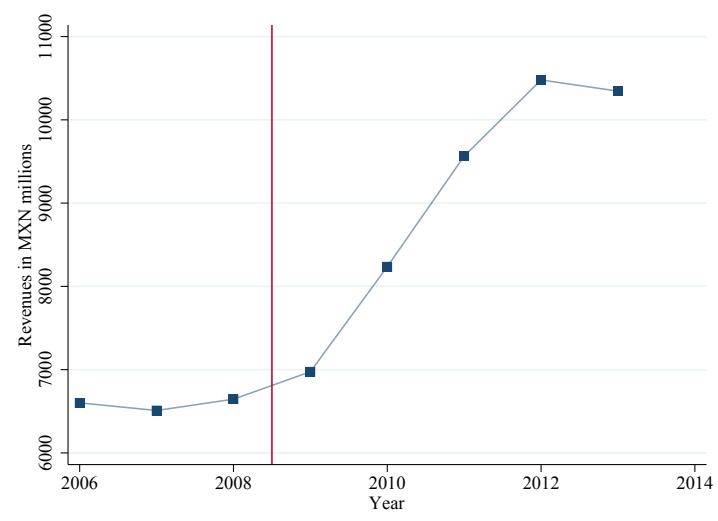

B: Cadastral Values and Property Prices

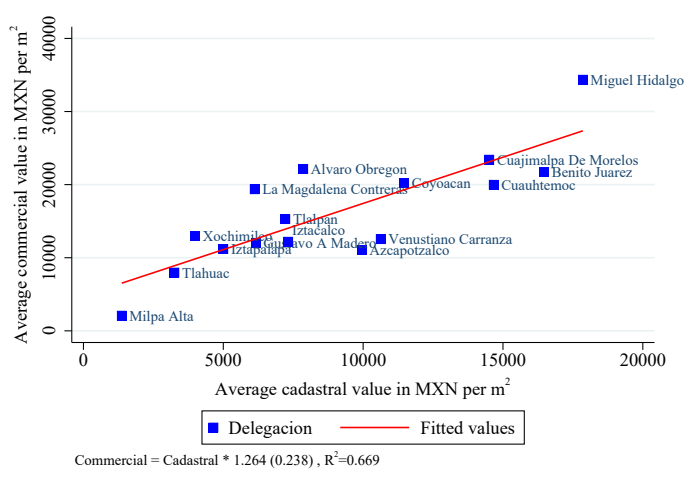

C: Tax Payment as Share of Income

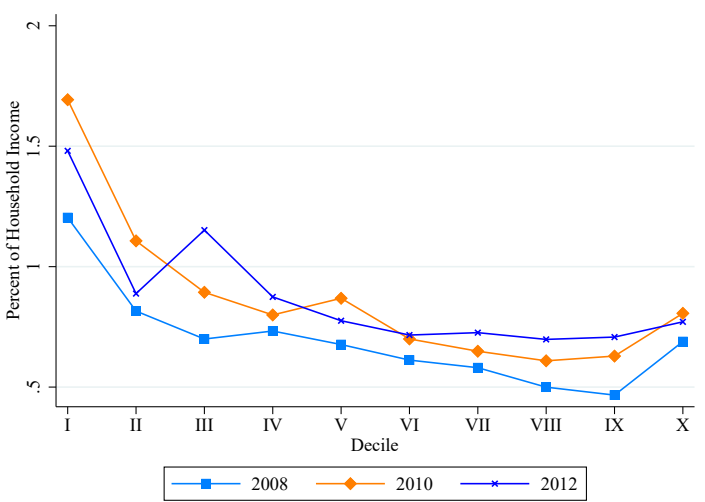

D: Year-on-Year Growth in Tax Payment Amounts

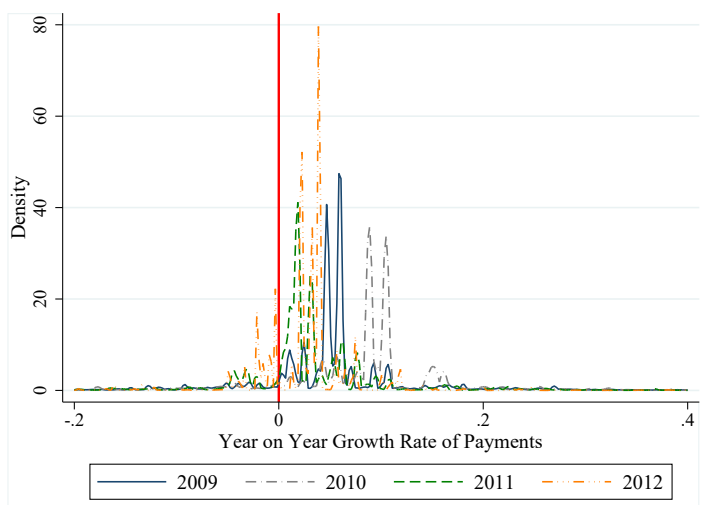

Notes: These figures show key facts about property taxes in Mexico City and are discussed in Sections 2.1 and 2.2. Panel A shows the total property tax revenue by year for Mexico City in nominal terms from government records. Panel $\mathrm{B}$ shows the correlation between average cadastral and commercial property values at the delegación level. Average commercial prices are obtained from propiedades.com, one of the largest real estate websites in Mexico. Prices were retrieved on the June 4, 2020, and are discounted for inflation using INEGI's inflation calculator. Cadastral values are from the administrative data. Panel $\mathrm{C}$ plots the property tax payment reported in the ENIGH household survey (Encuesta Nacional de Ingresos y Gastos de los Hogares) as a share of total household income, conditional on property tax payment being non-zero. Each line corresponds to a different survey round. Panel D displays the year-on-year growth rate of property tax payments, $\frac{P a y_{t}-P a y_{t-1}}{P a y_{t-1}}$. The sample is restricted to taxpayers who made a payment in both year $t$ and year $t-1$. The figure shows that there is no anchoring of tax payments at the previous year's liability or tax payment amount, as liabilities are inflation-adjusted each year. 
Figure B.2: Relevance and External Validity of the Mexico (City) Context

A: Tax Administration Capacity around the World

A1: Comprehensive Audit Rate

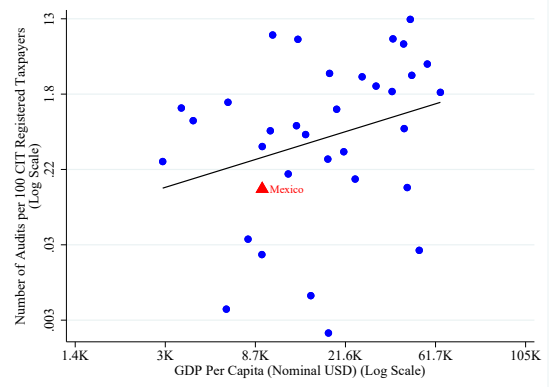

A2: CIT Audit Rate

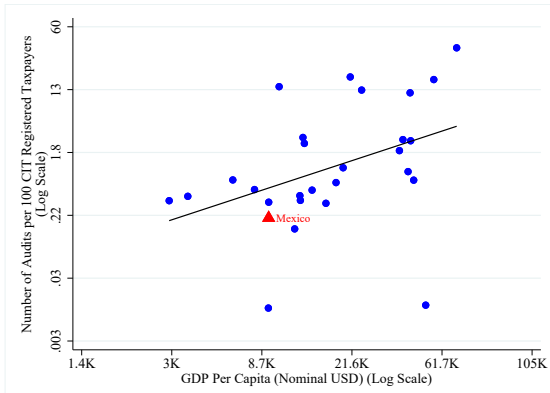

B: Household Liquidity Constraints around the World

B1: Share of Adults with a Bank Account B2: Share of Adults with a Credit Card

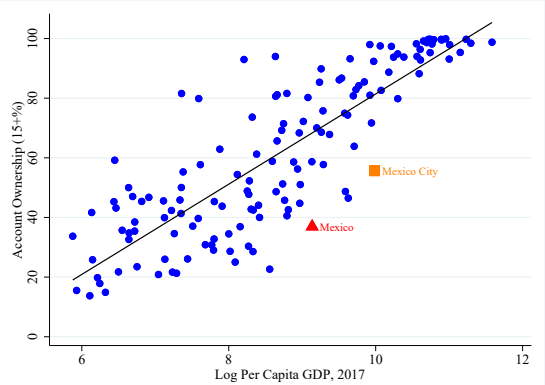

B3: Share of Adults with a Formal Loan

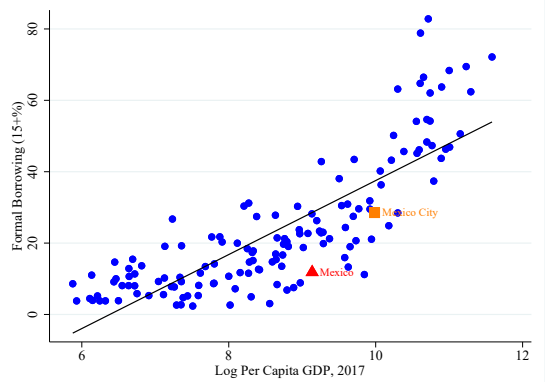

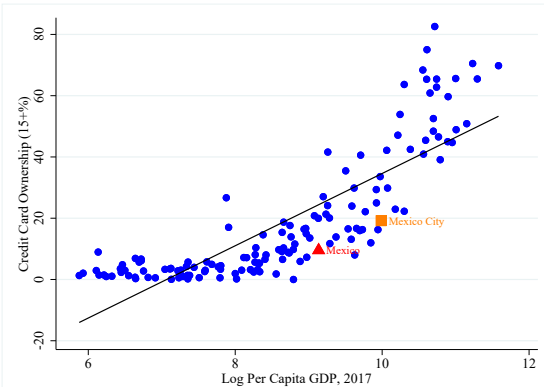

B4: Share of Adults Able to Cover an Emergency Expense from Savings

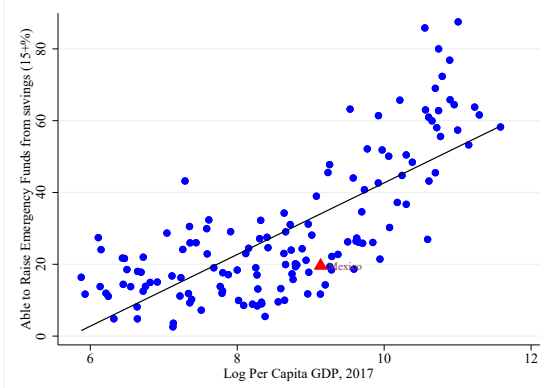

Notes: As discussed in the introduction, this figure shows the correlation between measures of government tax administration capacity and household liquidity constraints with GDP per capita and the levels of these indicators for Mexico, as well as for Mexico City where available. The data for Panels A1 and A2 are from the 2016 Revenue Administration Fiscal Information Tool (RA-FIT). The audit rate consists of the number of audits by each type conducted by the tax authority divided by the number of CIT-registered taxpayers. The data for Panels B1-B4 are from the 2017 World Bank Findex database for all countries and from the 2018 National Financial Inclusion Survey for Mexico City. Panel B4 displays the share of adults who can cover an emergency (an unexpected expense approximately equivalent to 500 USD) from personal savings (formal or informal). This statistic is not available for Mexico City only. 
Figure B.3: Property Tax Bill

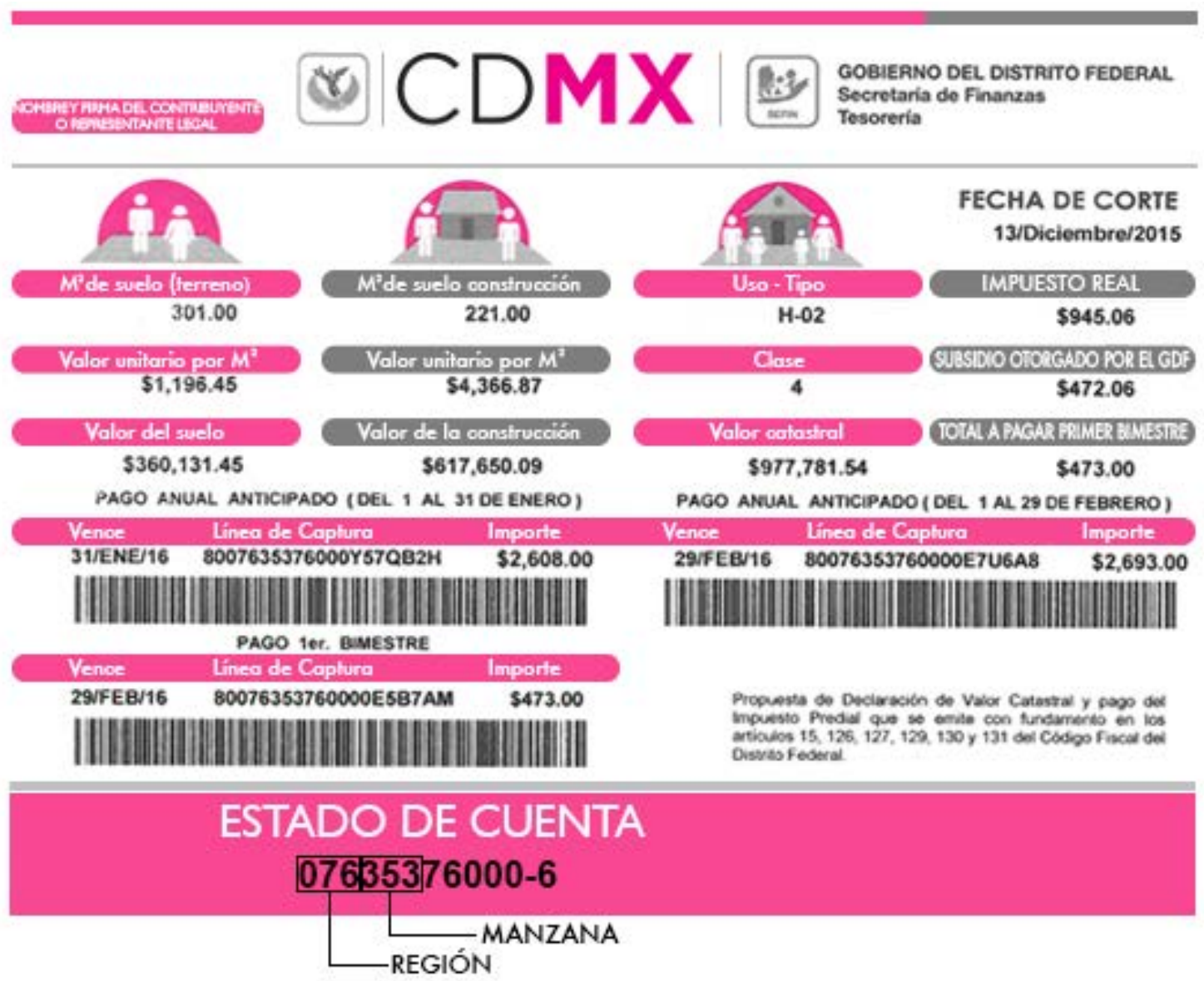

Notes: This figure displays a typical property tax bill sent to homeowners, as discussed in Section 2.3. 

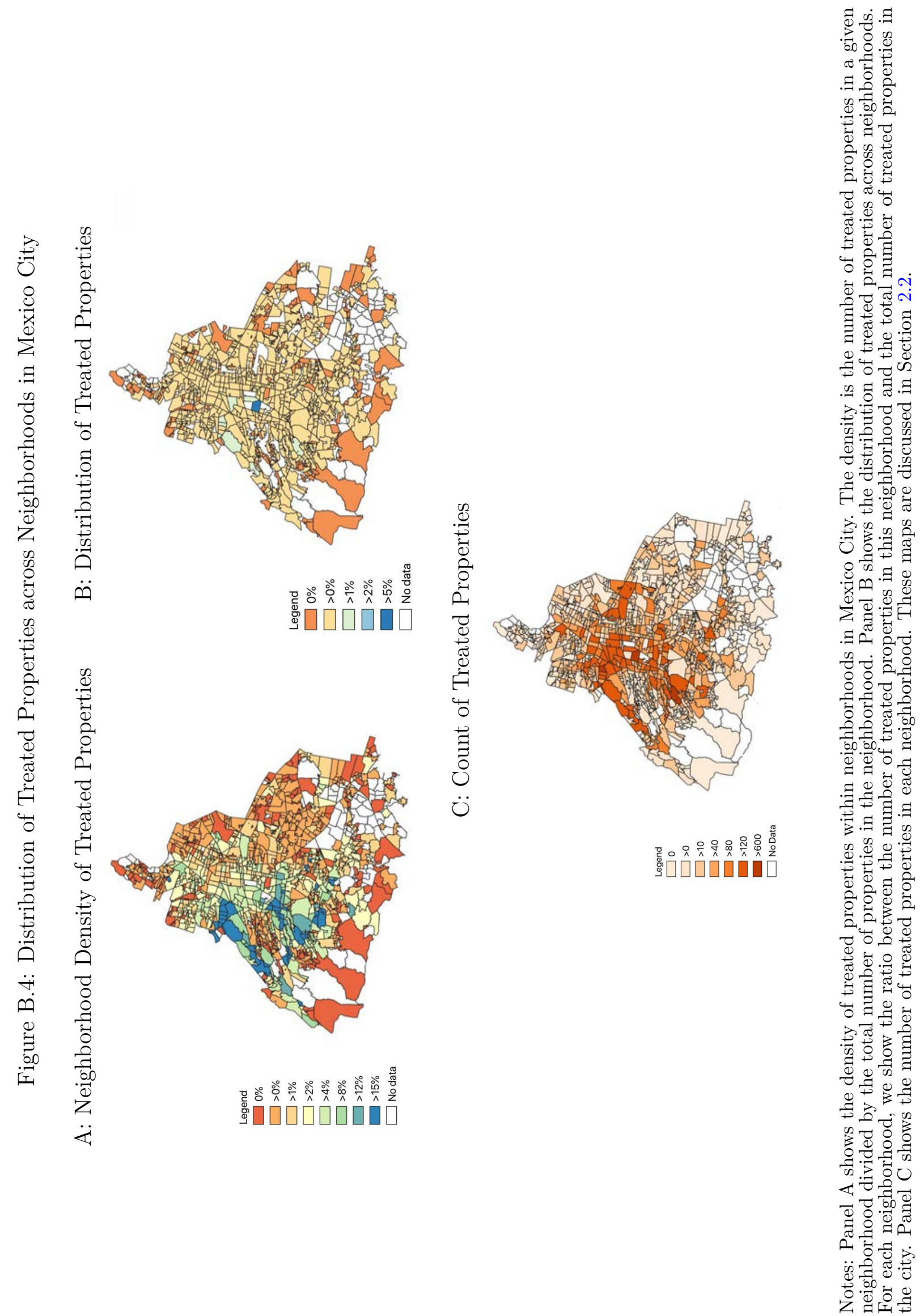
Figure B.5: Tax Payment Timing Around Reminder (Bill) Receipt

A. Compliant Taxpayers

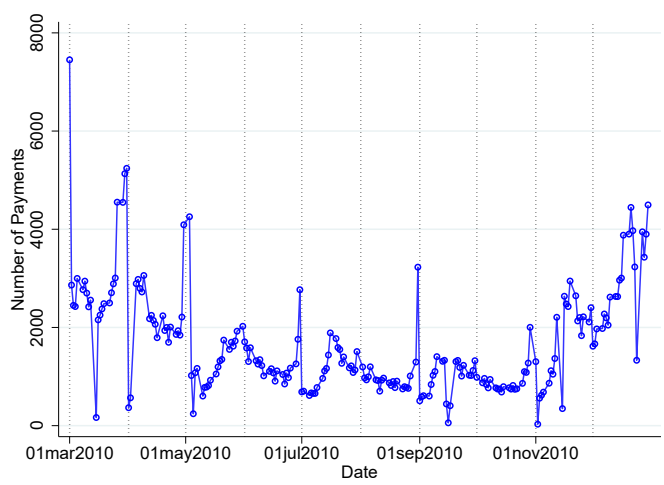

B. Delinquent Taxpayers

B1. Current Balance

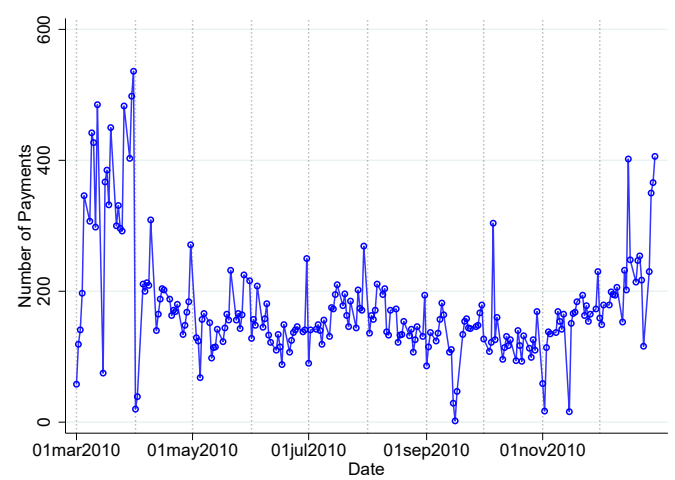

B2. Outstanding Balance

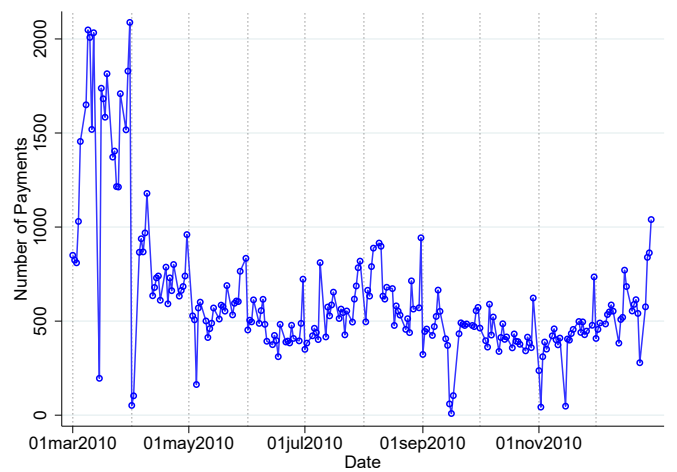

Notes: This figure examines the timing of tax payments throughout the year. For taxpayers who did not pay their annual liability in full by the early bird deadline, the deadlines to pay the tax liability in installments are February 28, April 30, June 30, August 31, October 31 and December 31 of each year (with minor year-specific divergences). The bimonthly tax bills reminding taxpayers of the upcoming deadline are sent around 5-15 days before the deadline. Featuring data for 2010, this figures show that payments among compliant taxpayers are bunched at the end of each bi-monthly period, after bill (reminder) receipt and before the deadline. For non-compliant taxpayers who have outstanding liabilities to pay, this is not the case, suggesting the bimonthly bills do not play a reminder role for these taxpayers. 


\section{Data Appendix}

Table C.1: Summary Statistics

Panel A: Property Characteristics

\begin{tabular}{lccccc}
\hline \hline & 2008 & 2009 & 2010 & 2011 & 2012 \\
& $(1)$ & $(2)$ & $(3)$ & $(4)$ & $(5)$ \\
\hline Property Value $(\mathrm{MXN})$ & 585,320 & 617,487 & 613,493 & 609,478 & 605,346 \\
& $(1,121,680)$ & $(1,185,320)$ & $(1,180,471)$ & $(1,174,999)$ & $(1,169,283)$ \\
Yearly Liability $(\mathrm{MXN})$ & 1,457 & 1,540 & 1,630 & 1,704 & 1,788 \\
& $(10,097)$ & $(10,671)$ & $(11,214)$ & $(11,607)$ & $(11,985)$ \\
Mean Tax Rate $\times 100$ & .1112 & .1114 & .1198 & .1259 & .1323 \\
& $(.1243)$ & $(.1245)$ & $(.1349)$ & $(.1427)$ & $(.1532)$ \\
\hline
\end{tabular}

Panel B: Payment Characteristics

\begin{tabular}{lccccc}
\hline \hline & 2008 & 2009 & 2010 & 2011 & 2012 \\
\hline Payment (current MXN) & 680 & 698 & 729 & 709 & 686 \\
& $(4078)$ & $(4126)$ & $(4439)$ & $(4703)$ & $(4563)$ \\
Compliance share & .628 & .61 & .591 & .538 & .488 \\
& $(.931)$ & $(.711)$ & $(.776)$ & $(.62)$ & $(1.149)$ \\
Payment type & & & & & \\
Zero payment & .275 & .276 & .307 & .366 & .432 \\
& $(.446)$ & $.447)$ & $(.461)$ & $(.482)$ & $(.495)$ \\
Partial payment & .172 & .174 & .174 & .136 & .097 \\
& $(.377)$ & $. .379)$ & $(.379)$ & $(.343)$ & $(.296)$ \\
Early Full Payment & .413 & .432 & .416 & .455 & .461 \\
& $(.492)$ & $. .495)$ & $(.493)$ & $(.498)$ & $(.498)$ \\
Non-Early Full Payment & .141 & .118 & .103 & .043 & .01 \\
& $(.348)$ & $. .323)$ & $(.304)$ & $(.204)$ & $(.1)$ \\
\hline
\end{tabular}

Panel C: Penalties and Fees

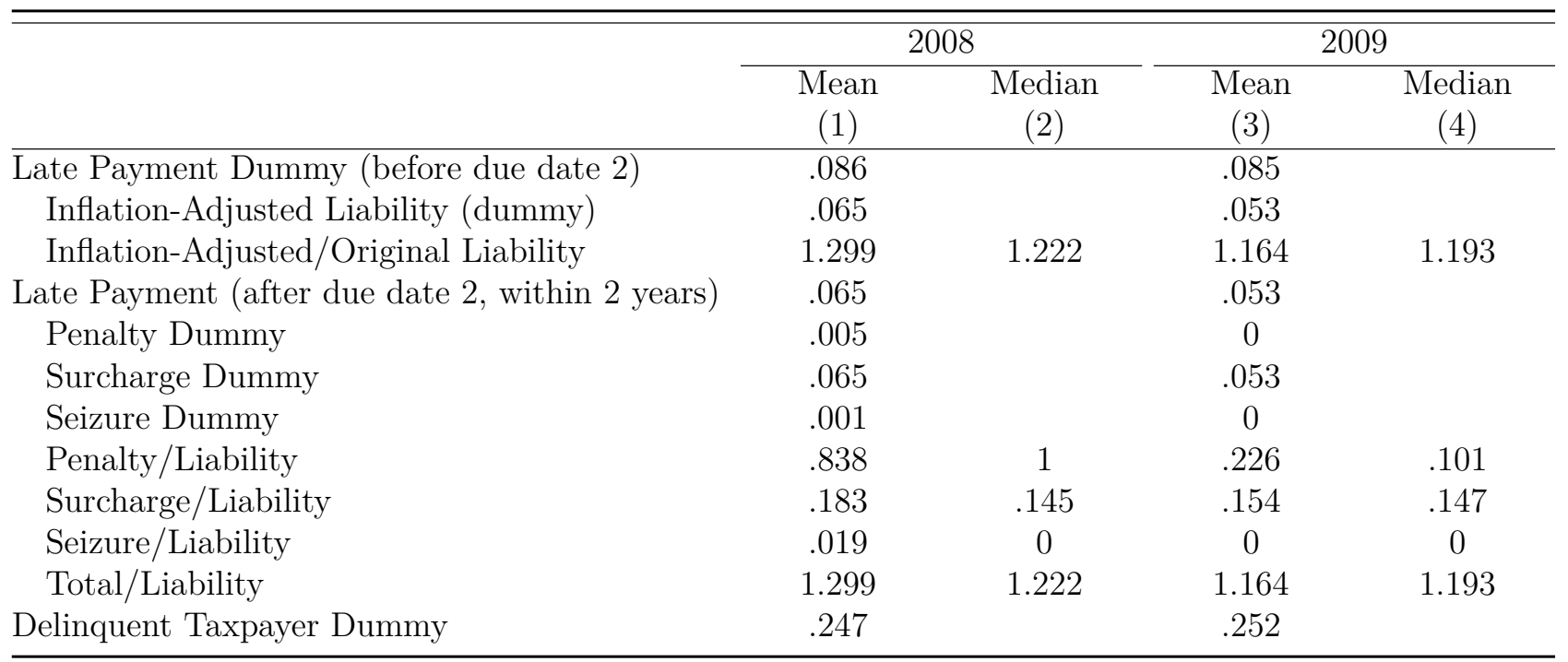

Notes: Panel A reports summary statistics for 1,420,259 properties with an average land area of 126 ( $\mathrm{SE}=381$ ) square meters and an average construction area of $126(\mathrm{SE}=161)$ square meters. Panel B reports summary statistics on payments. Panel C reports summary statistics on penalties and fees from the administrative tax data discussed in Section 3. 
Figure C.1: Distribution of Property Characteristics by Value Band

A. Properties

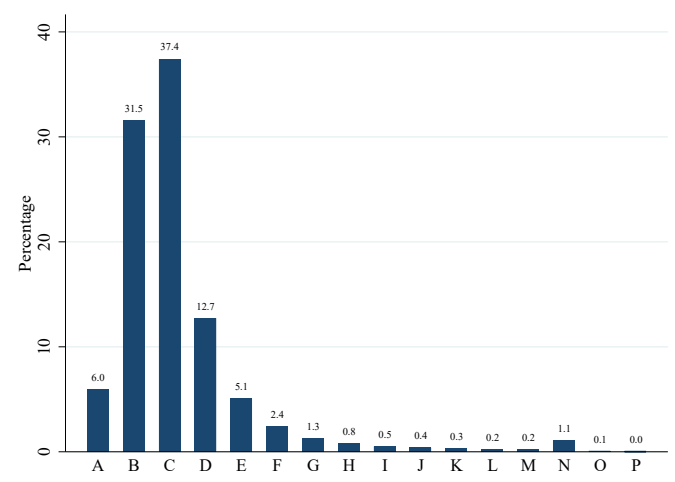

C. Liabilities

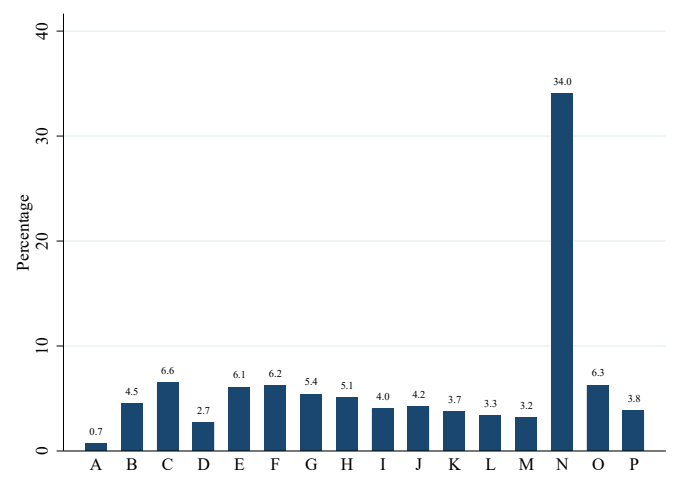

B. Cadastral Value

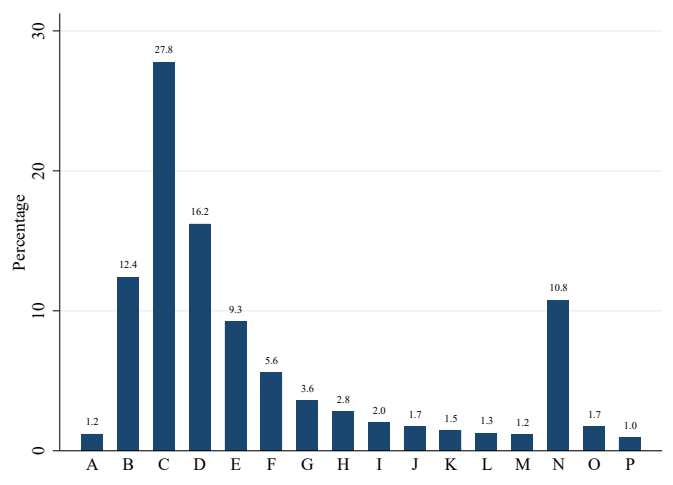

D. Revenues

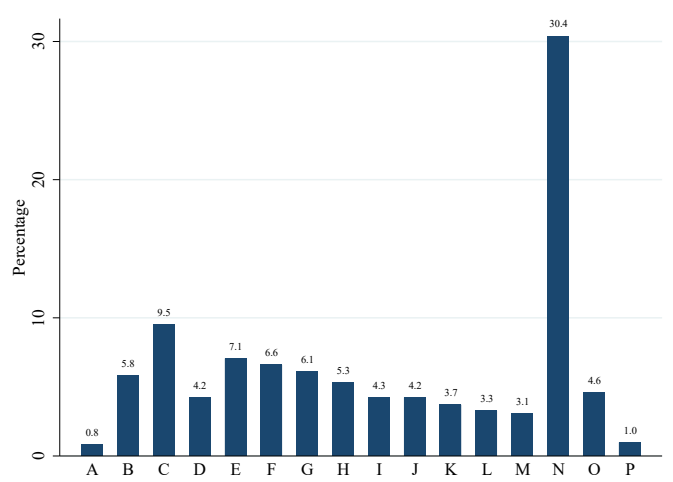

Notes: This figure shows the distribution of property characteristics by cadastral value band, as discussed in Section 3 , for the balanced panel of residential properties in Mexico City whose cadastral value did not change between 2009 and 2012 .

Figure C.2: Outstanding Property Tax Debt
A. All Properties
B. Experiment Sample
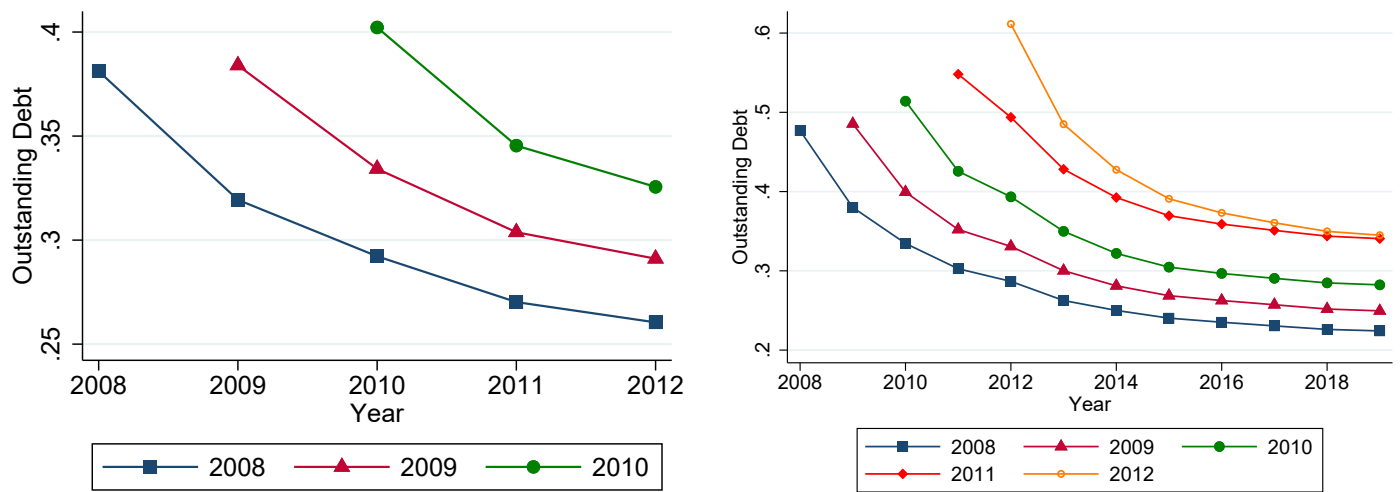

Notes: This figure shows how the share of each year's unpaid tax liability evolves over time. This is referenced in Section 1. Panel A includes all taxpayers with outstanding tax debt. Panel B restricts the sample to taxpayers targeted in the enforcement intervention. 


\section{Regression Discontinuity Appendix}

Table D.1: Identification Check for Regression Discontinuity Estimation

\begin{tabular}{lccc}
\hline \hline & Band I (2010) & Band H (2011) & Band G (2012) \\
& $(1)$ & $(2)$ & $(3)$ \\
\hline P-value $\left(H_{0}: f_{\text {Value }}^{+}=f_{\text {Value }}^{-}\right)$ & .444 & .828 & .752 \\
$\mathrm{q}$ & 138 & 190 & 250 \\
$\mathrm{~N}$ (left) & 1647 & 2237 & 3076 \\
$\mathrm{~N}$ (right) & 1059 & 2109 & 3501 \\
Total N & 2706 & 4346 & 6577 \\
Effective N (left) & 74 & 97 & 122 \\
Effective N (right) & 64 & 93 & 128 \\
\hline
\end{tabular}

Notes: This table reports results from the RD validity test proposed by Bugni and Canay (2020), as discussed in Section 4.1. This test examines the continuity of the running variable at the cut-off, an implication of the assumption of no manipulation. In particular, the fraction of units under treatment and control should be similar on both sides. The test statistic exploits the fact that under the null, the number of treated units out of the $q$ observations closest to the cut-off is approximately distributed as a binomial with sample size $q$ and probability $\frac{1}{2}$. The paper proposes a data-dependent rule for $q$, the number of "effective" observations near the cut-off.

Table D.2: Robustness of Regression Discontinuity Estimation - Using Local Linear Regressions with Optimal Bandwidth

\begin{tabular}{|c|c|c|c|c|}
\hline & $\begin{array}{c}\text { Mean Tax Rate } \\
\text { (basis points) } \\
(1)\end{array}$ & $\begin{array}{c}\text { Payment } \\
\text { Amount (MXN } \\
\text { thousands) } \\
(2)\end{array}$ & $\begin{array}{l}\text { Payment in Full } \\
\text { (percentage } \\
\text { points) } \\
(3)\end{array}$ & $\begin{array}{c}\text { Compliance } \\
\text { Share } \times 100 \\
(4)\end{array}$ \\
\hline & $I$. & Estimates for the & 2009-2010 treatm & \\
\hline \multirow[t]{2}{*}{$\mathrm{T}$} & $8.923 * * *$ & $.61 *$ & $-8.426 * *$ & -2.471 \\
\hline & $(.105)$ & $(.323)$ & $(3.606)$ & $(2.641)$ \\
\hline Properties & 17864 & 17864 & 17864 & 17864 \\
\hline Mean at Baseline (treated band) & 50.112 & 5.836 & 36.626 & 47.881 \\
\hline \multirow[t]{3}{*}{ Implied Elasticity } & & .587 & -1.292 & -.29 \\
\hline & & $(.311)$ & $(.553)$ & $(.31)$ \\
\hline & & Estimates for the & 2012-2011 treatm & \\
\hline \multirow[t]{2}{*}{$\mathrm{T}$} & $12.109 * * *$ & $.667 * * *$ & $-5.8 * *$ & -3.019 \\
\hline & $(.033)$ & $(.16)$ & $(2.573)$ & $(2.032)$ \\
\hline Properties & 28094 & 28094 & 28094 & 28094 \\
\hline Mean at Baseline (treated band) & 47.461 & 4.734 & 35.072 & 47.478 \\
\hline \multirow[t]{2}{*}{ Implied Elasticity } & & .552 & -.648 & -.249 \\
\hline & & $(.133)$ & $(.288)$ & $(.168)$ \\
\hline \multirow[t]{2}{*}{ P-value $\left(H_{0}: \epsilon_{2011}=\epsilon_{2010}\right)$} & & .918 & .302 & .908 \\
\hline & & Estimates for th & 2011-2012 treatm & \\
\hline \multirow[t]{2}{*}{$\mathrm{T}$} & $17.958 * * *$ & $.644 * * *$ & $-9.615 * * *$ & $-3.833 *$ \\
\hline & $(.018)$ & $(.134)$ & $(1.567)$ & $(2.051)$ \\
\hline Properties & 48838 & 48838 & 48838 & 48838 \\
\hline Mean at Baseline (treated band) & 41.06 & 3.287 & 37.969 & 44.885 \\
\hline \multirow[t]{2}{*}{ Implied Elasticity } & & .448 & -.579 & -.195 \\
\hline & & $(.093)$ & $(.094)$ & $(.104)$ \\
\hline $\mathrm{P}$-value $\left(H_{0}: \epsilon_{2012}=\epsilon_{2011}\right)$ & & .52 & .819 & .785 \\
\hline P-value $\left(H_{0}: \epsilon_{2012}=\epsilon_{2010}\right)$ & & .668 & .204 & .772 \\
\hline
\end{tabular}

Notes: This table is similar to Table 2, Panel A, but uses local linear regressions with optimal bandwidth as in Calonico et al. 2014. The estimates are statistically indistinguishable from the results of the preferred specification. 
Table D.3: Robustness of Regression Discontinuity Estimation - Differences-in-Discontinuities Estimates

\begin{tabular}{|c|c|c|c|c|}
\hline & $\begin{array}{c}\text { Mean Tax Rate } \\
\text { (basis points) } \\
(1)\end{array}$ & $\begin{array}{c}\text { Payment } \\
\text { Amount (MXN } \\
\text { thousands) } \\
(2)\end{array}$ & $\begin{array}{l}\text { Payment in Full } \\
\text { (percentage } \\
\text { points) } \\
(3)\end{array}$ & $\begin{array}{c}\text { Compliance } \\
\text { Share } \times 100 \\
(4)\end{array}$ \\
\hline & \multicolumn{4}{|c|}{ I. Estimates for the 2009-2010 treatment } \\
\hline$\beta_{1}$ & $\begin{array}{c}8.23 * * * \\
(.05)\end{array}$ & $\begin{array}{c}1.019 \text { *** } \\
(.183)\end{array}$ & $\begin{array}{c}-5.377 * * * \\
(1.695)\end{array}$ & $\begin{array}{c}1.521 \\
(1.399)\end{array}$ \\
\hline Properties & 17864 & 17864 & 17864 & 17864 \\
\hline Years of Data & 4 & 4 & 4 & 4 \\
\hline Adjusted R-Squared & .318 & .005 & .002 & .001 \\
\hline Mean at Baseline (treated band) & 50.112 & 5.836 & 36.626 & 47.881 \\
\hline \multirow[t]{2}{*}{ Implied Elasticity } & & 1.063 & -.894 & .193 \\
\hline & & $(.191)$ & $(.282)$ & $(.178)$ \\
\hline $\mathrm{P}$-value $\left(H_{0}: \beta_{0}=\beta_{1}\right)$ & .000 & .000 & .000 & .915 \\
\hline & \multicolumn{4}{|c|}{ II. Estimates for the 2010-2011 treatment } \\
\hline$\beta_{1}$ & $\begin{array}{c}9.71 * * * \\
(.066)\end{array}$ & $\begin{array}{c}.445^{* * *} \\
(.12)\end{array}$ & $\begin{array}{c}-2.568^{* *} \\
(1.248)\end{array}$ & $\begin{array}{c}-3.584 * * * \\
(1.081)\end{array}$ \\
\hline Properties & 28094 & 28094 & 28094 & 28094 \\
\hline Years of Data & 4 & 4 & 4 & 4 \\
\hline Adjusted R-Squared & .31 & .005 & .003 & .002 \\
\hline Mean at Baseline (treated band) & 47.461 & 4.734 & 35.072 & 47.478 \\
\hline Implied Elasticity & & $\begin{array}{l}.459 \\
(.124)\end{array}$ & $\begin{array}{l}-.358 \\
(.174)\end{array}$ & $\begin{array}{l}-.369 \\
(.111)\end{array}$ \\
\hline \multirow[t]{2}{*}{$\mathrm{P}$-value $\left(H_{0}: \beta_{0}=\beta_{1}\right)$} & .000 & .000 & .009 & .013 \\
\hline & \multicolumn{4}{|c|}{ III. Estimates for the 2011-2012 treatment } \\
\hline$\beta_{1}$ & $\begin{array}{c}20.017^{* * *} \\
(.038)\end{array}$ & $\begin{array}{c}.503 * * * \\
(.071)\end{array}$ & $\begin{array}{c}-11.6211^{* * *} \\
(1)\end{array}$ & $\begin{array}{c}-7.285 * * * \\
(.932)\end{array}$ \\
\hline Properties & 48838 & 48838 & 48838 & 48838 \\
\hline Years of Data & 4 & 4 & 4 & 4 \\
\hline Adjusted R-Squared & .934 & .006 & .003 & .002 \\
\hline Mean at Baseline (treated band) & 41.06 & 3.287 & 37.969 & 44.885 \\
\hline Implied Elasticity & & $\begin{array}{l}.314 \\
(.045)\end{array}$ & $\begin{array}{l}-.628 \\
(.054)\end{array}$ & $\begin{array}{l}-.333 \\
(.043)\end{array}$ \\
\hline $\mathrm{P}$-value $\left(H_{0}: \beta_{0}=\beta_{1}\right)$ & .000 & .000 & .000 & .000 \\
\hline
\end{tabular}

Notes: This table shows, as discussed in Section 4.1, the effect of the tax rate changes driven by the abatement removal, in excess of the effect of the smaller year-on-year tax rate changes, given by $\beta_{1}$ in the estimating equation $\Delta Y_{i, t}=\alpha_{0}+\beta_{0} T_{i}+f_{0}\left(\hat{V}_{i}\right)+g_{0}\left(\hat{V}_{i}\right) T_{i}+\left[\alpha_{1}+\beta_{1} T_{i}+f_{1}\left(\hat{V}_{i}\right)+g_{1}\left(\hat{V}_{i}\right) T_{i}\right] D_{t}+\epsilon_{i, t}$, where $D_{t}$ is an indicator for the time period when the abatement is removed. The results of this estimation are very similar to our main estimates in Table 2, Panel A. 


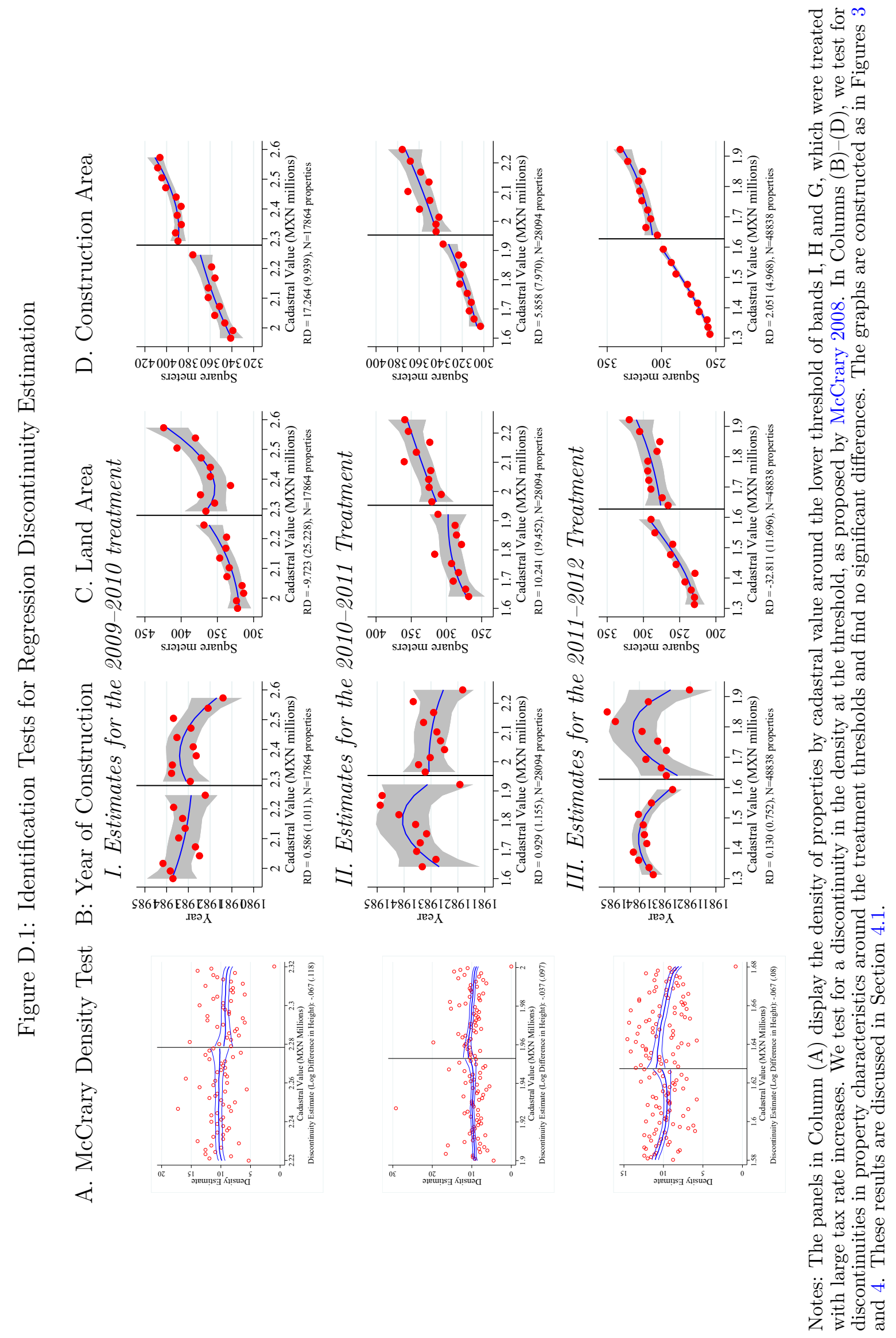




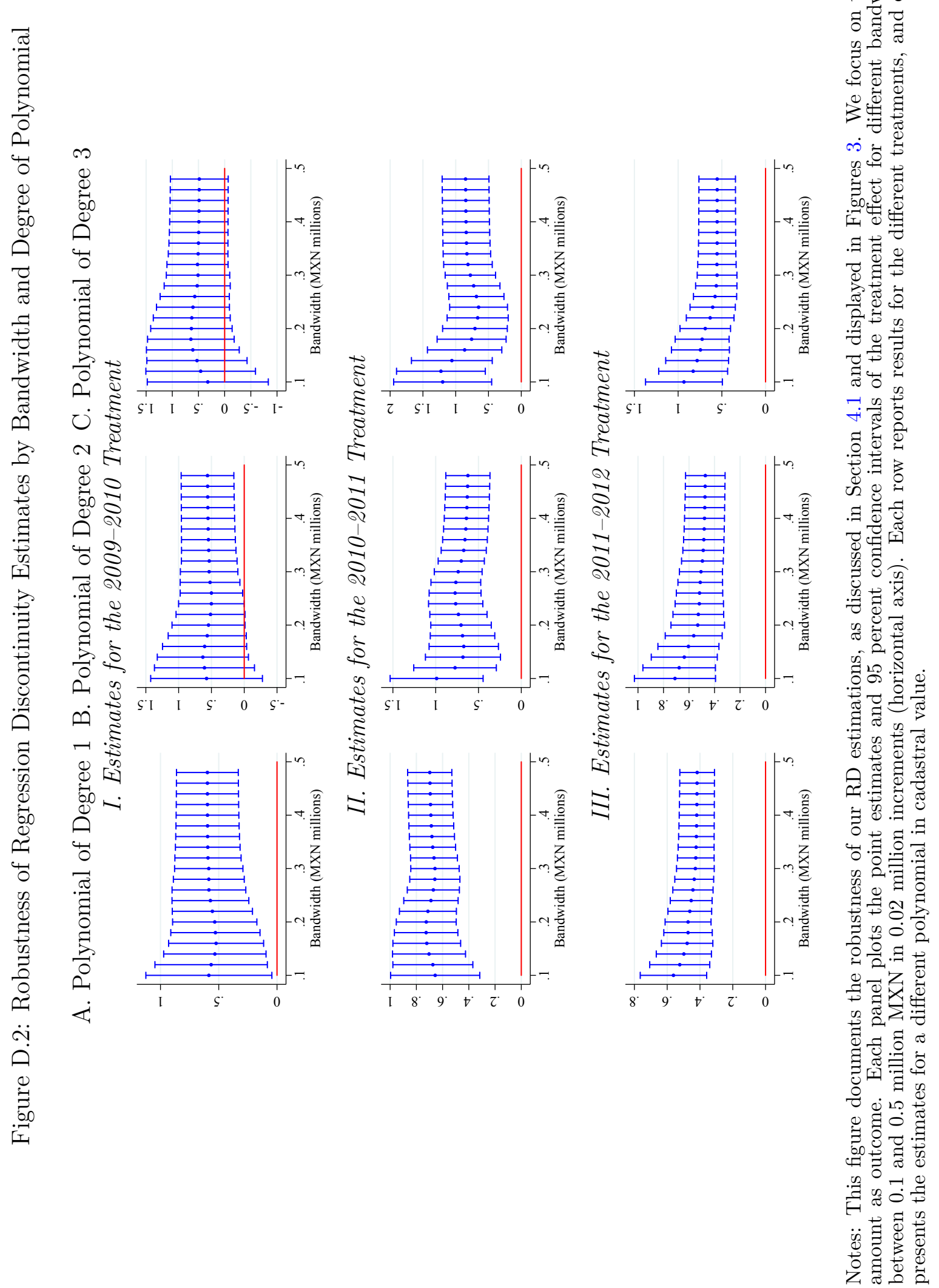


Table D.4: The Effect of Tax Rates on Tax Payment - Regression Discontinuity Estimates Robustness to Dropping Taxpayers with Exemptions

\begin{tabular}{|c|c|c|c|c|}
\hline & $\begin{array}{c}\text { Mean tax rate } \\
\text { (basis points) } \\
\text { (1) }\end{array}$ & $\begin{array}{c}\text { Payment } \\
\text { amount (MXN } \\
\text { thousands) } \\
(2)\end{array}$ & $\begin{array}{c}\text { Payment in full } \\
\text { (percentage } \\
\text { points) } \\
(3)\end{array}$ & $\begin{array}{c}\text { Compliance } \\
\text { share } \times 100 \\
\text { (4) }\end{array}$ \\
\hline \multirow{3}{*}{$\mathrm{T}$} & \multicolumn{4}{|c|}{ I. Estimates for the 2010 treatment } \\
\hline & $9.115 * * *$ & $.592 * *$ & $-4.916 * *$ & -2.836 \\
\hline & $(.066)$ & $(.259)$ & $(2.33)$ & $(2.184)$ \\
\hline Properties & 15190 & 15190 & 15190 & 15190 \\
\hline Adjusted R-squared & .98 & .008 & .003 & .001 \\
\hline Mean at baseline (treated band) & 50.109 & 5.635 & 39.227 & 46.239 \\
\hline \multirow[t]{2}{*}{ Implied elasticity } & & .577 & -.689 & -.337 \\
\hline & & $(.252)$ & $(.327)$ & $(.26)$ \\
\hline \multirow[t]{3}{*}{ Implied Semi-elasticity } & & .012 & -.014 & -.007 \\
\hline & & $(.005)$ & $(.007)$ & $(.005)$ \\
\hline & \multicolumn{4}{|c|}{ II. Estimates for the 2011 treatment } \\
\hline \multirow[t]{2}{*}{$\mathrm{T}$} & $12.141 * * *$ & $.679 * * *$ & $-6.18 * * *$ & $-3.268 * *$ \\
\hline & $(.035)$ & $(.133)$ & $(1.717)$ & $(1.298)$ \\
\hline Properties & 23882 & 23882 & 23882 & 23882 \\
\hline Adjusted R-squared & .993 & .017 & .003 & .001 \\
\hline Mean at baseline (treated band) & 47.473 & 4.546 & 37.465 & 45.552 \\
\hline \multirow[t]{2}{*}{ Implied elasticity } & & .584 & -.645 & -.281 \\
\hline & & $(.114)$ & $(.179)$ & $(.111)$ \\
\hline \multirow[t]{2}{*}{ Implied Semi-elasticity } & & .012 & -.014 & -.006 \\
\hline & & $(.002)$ & $(.004)$ & $(.002)$ \\
\hline \multirow[t]{2}{*}{ P-value $\left(H_{0}: \epsilon_{2011}=\epsilon_{2010}\right)$} & & .981 & .906 & .841 \\
\hline & \multicolumn{4}{|c|}{ III. Estimates for the 2012 treatment } \\
\hline \multirow[t]{2}{*}{$\mathrm{T}$} & $17.998 * * *$ & $.571 * * *$ & $-10.469 * * *$ & $-6.001 * * *$ \\
\hline & $(.028)$ & $(.092)$ & $(1.535)$ & $(1.295)$ \\
\hline Properties & 41040 & 41040 & 41040 & 41040 \\
\hline Adjusted R-squared & .996 & .027 & .008 & .003 \\
\hline Mean at baseline (treated band) & 41.073 & 3.367 & 40.627 & 46.04 \\
\hline \multirow[t]{2}{*}{ Implied elasticity } & & .387 & -.588 & -.297 \\
\hline & & $(.062)$ & $(.086)$ & $(.064)$ \\
\hline \multirow[t]{2}{*}{ Implied Semi-elasticity } & & .009 & -.014 & -.007 \\
\hline & & $(.002)$ & $(.002)$ & $(.002)$ \\
\hline P-value $\left(H_{0}: \epsilon_{2012}=\epsilon_{2011}\right)$ & & .131 & .775 & .895 \\
\hline P-value $\left(H_{0}: \epsilon_{2012}=\epsilon_{2010}\right)$ & & .465 & .765 & .882 \\
\hline
\end{tabular}

Notes: This table is similar to Table 2, Panel A, but excludes taxpayers who ever received a subsidy or exemption. It demonstrates the robustness of the RD results to dropping these taxpayers. 


\section{E DiD Appendix}

Figure E.1: The Effect of Tax Rates on Appeals

A. 2009-2010 Treatment

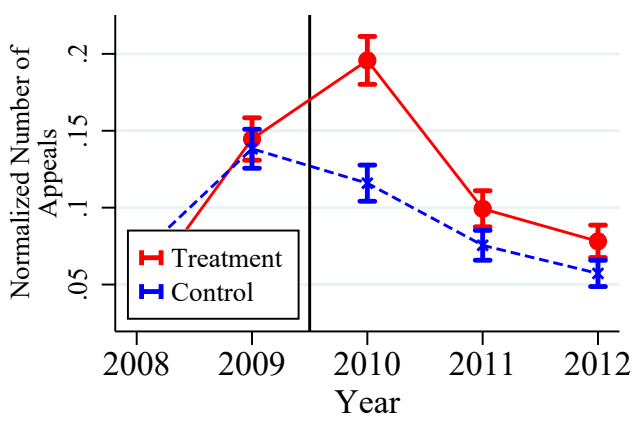

$\mathrm{DD}=0.968(0.097), \mathrm{N}=5345$ properties per year

B. 2010-2011 Treatment

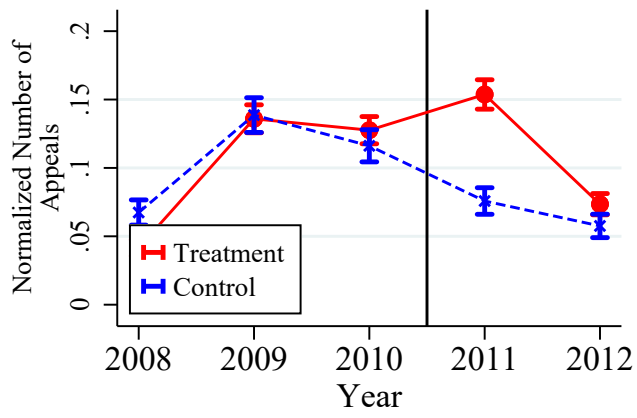

$\mathrm{DD}=0.823(0.069), \mathrm{N}=7175$ properties per year

C. 2011-2012 Treatment

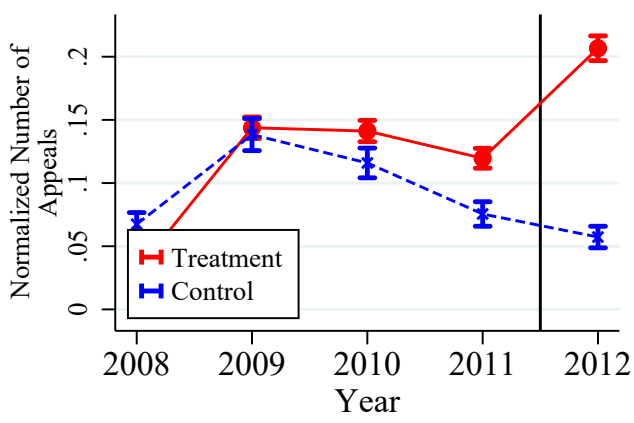

$\mathrm{DD}=1.288(0.057), \mathrm{N}=9393$ properties per year

Notes: This figure is identical to Figure 5, but the outcome variable is a dummy capturing whether the property owner appealed against the property tax liability. We restrict the sample to taxpayers making a payment every year, as we observe the appeals for these taxpayers only. Hardly any of the appeals result in a change in the tax liability (footnote 29). When calculating the DiD estimates displayed under the graphs, we take into account the first post-reform year only, as the graphical evidence suggests that the increase in appeals is primarily limited to the first post-reform year. Among taxpayers in the treatment group (in the restricted sample of taxpayers making a payment each year), the share filing an appeal is 14.46 percent in 2009, 12.76 percent in 2010 and 11.96 percent in 2011. These results are discussed in Section 4.2. 
Table E.1: The Effect of Tax Rates on Tax Payment - Differences-in-Differences Estimates Robustness to Using One Post-Reform Period Only

\begin{tabular}{|c|c|c|c|c|}
\hline & $\begin{array}{c}\text { Mean tax rate } \\
\text { (1) }\end{array}$ & $\begin{array}{l}\text { Payment } \\
\text { amount } \\
(2)\end{array}$ & $\begin{array}{c}\text { Payment in full } \\
(3)\end{array}$ & $\begin{array}{c}\text { Compliance } \\
\text { share } \\
(4)\end{array}$ \\
\hline & \multicolumn{4}{|c|}{ I. Estimates for the 2010 treatment } \\
\hline \multirow[t]{2}{*}{ DD } & $.171 * * *$ & $.110 * * *$ & $-.136 * * *$ & $-.034 * * *$ \\
\hline & $(.000)$ & $(.018)$ & $(.019)$ & $(.012)$ \\
\hline Adjusted R-squared & .996 & .014 & .006 & .002 \\
\hline Properties (treatment) & 5747 & 5747 & 5747 & 5747 \\
\hline Properties (control) & 6510 & 6510 & 6510 & 6510 \\
\hline \multirow[t]{3}{*}{ Implied elasticity } & & .643 & -.794 & -.200 \\
\hline & & $(.106)$ & $(.113)$ & $(.07)$ \\
\hline & \multicolumn{4}{|c|}{ II. Estimates for the 2011 treatment } \\
\hline \multirow[t]{2}{*}{ DD } & $.236 * * *$ & $.163 * * *$ & $-.178 * * *$ & $-.063 * * *$ \\
\hline & $(.000)$ & $(.022)$ & $(.017)$ & $(.011)$ \\
\hline Adjusted R-squared & .993 & .008 & .006 & .009 \\
\hline Properties (treatment) & 9661 & 9661 & 9661 & 9661 \\
\hline Properties (control) & 6511 & 6511 & 6511 & 6511 \\
\hline \multirow[t]{2}{*}{ Implied elasticity } & & .690 & -.753 & -.267 \\
\hline & & $(.092)$ & $(.071)$ & $(.047)$ \\
\hline \multirow[t]{2}{*}{$\mathrm{P}$-value $\left(H_{0}: \epsilon_{2011}=\epsilon_{2010}\right)$} & & .777 & .812 & .279 \\
\hline & \multicolumn{4}{|c|}{ III. Estimates for the 2012 treatment } \\
\hline \multirow[t]{2}{*}{ DD } & $.401 * * *$ & $.196 * * *$ & $-.300 * * *$ & $-.182 * * *$ \\
\hline & $(.000)$ & $(.029)$ & $(.014)$ & $(.010)$ \\
\hline Adjusted R-squared & .994 & .003 & .016 & .038 \\
\hline Properties (treatment) & 15227 & 15227 & 15227 & 15227 \\
\hline Properties (control) & 6508 & 6508 & 6508 & 6508 \\
\hline \multirow[t]{2}{*}{ Implied elasticity } & & .489 & -.747 & -.455 \\
\hline & & $(.073)$ & $(.035)$ & $(.025)$ \\
\hline $\mathrm{P}$-value $\left(H_{0}: \epsilon_{2012}=\epsilon_{2011}\right)$ & & .016 & .021 & .000 \\
\hline P-value $\left(H_{0}: \epsilon_{2012}=\epsilon_{2010}\right)$ & & .023 & .048 & .000 \\
\hline
\end{tabular}

Notes: This table is similar to Table 2, Panel B, but uses one post-reform period only for each reform episode. This confirms the robustness of our main DiD estimates, in which we use between one and three post-reform years, depending on the reform. These results are discussed in Section 4.2. 
Table E.2: The Effect of Tax Rates on Tax Payment - Differences-in-Differences Estimates Robustness to Different Control Bands

\begin{tabular}{|c|c|c|c|c|}
\hline & $\begin{array}{c}\text { Mean Tax Rate } \\
\text { (basis points) } \\
(1)\end{array}$ & $\begin{array}{c}\text { Payment amount } \\
\text { (MXN thousands) } \\
(2)\end{array}$ & $\begin{array}{c}\text { Payment in full } \\
(3)\end{array}$ & $\begin{array}{c}\text { Compliance share } \\
(4)\end{array}$ \\
\hline & \multicolumn{4}{|c|}{ I. Estimates for the 2009-2010 treatment } \\
\hline \multirow[t]{2}{*}{$\mathrm{K}$ and $\mathrm{L}$} & .166 & .116 & -.103 & -.041 \\
\hline & $(.000)$ & $(.017)$ & $(.017)$ & $(.011)$ \\
\hline \multirow[t]{2}{*}{$\mathrm{E}$ and $\mathrm{F}$} & .255 & .169 & -.029 & -.001 \\
\hline & $(.000)$ & $(.010)$ & $(.013)$ & $(.009)$ \\
\hline \multirow[t]{2}{*}{$\mathrm{M}$ and $\mathrm{N}$} & .275 & .163 & .001 & .024 \\
\hline & $(.000)$ & $(.010)$ & $(.013)$ & $(.009)$ \\
\hline \multirow[t]{2}{*}{$\mathrm{K}, \mathrm{L}, \mathrm{E}, \mathrm{F}, \mathrm{M}$ and $\mathrm{N}$} & .268 & .165 & -.018 & .01 \\
\hline & $(.000)$ & $(.010)$ & $(.013)$ & $(.009)$ \\
\hline \multirow{3}{*}{$\mathrm{K}$ and $\mathrm{L}$} & \multicolumn{4}{|c|}{ II. Estimates for the 2010-2011 treatment } \\
\hline & .232 & .169 & -.149 & -.07 \\
\hline & $(.000)$ & $(.02)$ & $(.015)$ & $(.010)$ \\
\hline \multirow[t]{2}{*}{$\mathrm{E}$ and $\mathrm{F}$} & .331 & .175 & -.073 & -.038 \\
\hline & $(.000)$ & $(.008)$ & $(.010)$ & $(.007)$ \\
\hline \multirow[t]{2}{*}{$\mathrm{M}$ and $\mathrm{N}$} & .355 & .166 & -.021 & .018 \\
\hline & $(.000)$ & $(.008)$ & $(.010)$ & $(.007)$ \\
\hline \multirow[t]{2}{*}{$\mathrm{K}, \mathrm{L}, \mathrm{E}, \mathrm{F}, \mathrm{M}$ and $\mathrm{N}$} & .347 & .17 & -.049 & -.008 \\
\hline & $(.000)$ & $(.008)$ & $(.010)$ & $(.007)$ \\
\hline \multirow{3}{*}{$\mathrm{K}$ and $\mathrm{L}$} & \multicolumn{4}{|c|}{ III. Estimates for the 2011-2012 treatment } \\
\hline & .401 & .196 & -.3 & -.182 \\
\hline & $(.000)$ & $(.029)$ & $(.014)$ & $(.010)$ \\
\hline \multirow[t]{2}{*}{$\mathrm{E}$ and $\mathrm{F}$} & .517 & .16 & -.216 & -.145 \\
\hline & $(.000)$ & $(.009)$ & $(.009)$ & $(.007)$ \\
\hline \multirow[t]{2}{*}{$\mathrm{M}$ and $\mathrm{N}$} & .545 & .138 & -.161 & -.087 \\
\hline & $(.000)$ & $(.009)$ & $(.009)$ & $(.007)$ \\
\hline \multirow[t]{2}{*}{$\mathrm{K}, \mathrm{L}, \mathrm{E}, \mathrm{F}, \mathrm{M}$ and $\mathrm{N}$} & .536 & .151 & -.189 & -.114 \\
\hline & $(.000)$ & $(.009)$ & $(.009)$ & $(.006)$ \\
\hline
\end{tabular}

Notes: This table is similar to Table 2, Panel B, but displays the point estimates from the DiD estimation using alternative value bands as control groups. In each panel, the first line reproduces our preferred estimates from Table 2 , using properties in bands $\mathrm{K}$ and $\mathrm{L}$ as the control group. The remaining lines display estimates using alternative control groups. Using band $\mathrm{J}$ as a control group is not an option, as properties in this band were treated in 2008-2009. The table shows that our preferred specification yields results similar to those of the alternative specifications but slightly less optimistic about the tax rate increases. In our preferred specification, tax payments increase a bit less and compliance falls a bit more than in alternative specifications. Yet we still conclude that tax rate increases are welfare improving. Choosing a different specification would only strengthen this conclusion. These results are discussed in Section 4.2. 
Figure E.2: Parallel Trends with Different Control Groups - 2009-2010 Treatment

A. Bands $\mathrm{K}$ and L
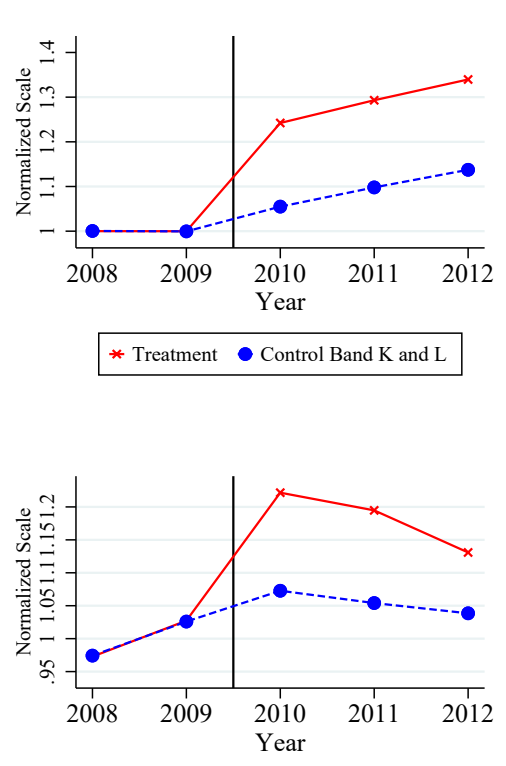

* Treatment $\bullet$ Control Band $\mathrm{K}$ and L
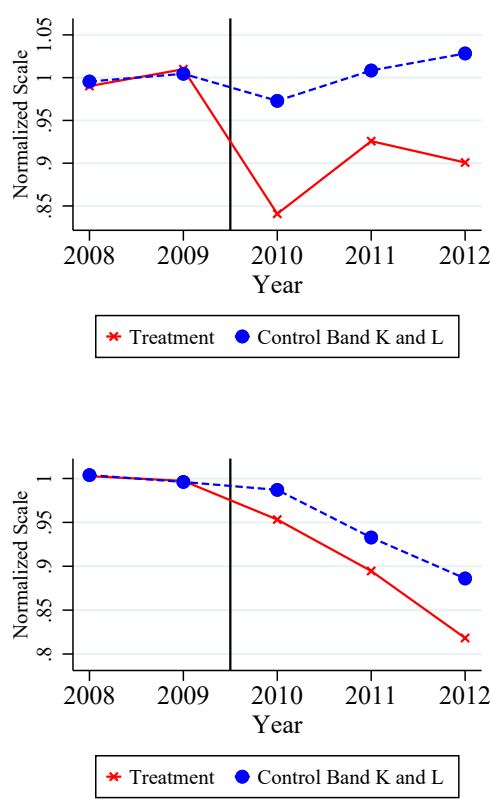

B. Bands E and F

\section{Mean Tax Rate}

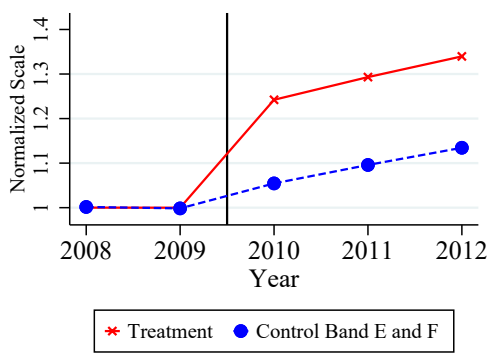

II. Payment Amount
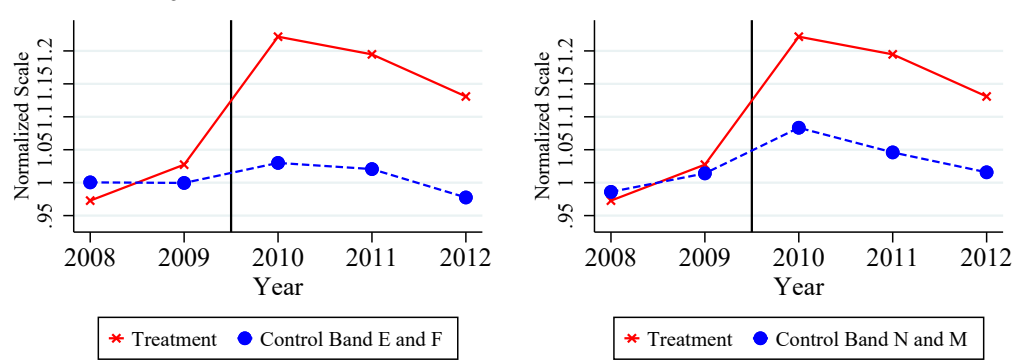

III. Payment in Full
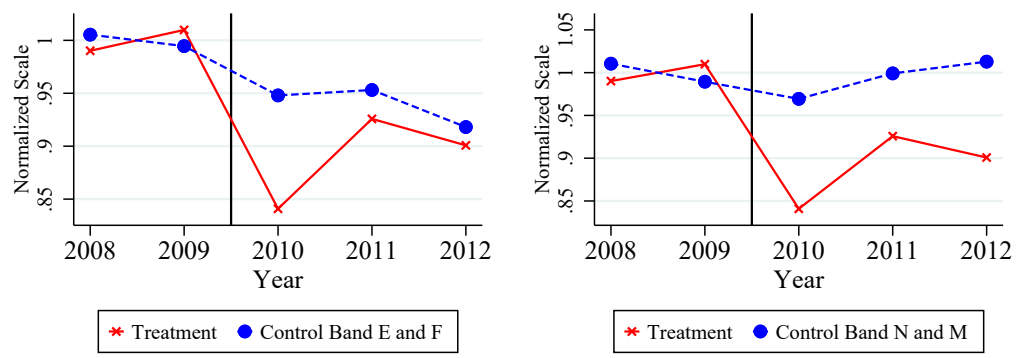

IV. Compliance Share

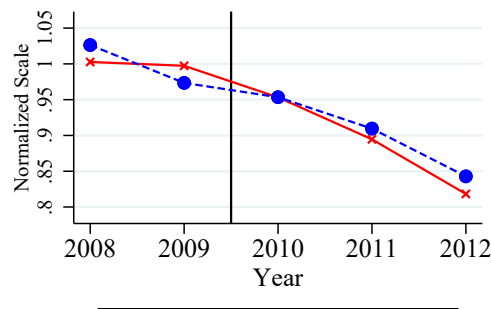

* Treatment $\bullet$ Control Band $\mathrm{E}$ and $\mathrm{F}$

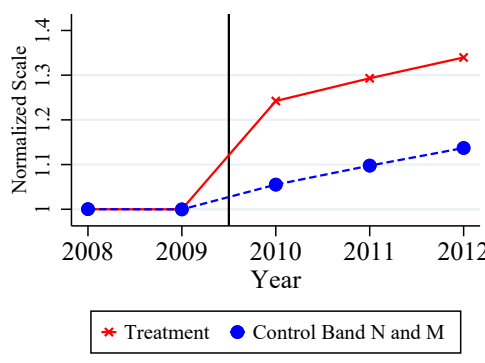

* Treatment $\bullet$ Control Band $\mathrm{N}$ and $\mathrm{M}$

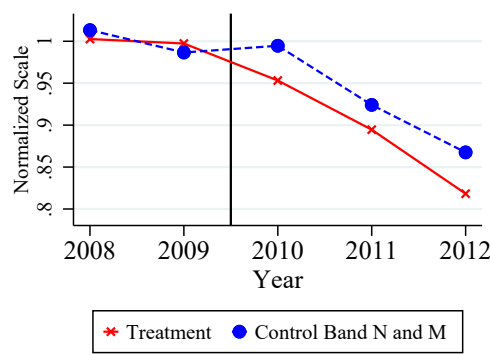

Notes: This figure is similar to Figures 5 and 6 but considers two alternative control groups: bands E and F Column (B)), and bands M and N (Column (C)). Using band J as a control group is not an option, as properties in this band were treated in 2008-2009. Column (A) reproduces the preferred specification in which bands K and L are the control group. The treated band in this figure contains properties in band I, as the figure focuses on the 2009-2010 reform, in which properties in band I were treated with a quasi-exogenous tax rate increase. Figures E.3 and E.4 show similar graphs, focusing on the 2010-2011 and the 2011-2012 reforms, respectively. The corresponding DiD estimates for all reform episodes are displayed in Table E.2. These results are discussed in Section 4.2. 
Figure E.3: Parallel Trends with Different Control Groups - 2010-2011 Treatment
A. Bands $\mathrm{K}$ and $\mathrm{L}$
B. Bands E and F
C. Bands M and N

\section{Mean Tax Rate}
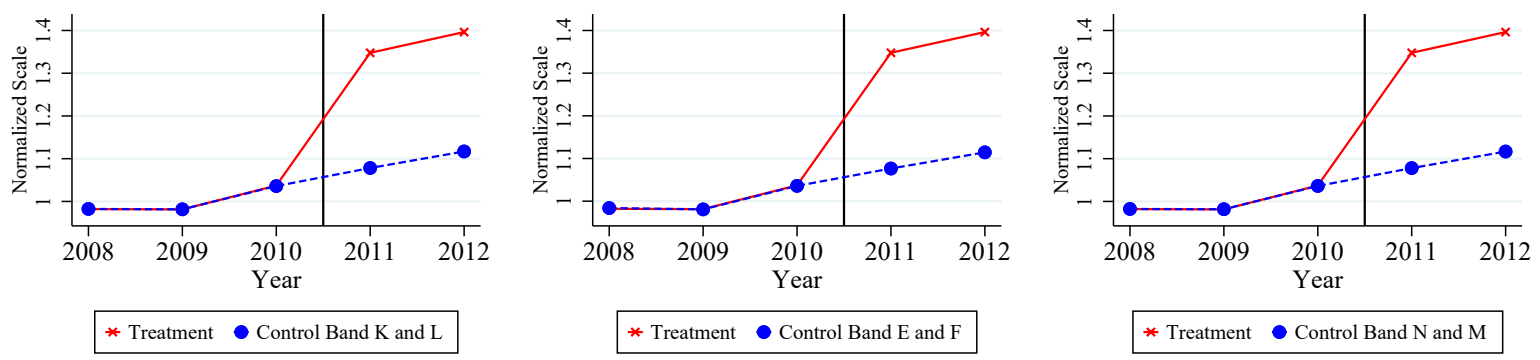

\section{Payment Amount}
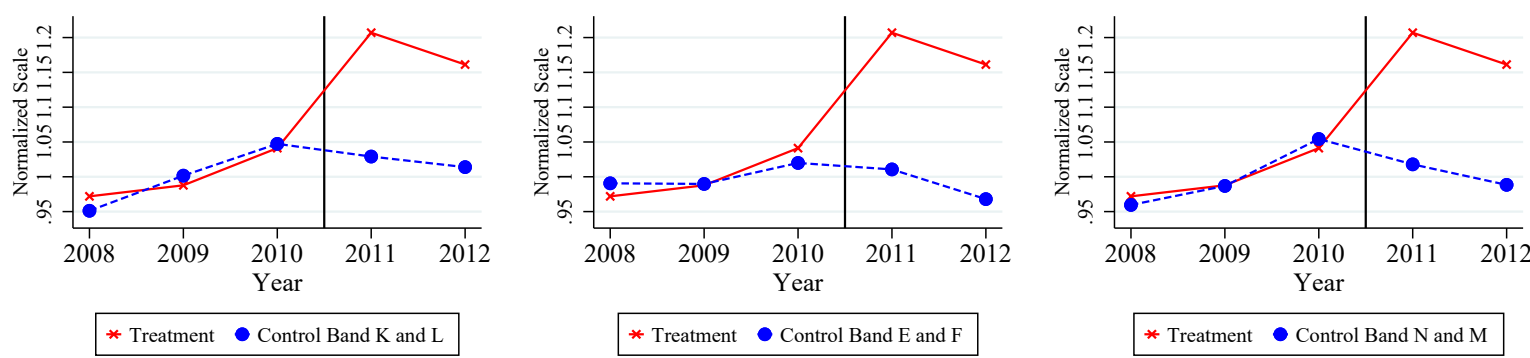

III. Payment in Full
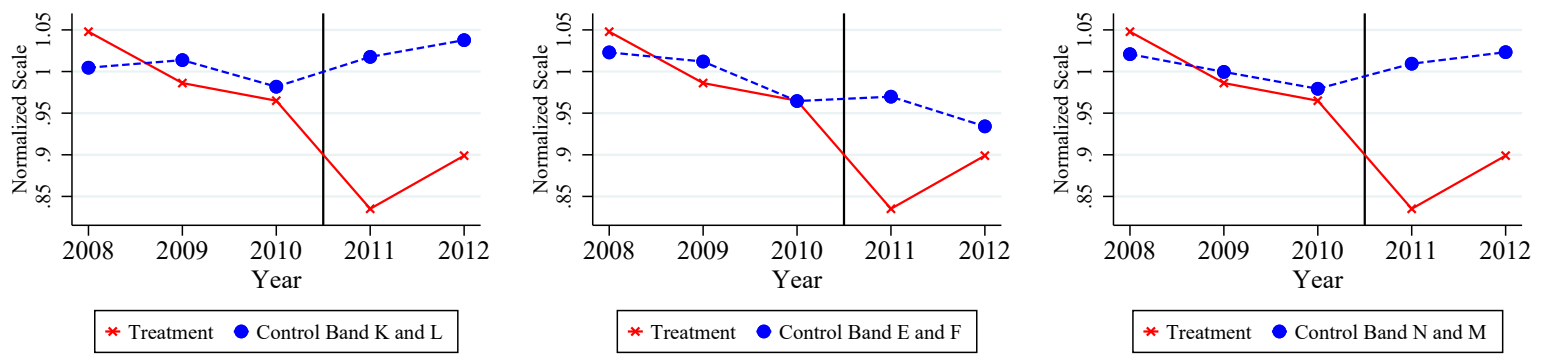

IV. Compliance Share
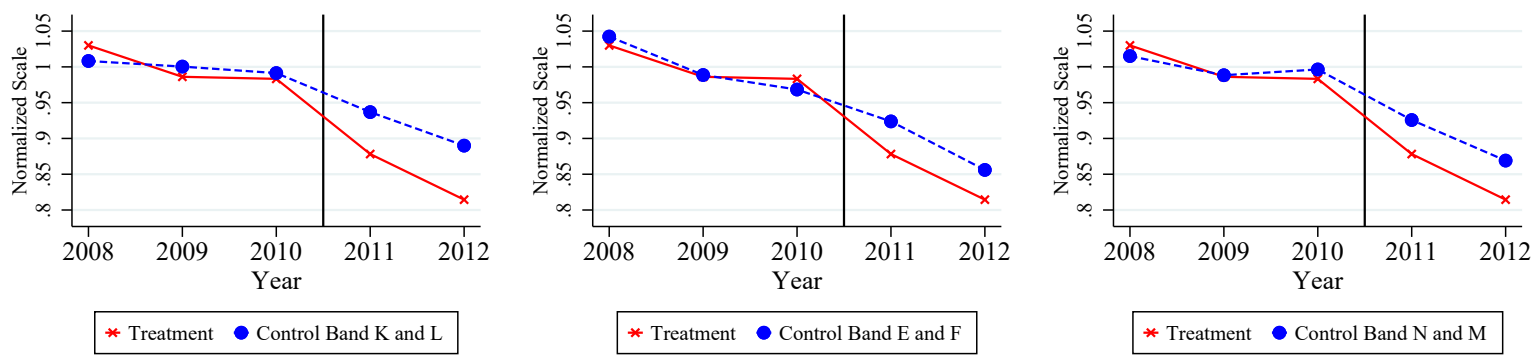

Notes: This figure is identical to Figure E.2 but focuses on the 2010-2011 reform, in which properties in band H were treated with a quasi-exogenous tax rate increase. The treatment group in this figure thus contains properties in band H. The corresponding DiD estimates are displayed in Table E.2. 
Figure E.4: Parallel Trends with Different Control Groups - 2011-2012 Treatment
A. Bands $\mathrm{K}$ and $\mathrm{L}$
B. Bands E and F
C. Bands M and N

\section{Mean Tax Rate}
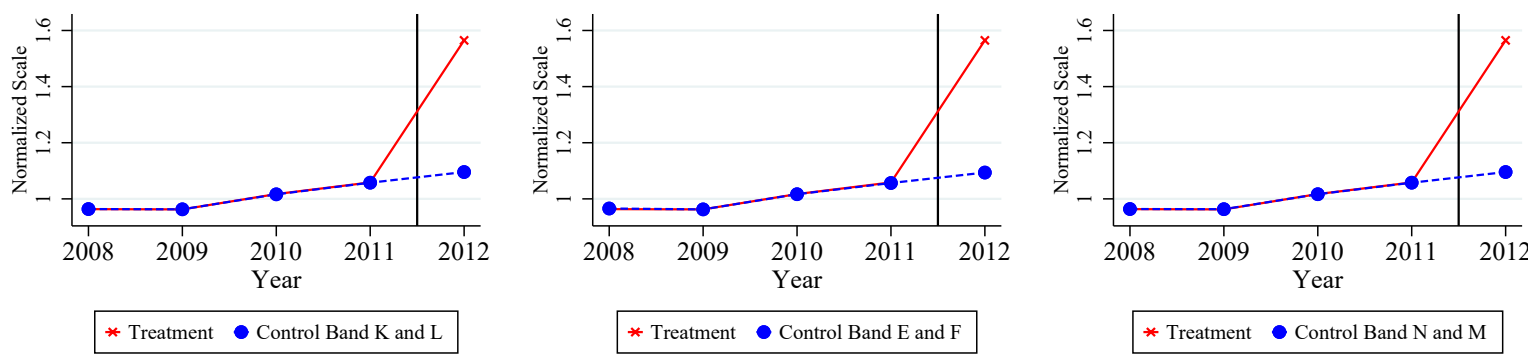

\section{Payment Amount}
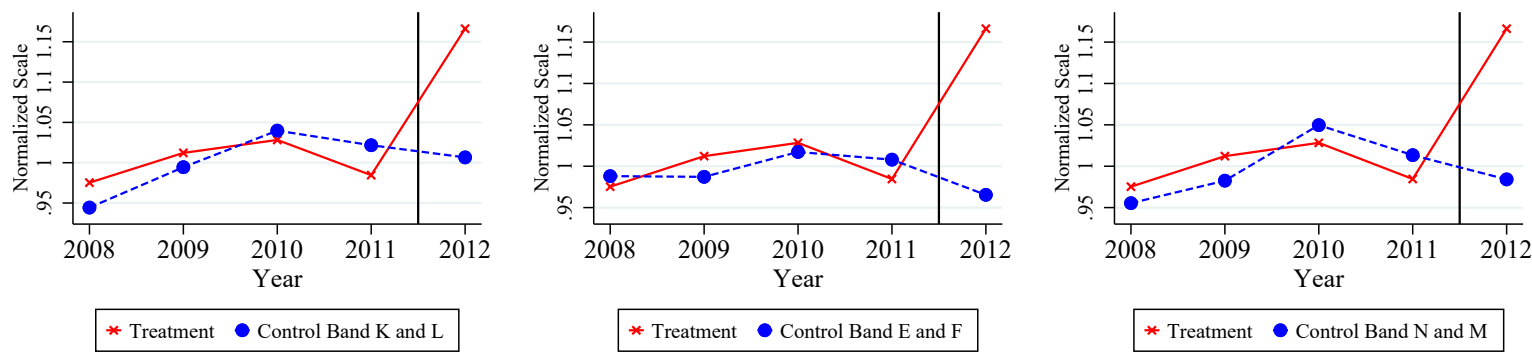

III. Payment in Full
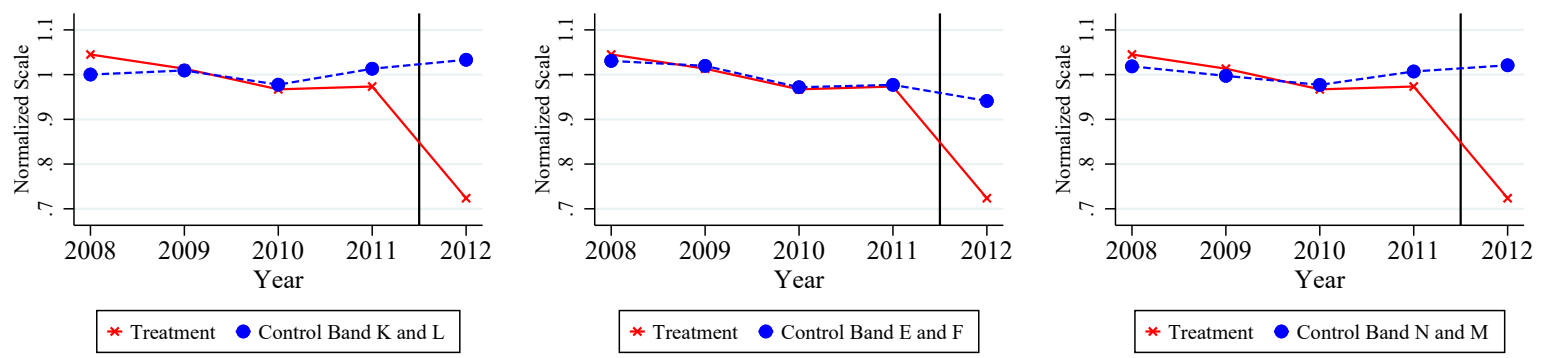

IV. Compliance Share
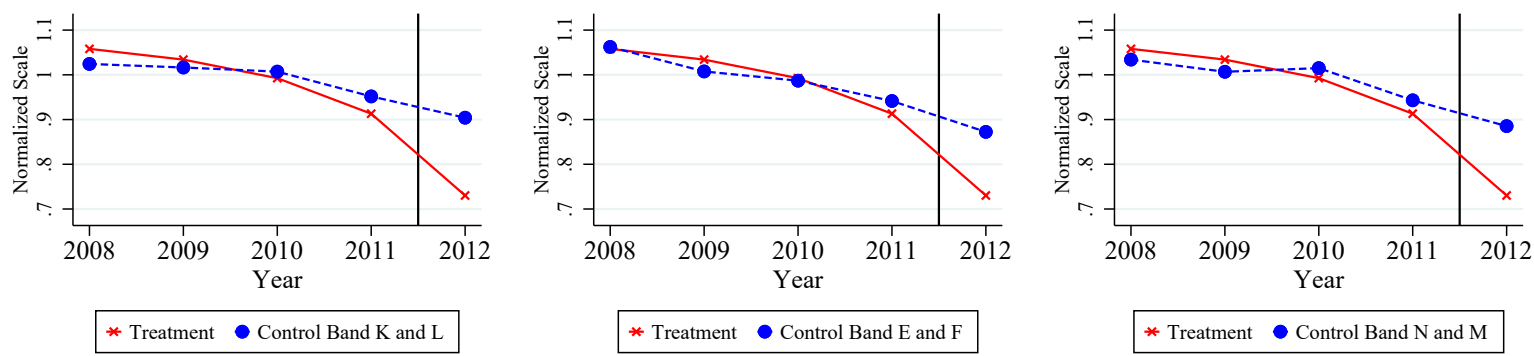

Notes: This figure is identical to Figure E.2 but focuses on the 2011-2012 reform, in which properties in band G were treated with a quasi-exogenous tax rate increase. The treatment group in this figure thus contains properties in band G. The corresponding DiD estimates are displayed in Table E.2. 
Table E.3: The Effect of Tax Rates on Tax Payment - Differences-in-Differences Estimates Robustness to Dropping Taxpayers with Exemptions

\begin{tabular}{|c|c|c|c|c|}
\hline & $\begin{array}{c}\text { Mean tax rate } \\
\text { (1) }\end{array}$ & $\begin{array}{l}\text { Payment } \\
\text { amount } \\
(2)\end{array}$ & $\begin{array}{c}\text { Payment in full } \\
(3)\end{array}$ & $\begin{array}{c}\text { Compliance } \\
\text { share } \\
(4)\end{array}$ \\
\hline \multirow{3}{*}{ DD } & \multicolumn{4}{|c|}{ I. Estimates for the 2010 treatment } \\
\hline & $.167 * * *$ & $.084 * * *$ & $-.093 * * *$ & $-.048 * * *$ \\
\hline & $(.000)$ & $(.019)$ & $(.018)$ & $(.012)$ \\
\hline Adjusted R-squared & .998 & .011 & .005 & .004 \\
\hline Properties (treatment) & 4854 & 4854 & 4854 & 4854 \\
\hline Properties (control) & 5530 & 5530 & 5530 & 5530 \\
\hline \multirow[t]{2}{*}{ Implied elasticity } & & .502 & -.558 & -.289 \\
\hline & & $(.112)$ & $(.107)$ & $(.074)$ \\
\hline \multirow[t]{2}{*}{ Implied Semi-elasticity } & & .01 & -.011 & -.006 \\
\hline & & $(.002)$ & $(.002)$ & $(.001)$ \\
\hline \multirow{3}{*}{ DD } & \multicolumn{4}{|c|}{ II. Estimates for the 2011 treatment } \\
\hline & $.232 * * *$ & $.107^{* * *}$ & $-.142 * * *$ & $-.077 * * *$ \\
\hline & $(.000)$ & $(.021)$ & $(.015)$ & $(.011)$ \\
\hline Adjusted R-squared & .995 & .012 & .004 & .008 \\
\hline Properties (treatment) & 8194 & 8194 & 8194 & 8194 \\
\hline Properties (control) & 5531 & 5531 & 5531 & 5531 \\
\hline \multirow[t]{2}{*}{ Implied elasticity } & & .463 & -.611 & -.332 \\
\hline & & $(.092)$ & $(.066)$ & $(.047)$ \\
\hline \multirow[t]{2}{*}{ Implied Semi-elasticity } & & .01 & -.013 & -.007 \\
\hline & & $(.002)$ & $(.001)$ & $(.001)$ \\
\hline \multirow[t]{2}{*}{ P-value $\left(H_{0}: \epsilon_{2011}=\epsilon_{2010}\right)$} & & .489 & .331 & .393 \\
\hline & \multicolumn{4}{|c|}{ III. Estimates for the 2012 treatment } \\
\hline \multirow[t]{2}{*}{ DD } & $.401 * * *$ & $.14^{* * *}$ & $-.282 * * *$ & $-.16 * * *$ \\
\hline & $(.000)$ & $(.031)$ & $(.015)$ & $(.011)$ \\
\hline Adjusted R-squared & .993 & .009 & .013 & .019 \\
\hline Properties (treatment) & 12928 & 12928 & 12928 & 12928 \\
\hline Properties (control) & 5528 & 5528 & 5528 & 5528 \\
\hline \multirow[t]{2}{*}{ Implied elasticity } & & .35 & -.705 & -.399 \\
\hline & & $(.077)$ & $(.037)$ & $(.027)$ \\
\hline \multirow[t]{2}{*}{ Implied Semi-elasticity } & & .009 & -.017 & -.01 \\
\hline & & $(.002)$ & $(.001)$ & $(.001)$ \\
\hline P-value $\left(H_{0}: \epsilon_{2012}=\epsilon_{2011}\right)$ & & .182 & .000 & .006 \\
\hline P-value $\left(H_{0}: \epsilon_{2012}=\epsilon_{2010}\right)$ & & .071 & .000 & .002 \\
\hline
\end{tabular}

Notes: This table is similar to Table 2, Panel B, but excludes taxpayers who ever received a subsidy or exemption. It demonstrates the robustness of the DiD results to dropping these taxpayers. These results are discussed in Section 4.2 . 
Table E.4: The Effect of Tax Rates on Tax Payment - Differences-in-Differences Estimates Robustness to Different Clustering Levels

\begin{tabular}{|c|c|c|c|c|}
\hline & \multirow{4}{*}{$\begin{array}{c}\text { Point } \\
\text { Estimate } \\
(1)\end{array}$} & \multicolumn{3}{|c|}{ Standard Error Cluster Level: } \\
\hline & & Taxpayer & Postal Code & Bootstrap \\
\hline & & & & Delegacion \\
\hline & & $(2)$ & $(3)$ & $(4)$ \\
\hline & \multicolumn{4}{|c|}{ I. Estimates for the 2009-2010 treatment } \\
\hline Mean Tax Rate (basis points) & .166 & 0 & 0 & 0 \\
\hline Payment amount (MXN thousands) & .116 & .017 & .015 & .01 \\
\hline Payment in full (percentage points) & -.103 & .017 & .017 & .015 \\
\hline \multirow{2}{*}{ Compliance share $\times 100$} & -.041 & .011 & .011 & .008 \\
\hline & \multicolumn{4}{|c|}{ II. Estimates for the 2010-2011 treatment } \\
\hline Mean Tax Rate (basis points) & .232 & 0 & 0 & .001 \\
\hline Payment amount (MXN thousands) & .169 & .02 & .024 & .022 \\
\hline Payment in full (percentage points) & -.149 & .015 & .016 & .01 \\
\hline \multirow[t]{2}{*}{ Compliance share $\times 100$} & -.07 & .01 & .011 & .008 \\
\hline & \multicolumn{4}{|c|}{ III. Estimates for the 2011-2012 treatment } \\
\hline Mean Tax Rate (basis points) & .401 & 0 & .001 & .001 \\
\hline Payment amount (MXN thousands) & .196 & .029 & .029 & .039 \\
\hline Payment in full (percentage points) & -.3 & .014 & .015 & .014 \\
\hline Compliance share $\times 100$ & -.182 & .01 & .01 & .011 \\
\hline
\end{tabular}

Notes: This table is similar to Table 2, Panel B. Column (1) displays the point estimates from the DiD estimation. Columns (2)-(4) display the standard errors at different clustering levels. Column (4) performs a bootstrap where the 16 delegaciones are the resampling clusters. 
Table E.5: Robustness of Tax Rate Elasticity Estimations - Panel Regressions

\begin{tabular}{|c|c|c|c|c|}
\hline & $\begin{array}{c}\text { Mean tax rate } \\
\text { (1) }\end{array}$ & $\begin{array}{c}\text { Payment } \\
\text { amount } \\
(2)\end{array}$ & $\begin{array}{c}\text { Payment in } \\
\text { full } \\
(3)\end{array}$ & $\begin{array}{c}\text { Compliance } \\
\text { share } \\
(4)\end{array}$ \\
\hline & \multicolumn{4}{|c|}{ A. Value Band FE } \\
\hline PE Tax Rate & & $\begin{array}{c}.694 * * * \\
(.086)\end{array}$ & $\begin{array}{c}.203 * * * \\
(.046)\end{array}$ & $\begin{array}{c}-.132^{* * *} \\
(.045)\end{array}$ \\
\hline Tax Rate Elasticity & & $\begin{array}{c}.694 \\
(.086)\end{array}$ & $\begin{array}{l}-.551 \\
(.125)\end{array}$ & $\begin{array}{l}-.292 \\
(.098)\end{array}$ \\
\hline Mean Tax Rate & 49.53 & & & \\
\hline $\begin{array}{l}\text { Mean } \\
\text { Cadastral Value Band FE } \\
\text { Year FE } \\
\text { Band G, H, I * Tax Rate } \\
\text { Observations }\end{array}$ & & $\begin{array}{l}11301.63 \\
\text { Yes } \\
\text { Yes } \\
\text { No } \\
80 \\
\end{array}$ & $\begin{array}{l}.37 \\
\text { Yes } \\
\text { Yes } \\
\text { No } \\
80\end{array}$ & $\begin{array}{l}.45 \\
\text { Yes } \\
\text { Yes } \\
\text { No } \\
80\end{array}$ \\
\hline Observations & \multicolumn{4}{|c|}{ B. Heteregeneity by treated bands } \\
\hline PE Tax Rate & & $\begin{array}{c}.702 * * \\
(.275)\end{array}$ & $\begin{array}{c}-.294 * * \\
(.146)\end{array}$ & $\begin{array}{l}-.115 \\
(.142)\end{array}$ \\
\hline PE Treated Bands * Tax Rate & & $\begin{array}{l}. .006 \\
(.205)\end{array}$ & $\begin{array}{c}.072 \\
(.109)\end{array}$ & $\begin{array}{l}-.014 \\
(.106)\end{array}$ \\
\hline Tax Rate Elasticity Control Bands & & $\begin{array}{l}.702 \\
(.275)\end{array}$ & $\begin{array}{l}-.799 \\
(.396)\end{array}$ & $\begin{array}{l}-.254 \\
(.313)\end{array}$ \\
\hline Tax Rate Elasticity Treated Bands & & $\begin{array}{l}.696 \\
(.038)\end{array}$ & $\begin{array}{l}-.604 \\
(.055)\end{array}$ & $\begin{array}{l}-.284 \\
(.044)\end{array}$ \\
\hline Mean Tax Rate & 49.53 & & & \\
\hline Mean & & 11301.63 & .37 & .45 \\
\hline Cadastral Value Band FE & & Yes & Yes & Yes \\
\hline Year FE & & Yes & Yes & Yes \\
\hline Band G, H, I * Tax Rate & & Yes & Yes & Yes \\
\hline Observations & & 80 & 80 & 80 \\
\hline
\end{tabular}

Notes: This table demonstrates the robustness of the estimates for the elasticity of tax compliance to the tax rate, displayed in Tables 2. Panel A here displays estimates for $Y_{i t}=\beta_{1} R_{i t}+\gamma_{i}+\delta_{t}+\epsilon_{i t}$, where $Y_{i t}$ is the average outcome for band $i$ in year $t, R_{i t}$ is the $\log$ average tax rate for band $i$ in year $t, \delta_{t}$ and $\gamma_{i}$ denote year and value band fixed effects, and $\epsilon_{i}$ is the error term. Payment is in logs; the other outcomes are not. The elasticities are calculated as in Table 2. Standard errors are in parentheses. Panel B is similar to Panel A but includes an interaction between the tax rate and an indicator for bands $\mathrm{G}, \mathrm{H}$ and I (the treated bands in the RD and DiD estimations). The elasticity estimates are very similar to our main RD and DiD estimates. These results are discussed in Section 4.2 . 


\section{F Real Response Appendix}

A potential concern for tax rate increases is that while they may raise revenue, they may also be accompanied by a reduction in real estate investment. One possibility is that owners of existing properties might be less likely to invest in maintaining or upgrading their properties. However, because the cadastral value of a given property would not be affected by maintenance or upgrades, raising property tax rates does not disincentivize these forms of investment. Nonetheless, it may be the case that higher property tax rates can decrease investment in new housing units.

One way in which developers can respond to tax rate hikes is by using the cadastral value formula to design houses so that they fall below the threshold of a given value band. To test for this, Panels A and B of Figure F.1 plot the number of properties built after the 2010 and 2011 tax increases. ${ }^{73}$ We group properties into small cadastral value bins around the lower threshold of each treated value band. If the tax rate increase dissuaded developers from building properties in this value band, we should see a bunching of new properties just below the lower threshold of the treated band. The graphs show that this is not the case: the number of new properties is weakly decreasing with property value and is smooth around the threshold of the treated band. That is, we find no evidence of bunching. To further investigate this type of response, in Panels C and D of Figure F.1, we plot the percentage change in new properties by bin, relative to the average number of new units in the previous two years. As in the previous graphs, there is no sign of bunching and no discontinuity at the threshold of the treated band.

Building on our analyses in Section 4.2, we also conduct a DiD analysis on the number of new property developments. To do so, we first rank properties by cadastral value and divide each value band into 5 sub-bins of equal size. We then construct a count of the number of new properties in each sub-bin and year. Finally, we estimate a regression similar to Equation 7 where the outcome is the log number of new properties at the sub-bin-year level. Panel E in Figure F.1 shows the results of this estimation where we stack the 2010 and 2011 reforms and where we use properties in bands K and L as controls. This figure shows that we do not find a decrease in the number of new properties in bands that experience increases in property tax rates.

Although other studies have found evidence of real responses to property tax changes (e.g., Singh 2020), our results can be rationalized when we consider the context. The quasi-exogenous tax rate increases that we study apply to a very small range of property values. To determine whether their future properties would fall into one of the treated bands, property developers need precise knowledge of the tax code and clarity on the exact features of the property to be constructed. The applicability of the tax rate changes may be too narrow to warrant such an analysis. In addition, developers may anticipate future tax rate changes, reducing their responsiveness to recent reforms.

Overall, we do not find evidence that increases in property tax rates disincentivized the construction of new housing units. Based on these results, we focus the policy analysis in Section 7 on the roles that compliance, enforcement, and liquidity constraints play in the administration of the property tax.

\footnotetext{
${ }^{73}$ We exclude the 2012 reform because our data end in 2013, which limits the number of new units that we observe.
} 
Figure F.1: Absence of a Real Estate Response to Tax Rate Increases

A: Number of New Properties, Band I

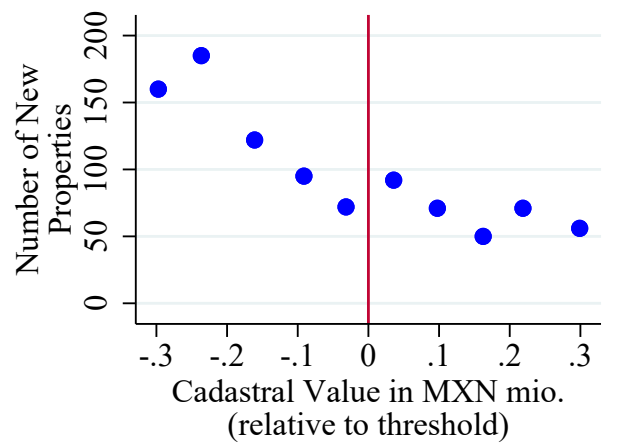

B: Number of New Properties, Band H

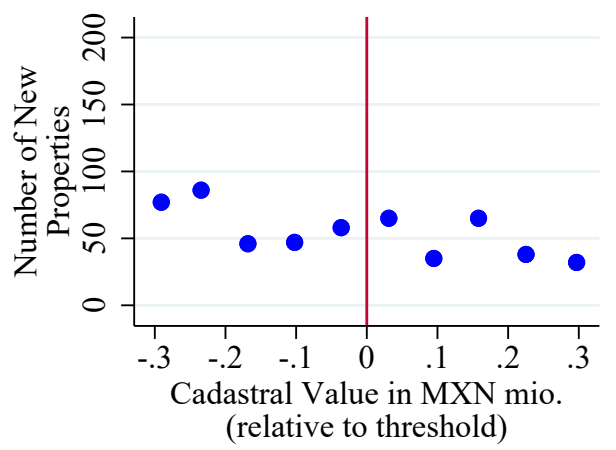

C: Growth in Number of Properties, Band I D: Growth in Number of Properties, Band H
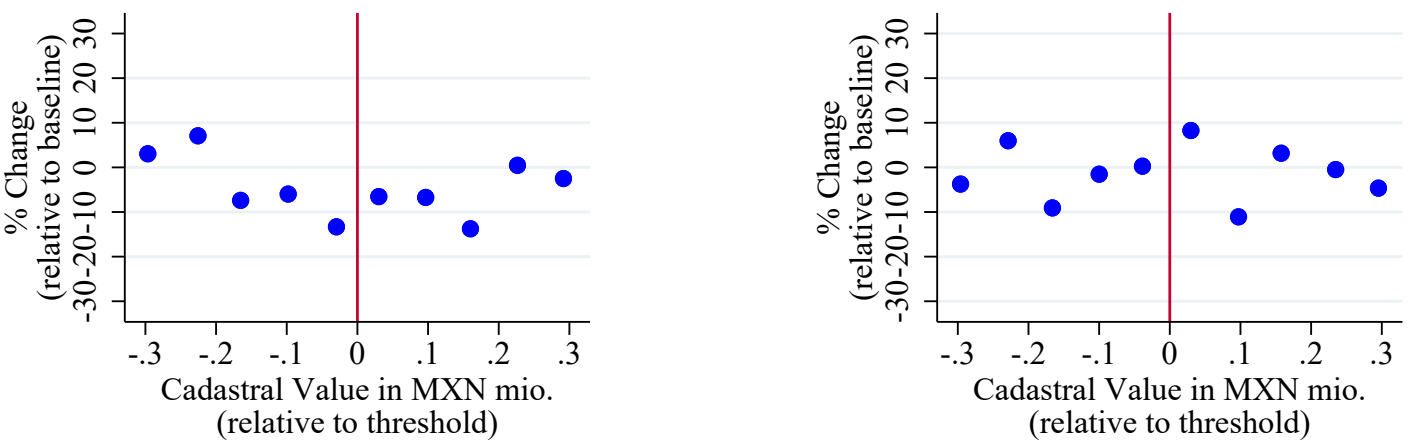

E: Differences-in-Differences Estimation

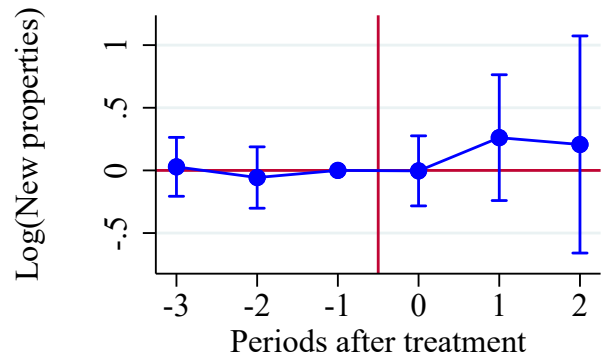

- Coefficient $\mapsto 95 \%$ conf. int.

Notes: This figure examines the effect of tax rate increases on real estate investment. Panel A plots the number of new properties constructed around the lower threshold of band I during the post-reform years 2011-2013. We plot the number of new properties in equally sized cadastral value bins in bands $\mathrm{H}$ and $\mathrm{I}$, within a 0.3 million MXN cadastral value range around the threshold. Panel B is similar but plots the number of new properties in bands $\mathrm{G}$ and $\mathrm{H}$, constructed in the years 2012 and 2013. Panels C and D are similar to Panels A and B, respectively, but plot the growth rate in new properties. The numerator of the growth rate is the number of new properties plotted in Panel A (B). The denominator is the yearly average number of properties in the last two (three) prereform years (we use an average to minimize noise). Panel E plots the results of the difference-in-difference estimation $\log \left(N_{b t}\right)=\alpha_{b}+\mu_{t}+\gamma \cdot$ Treat $_{b} \cdot$ Post $_{t}+\epsilon_{b t}$, where $N_{b t}$ is the number of new properties constructed in property value bin $b$ in year $t$ and $\alpha_{b}$ and $\mu_{t}$ are bin and time fixed effects. Each value band is divided into equally sized bins, and standard errors are clustered at the bin level. Value bands I, H, and G are treated; value bands J, K and L serve as controls. The other bands are omitted. The reforms are stacked, so that $t$ is the time relative to reform. 


\section{G Experiment Appendix}

Table G.1: Cadastral Value Distribution of Experiment Sample

\begin{tabular}{lcc}
\hline \hline & All Taxpayers & Experiment Sample \\
\hline Mean & $589,530.8$ & $533,087.3$ \\
SE & $(636.2)$ & $(2310.3)$ \\
Min & 993.7 & $17,178.4$ \\
Max & $11,711,063.3$ & $11,670,532.6$ \\
20th Percentile & $229,784.6$ & $256,034.0$ \\
50th Percentile & $391,487.2$ & $419,170.5$ \\
80th Percentile & $730,281.1$ & $678,949.6$ \\
\hline
\end{tabular}

Notes: As discussed in Section 5.1, this table compares the cadastral value between the delinquent taxpayers targeted in the tax compliance intervention and the full population of taxpayers, showing very similar distributions.

Figure G.1: Experiment Design

\section{Enforcement Letters}

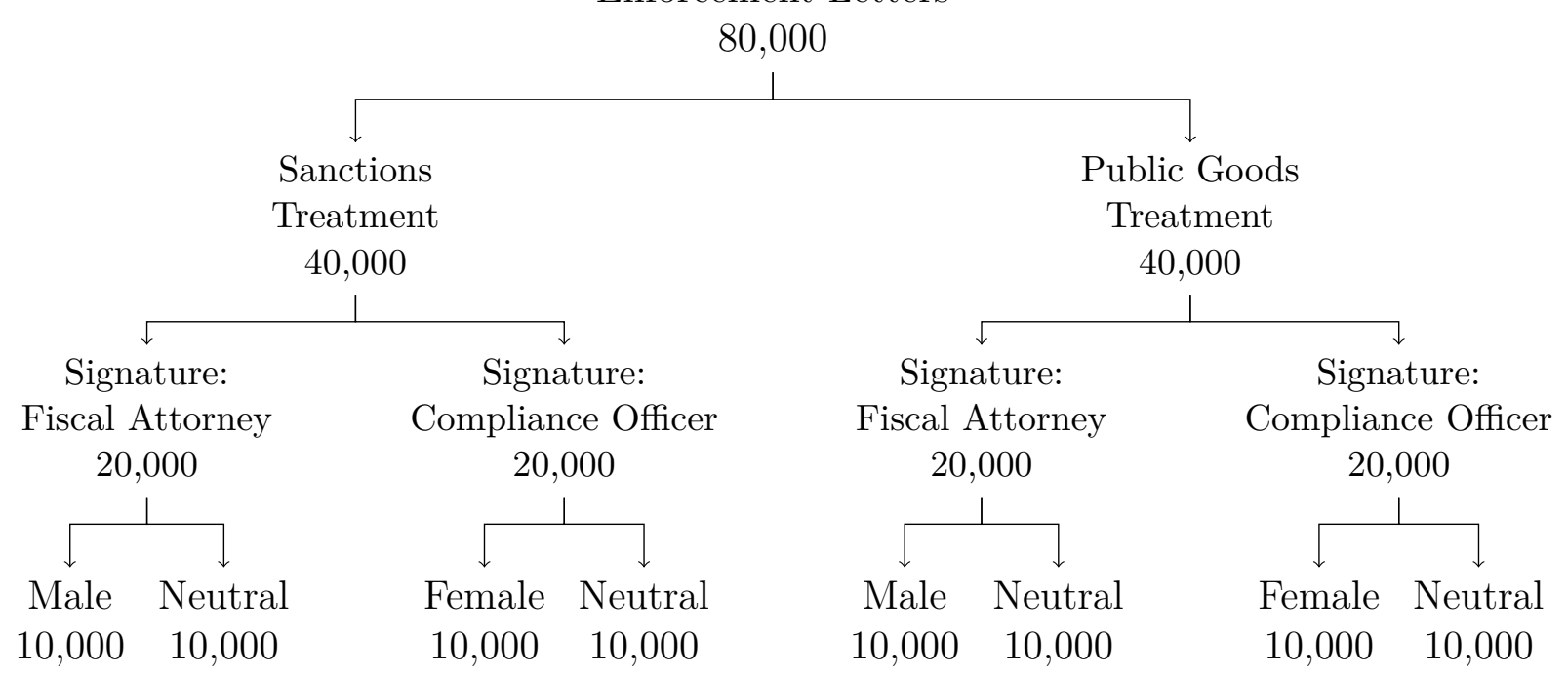

Notes: This diagram represents the different treatment arms of the enforcement intervention discussed in Section 5, in which the Ministry of Finance sent letters to encourage payment of outstanding property tax debt. Letter recipients were selected from a pool of taxpayers who had become delinquent between bimester 4 of 2009 and bimester 3 of 2014. The letters were sent between July 28 and August 11, 2014. A control group of 10,000 delinquent taxpayers received no letters. 
Table G.2: The Effect of Enforcement Letters on Tax Payment: Robustness

\begin{tabular}{|c|c|c|c|c|c|c|c|}
\hline \multicolumn{2}{|c|}{ 1: Letter Content } & \multicolumn{2}{|c|}{ 2: Sender Position } & \multicolumn{2}{|c|}{ 3: Male Sender } & \multicolumn{2}{|c|}{ 4: Female Sender } \\
\hline Sanctions & $\begin{array}{l}\text { Public } \\
\text { Good }\end{array}$ & $\begin{array}{c}\text { Fiscal } \\
\text { Attorney }\end{array}$ & $\begin{array}{c}\text { Compliance } \\
\text { Officer }\end{array}$ & Male & Neutral & Female & Neutral \\
\hline \multicolumn{8}{|c|}{ Panel A: Cross Sectional Regressions with Controls } \\
\hline \multicolumn{8}{|c|}{ Panel A1: Any Payment } \\
\hline $\begin{array}{c}9.463^{* * *} \\
(.312)\end{array}$ & $\begin{array}{c}4.815^{* * *} \\
(.292)\end{array}$ & $\begin{array}{c}7.585^{* * * *} \\
(.304)\end{array}$ & $\begin{array}{c}6.637^{* * *} \\
(.3)\end{array}$ & $\begin{array}{c}7.059 * * * \\
(.361)\end{array}$ & $\begin{array}{c}8.07^{* * *} \\
(.364)\end{array}$ & $\begin{array}{c}7.039 * * * \\
(.357)\end{array}$ & $\begin{array}{c}6.308 * * * \\
(.353)\end{array}$ \\
\hline \multicolumn{8}{|c|}{ Panel A2: Payment Amount (MX Pesos) } \\
\hline $\begin{array}{c}39.018^{* * *} \\
(1.98)\end{array}$ & $\begin{array}{c}9.306^{* * *} \\
(1.678)\end{array}$ & $\begin{array}{c}28.95 * * * \\
(1.872)\end{array}$ & $\begin{array}{c}18.961^{* * *} \\
(1.801)\end{array}$ & $\begin{array}{c}27.041^{* * *} \\
(2.36)\end{array}$ & $\begin{array}{c}30.98^{* * *} \\
(2.251)\end{array}$ & \begin{tabular}{|c}
$21.843^{* * *}$ \\
$(2.209)$
\end{tabular} & $\begin{array}{c}17.169 * * * \\
(2.151)\end{array}$ \\
\hline \multicolumn{8}{|c|}{ Panel B: Difference in Difference Estimates } \\
\hline \multicolumn{8}{|c|}{ Panel B1: Any Payment } \\
\hline $\begin{array}{c}9.591^{* * *} \\
(.256)\end{array}$ & $\begin{array}{c}4.975^{* * *} \\
(.238)\end{array}$ & $\begin{array}{c}7.814^{* * *} \\
(.249)\end{array}$ & $\begin{array}{c}6.751^{* * *} \\
(.245)\end{array}$ & $\begin{array}{c}7.173^{* * *} \\
(.296)\end{array}$ & $\begin{array}{c}8.455^{* * *} \\
(.302)\end{array}$ & $\begin{array}{c}7.004^{* * *} \\
(.293)\end{array}$ & $\begin{array}{c}6.499 * * * \\
(.291)\end{array}$ \\
\hline \multicolumn{8}{|c|}{ Panel B2: Payment Amount (MX Pesos) } \\
\hline $\begin{array}{c}55.564^{* * * *} \\
(2.292)\end{array}$ & $\begin{array}{c}16.049^{* * * *} \\
(1.957)\end{array}$ & $\begin{array}{c}43.656^{* * * *} \\
(2.192)\end{array}$ & $\begin{array}{c}27.956^{* * *} \\
(2.075)\end{array}$ & $\begin{array}{c}40.283^{* * * *} \\
(2.642)\end{array}$ & $\begin{array}{c}47.029 * * * \\
(2.648)\end{array}$ & $\begin{array}{c}29.431^{* * *} \\
(2.454)\end{array}$ & $\begin{array}{c}26.482^{* * * *} \\
(2.444)\end{array}$ \\
\hline
\end{tabular}

Notes: This table is similar to Table 3. Each of Columns (1)-(4) and each row displays results from one regression. Panel A displays estimates from a cross-sectional regression that includes the cadastral value and age of the property as controls in the estimation. Panel $\mathrm{B}$ displays estimates for $\beta_{5}$ and $\beta_{6}$ from the difference-in-difference specification $Y_{i g t}=\alpha_{i}+\lambda_{t}+\beta_{1} T 1_{i 20}+\beta_{2} T 2_{i 20}+\beta_{3} T 1_{i 40}+\beta_{4} T 2_{i 40}+\beta_{5} T 1_{i 60}+\beta_{6} T 2_{i 60}+\epsilon_{i g t}$, where $Y_{i g t}$ is the outcome for property $i$ in treatment group $g$ on day $t, \alpha_{i}$ and $\lambda_{t}$ are property and day fixed effects, $T 1_{i 20}$ and $T 2_{i 20}$ are treatment indicators that switch on for the first 20 days after all letters were sent, $T 1_{i 40}$ and $T 2_{i 40}$ are treatment indicators that switch on between days 20 and 40 , and $T 1_{i 60}$ and $T 2_{i 60}$ are treatment indicators that switch on between days 40 and 60 . 
Figure G.2: The Effect of Enforcement Letters on Tax Payment
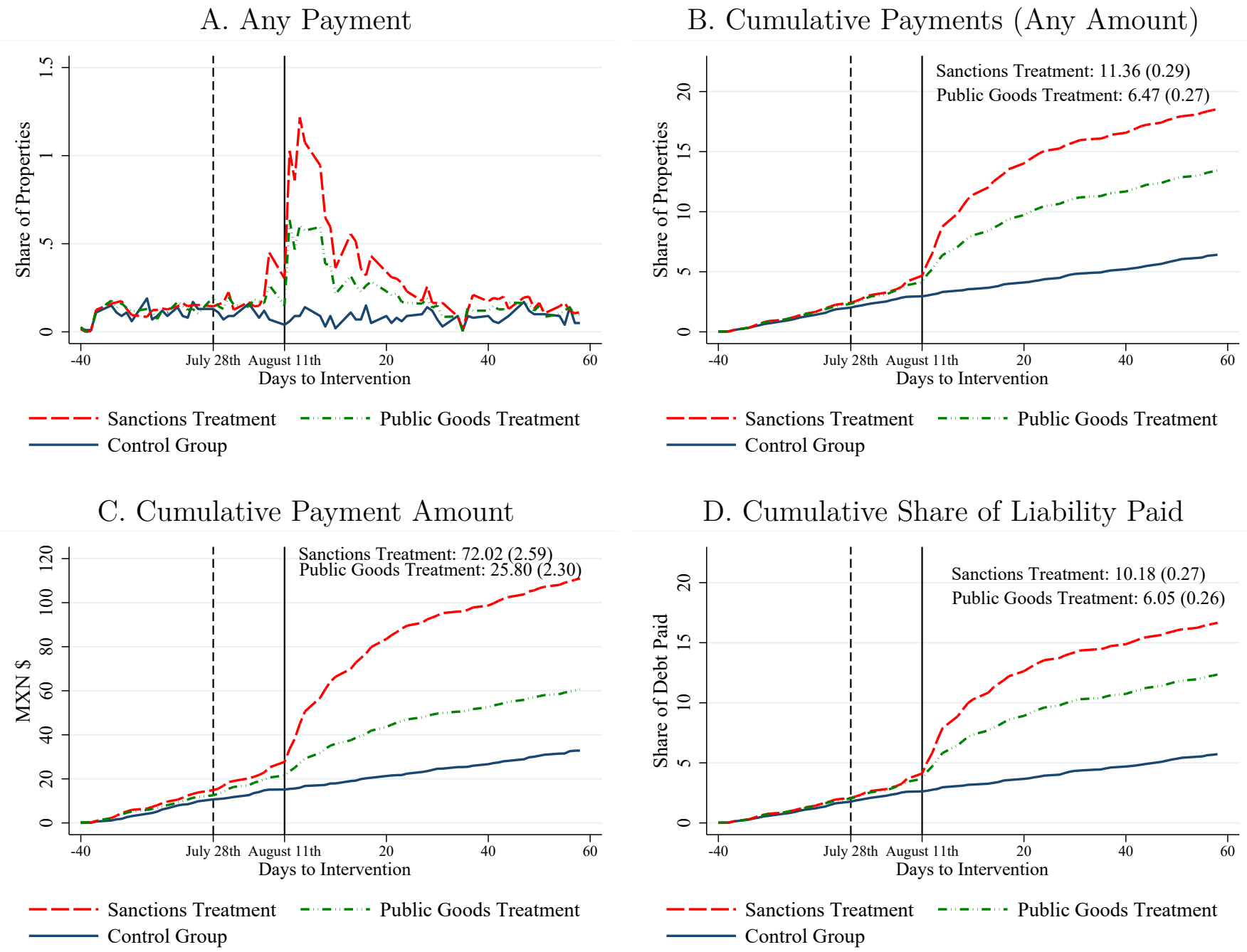

Notes: This figure is identical to Figure 7 except that it displays the raw data before detrending and the estimates are from a regression run on the non-detrended data. This results in slightly larger treatment effect estimates than those of our preferred specification. 
Figure G.3: Translation of Enforcement Letters

Taxpayer name

Taxpayer address

\section{Sanctions Treatment}

\section{Avoid major inconvenience and regularize your tax status Invitation Letter for Payment of Property Tax}

According to the registers of the Federal District's Treasury, you have outstanding property tax debt for the tax period(s) *****. We would therefore be grateful if you could update your tax status within 15 working days of receipt of this letter.

Delay in property tax payment can be sanctioned with fines and interest costs, and with interventions that the fiscal authority conducts to ensure effective tax collection, as per the Tax Code, which can lead to the seizure of property.

Avoid major inconvenience and regularize your tax status.

\section{Public Goods Treatment}

With our tax payment, we all contribute to improving our city

\section{Invitation Letter for Payment of the Property Tax}

As you know, a large part of the social programs and investments in infrastructure and security that the Government of Mexico City implements are financed by property tax revenues. Your contribution is therefore very important, and we would be pleased if you could update your property tax account as soon as possible and cover the outstanding tax debt for the above mentioned building for the tax period(s) ***** within 15 working days upon receipt of this letter. We ask you to update your account to avoid incurring surcharges.

With the revenues obtained from property taxes in your city, we finance the following public goods, among others:

- Food pensions for the elderly;

- School uniforms and school supplies for children;

- The operation of health centers and hospitals of the Government of Mexico City;

- Street lights and sidewalks in your neighborhood.

Boxed: Information about payment and further details on the back

Signature: Name, Title

(For gender-neutral signatures, only the initials of the first name are provided.) 


\section{H Liquidity Constraints Appendix}

This appendix documents the inability of Mexico City's households to fully insure consumption and tax payments against idiosyncratic income risk. In general, imperfect or partial income insurance is taken by the literature as evidence of liquidity and credit constraints (see Attanasio, 1999). To test for partial income insurance, a usual practice in the literature is to use longitudinal data to regress household consumption on household income, as follows:

$$
\log \left(\text { Consumption }_{i t}\right)=\log \left(\text { Income }_{i t}\right) \beta+\gamma_{i}+\delta_{t}+\epsilon_{i t}
$$

where $\gamma_{i}$ represents household fixed effects and $\delta_{t}$ represents time dummies. The inclusion of household fixed effects and time dummies enables the interpretation of $\beta$ as the elasticity of consumption with respect to temporary, idiosyncratic deviations of household income from its mean. A significant $\beta$ estimate constitutes evidence of partial income insurance because it indicates that consumption responds to temporary income shocks.

The estimation of Equation H.1 is complicated by the fact that our consumption data for Mexico City from the Encuesta Nacional de Ingresos y Gastos de los Hogares (ENIGH) is a repeated cross-sectional survey. Hence, we cannot include household fixed effects in the above regression. To overcome this limitation, we follow the strategy proposed by Attanasio and Székely (2004) to test for partial income insurance. In particular, they propose regressing the variance of household consumption on the variance of household income by year-of-birth $\times$ education cohort as follows:

$$
\operatorname{var}_{g}\left[\log \left(\text { Consumption }_{i t}\right)\right]=\operatorname{var}_{g}\left[\log \left(\text { Income }_{i t}\right)\right] \beta+\gamma_{g}+\epsilon_{g t} \text {, }
$$

where $\gamma_{g}$ is a cohort-specific fixed effect. Note that the parameter $\beta$ is the same across specifications H.1 and H.2 under the assumption that the covariance terms resulting from taking the variances from both sides of Equation H.1 are constant over time, precisely the assumption made by Attanasio and Székely (2004). The advantage of this strategy is that we can calculate the cohort-specific variances of income, consumption, and tax payments from a nationally representative cross-sectional survey like the ENIGH.

To estimate Equation H.2, we use data from the 2008, 2010, 2012, and 2014 waves of the ENIGH for Mexico City. We include households where the year of birth of the head of household is between 1948 and 1982. We classify all households into 48 year-of-birth ×age cohorts. In particular, we create 8 five-year age-of-birth categories and 6 education categories, which include no formal education, primary school, middle school, high school, bachelor's degree, and postgraduate degree.

Next, we calculate the cohort-level variance of log income and log consumption as well as the variances of two additional outcomes that capture the extent to which idiosyncratic income risk affects property tax compliance: the log of one plus the annual property tax payment and a dummy for positive property tax payments. We then estimate Equation H.2 via OLS both in levels and in differences for each of the three outcome variables above.

Table H.1 presents the results from the estimation. Column (1) shows that in response to a negative yet temporary shock of 1 percent to household income, consumption drops by 0.617 percent, implying that Mexico City's households are able to insure consumption by only 0.383 percent against the shock. Column (2) shows the results from estimating the same equation by first differences instead of including cohort-specific fixed effects in the regression. The first-differences coefficient of 0.556 is statistically indistinguishable from the 0.617 obtained through the fixed-effects estimation.

Column (3) shows that households are even less able to insure property tax payments than con- 
sumption against income shocks. In particular, a 1 percent temporary income shock reduces the annual payment amount by 0.787 percent. Once again, estimating the regression by first differences does not change the result, as the coefficient of 0.915 shown in Column (5) is statistically indistinguishable from the fixed-effects estimate of 0.787 .

Finally, Column (5) shows that income shocks affect the extensive margin of payment, since a temporary income reduction of 1 percent decreases the probability of payment by 0.097 percentage points. Estimating the regression by first differences yields a similar coefficient of 0.12 , as shown in Column (6). Overall, these results confirm the importance of liquidity constraints in explaining consumer and taxpayer behavior in Mexico City.

Table H.1: Income Shocks, Consumption, and Property Tax Payment Variability in Mexico City

\begin{tabular}{|c|c|c|c|c|c|c|}
\hline & \multicolumn{2}{|c|}{$\operatorname{var}_{q}\left[\log \left(\right.\right.$ Consumption $\left.\left._{i t}\right)\right]$} & \multicolumn{2}{|c|}{$\operatorname{var}_{g}\left[\log \left(1+\right.\right.$ Payment $\left.\left._{i t}\right)\right]$} & \multicolumn{2}{|c|}{$\operatorname{var}_{g}\left[\mathbb{1}_{\left\{\text {Payment }_{i t}>0\right\}}\right]$} \\
\hline & $\begin{array}{l}\text { Levels } \\
\text { (1) }\end{array}$ & $\begin{array}{c}\text { Diffs. } \\
(2)\end{array}$ & $\begin{array}{c}\text { Levels } \\
(3)\end{array}$ & $\begin{array}{c}\text { Diffs. } \\
(4)\end{array}$ & $\begin{array}{c}\text { Levels } \\
(5)\end{array}$ & $\begin{array}{c}\text { Diffs. } \\
(6)\end{array}$ \\
\hline$\overline{\operatorname{var}_{g}\left[\log \left(\operatorname{Income}_{i t}\right)\right]}$ & $\begin{array}{c}.617 * * * \\
(.07)\end{array}$ & $\begin{array}{c}.556 * * * \\
(.071)\end{array}$ & $\begin{array}{c}.787 * * * \\
(.166)\end{array}$ & $\begin{array}{c}.915 * * * \\
(.286)\end{array}$ & $\begin{array}{c}.097^{* * *} \\
(.024)\end{array}$ & $\begin{array}{l}.12^{* * *} \\
(.022)\end{array}$ \\
\hline Outcome mean & .454 & .023 & 2.026 & -.012 & .124 & -.008 \\
\hline Group dummies & $\mathrm{Y}$ & $\mathrm{N}$ & $\mathrm{Y}$ & $\mathrm{N}$ & $\mathrm{Y}$ & $\mathrm{N}$ \\
\hline $\bar{N}$ & 167 & 115 & 167 & 115 & 167 & 115 \\
\hline$R^{2}$ & .351 & .282 & .137 & .148 & .132 & .173 \\
\hline
\end{tabular}

Notes: Standard errors are clustered by bin. ${ }^{*} p<0.1,{ }^{* *} p<0.05,{ }^{* * *} p<0.01$. The total number of bins is $192(8$ year-of-birth categories $\times 6$ education categories $\times 4$ years), but for 25 of these bins, there are no observations in the ENIGH for Mexico City.

\section{Payment Timing Appendix}

As we show in Section 1, the interaction between property taxes and liquidity constraints implies that governments can improve tax administration by providing liquidity. The government of Mexico City provides liquidity by offering discounts to taxpayers who pay in full before a given deadline. ${ }^{74}$ In this section, we study how the timing of payments is affected by changes in discounts - through both deadlines and rates - and use this variation to infer households' value for liquidity.

Households choose to pay the property tax on a given day by trading off a lower overall tax payment against the cost of giving up interest-bearing liquid assets and the hassle cost of paying taxes on a given day. In the absence of a value for liquidity, taxpayers would prefer to pay ahead of the deadline to avoid uncertain hassle costs and time constraints that might prevent them from obtaining the discount. If households face liquidity constraints, they may risk missing out on the discount for the benefit of holding on to liquid assets until immediately before the deadline.

The government offered up to three types of discounts between 2009 and 2013. Figure I.1 plots the discount rate and the histogram of property tax revenue for every year. The size of the discounts and the deadlines varied substantially over the years. These discount deadlines can be interpreted as time notches in the sense of Slemrod (2013). Figure I.1 shows a clear pattern where taxpayers

\footnotetext{
${ }^{74}$ Discounts provide liquidity by effectively lending money to those who do not take up the discount. Assuming the discount rate is $d$, households can pay $1-d$ today or borrow from the government at the rate of $\frac{d}{1-d}$. Governments provide liquidity through several mechanisms, including unemployment insurance schemes or accelerated depreciation deductions for firms.
} 
respond very strongly to these incentives by bunching payments immediately before the deadline. This strong response to discounts is consistent with a high value for liquidity. ${ }^{75}$

To quantify the value for liquidity, we use this variation to estimate a dynamic model of payment timing where households trade off discounts, interest income, and the hassle costs of paying the tax. $^{76}$ For a given date $t$ in year $y$, households obtain utility $v_{0}(t, y)$ when they pay their taxes. $v_{0}(t, y)=\theta_{t, y}+\theta_{1} \operatorname{Tax}(t, y)$, where $\theta_{t, y}$ captures the benefit of paying taxes net of the hassle cost of paying on day $t$ and where $\operatorname{Tax}(t, y)$ equals one minus the discount applicable on day $t$ and year $y{ }^{77}$ Alternatively, households can choose to delay paying taxes at time $t$. The value of this choice is given by $v_{1}(t, y)=\theta_{2}$ Interest $_{y}+\beta E V_{1}(t+1, y)$, which captures the interest income from delaying payment and the discounted value function in the next period. Finally, every day households face idiosyncratic hassle costs of paying taxes that follow a logistic distribution.

We study the timing of payments by modeling $P_{0}(t, y)$ : the probability of paying on any given day conditional on not having paid yet. Following Hotz and Miller (1993), $P_{0}(t, y)$ captures the value of delaying payment since $E V_{1}(t+1, y)=v_{0}(t+1, y)-\ln P_{0}(t+1, y)+\gamma$, where $\gamma$ is Euler's constant. The relative log-likelihood of paying on any given day is then:

$$
\begin{aligned}
\ln \left(\frac{P_{0}(t, y)}{1-P_{0}(t, y)}\right)= & v_{0}(t, y)-v_{1}(t, y)=v_{0}(t, y)-\beta v_{0}(t+1, y)-\theta_{2} \text { Interest }_{y}-\beta \ln P_{0}(t+1, y)-\beta \gamma \\
= & -\theta_{1}\{\operatorname{Tax}(t, y)-\beta \operatorname{Tax}(t+1, y)\}-\theta_{2} \text { Interest }_{y} \\
& -\beta \ln P_{0}(t+1, y)+\theta_{t, y}-\beta \theta_{t+1, y} .
\end{aligned}
$$

The first line follows from the logistic distribution and the expression for $E V_{1}(t+1, y)$ above. The second line substitutes the definitions of choice value $v_{0}(t, y)$. To implement this model, we assume that the hassle costs $\theta_{t, y}$ have three components: a day-of-the-year effect, $\theta_{t}$; a day-of-the-week effect, $\theta_{t, d}$; and a residual component, $\varepsilon_{t, y} .{ }^{78}$ The identifying assumption of this equation is that conditional on day-of-the year and day-of-the-week fixed effects, the daily changes in residual time costs, $\Delta_{t} \varepsilon_{t, y}$, are unrelated to yearly variation in interest rates or in the size and timing of discounts. This

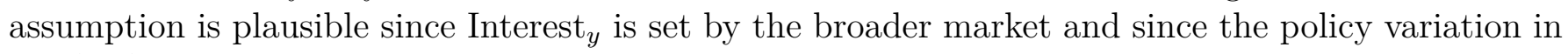
$\operatorname{Tax}(t, y)$ features significant changes in the number of deadlines, due dates, and magnitude of the discounts that are unrelated to daily hassle costs.

Given the rich variation in discounts, we estimate the parameters of the dynamic discrete choice model $\left(\theta_{1}, \theta_{2}, \beta\right)$ via non-linear least squares, where the fixed effects recover day-of-the-year and day-of-the-week hassle costs. Figure I.2 plots $P_{0}(t, y)$ along with the model fit and shows that this relatively simple model does a remarkably good job of matching the data patterns. Panel A of Table

\footnotetext{
${ }^{75} \mathrm{It}$ is worth noting that leading behavioral models are not consistent with these data patterns. First, because deadlines change across years, the bunching patterns that we observe are not consistent with the salience of specific dates - e.g., first-of-the-month effects. Second, because the bunching patterns are very pronounced, these patterns are likely not driven by rational inattention. Finally, one may worry that these patterns are a result of hyperbolic discounting. Fang and Silverman (2004) develop a model of present-biased preferences to study the effects of time limits in public policy. A prediction of this model is that present-biased households would likely miss the deadline, which is inconsistent with the sharp bunching patterns in the data.

${ }^{76}$ Hassle costs include time spent withdrawing cash and traveling to a payment location. Note that automatic payments were not allowed and online payments are only now being introduced.

${ }^{77}$ The problem ends when households pay the tax, so that action 0 constitutes a terminal option.

${ }^{78}$ Day-of-the-year effects capture holidays that are tied to specific days of the year (e.g., January $6^{\text {th }}$ is the day of the Three Wise Men). Day-of-the-week fixed effects capture the fact that different days of the week have different hassle costs (e.g., taxpayers can remit taxes during weekends by paying at convenience stores).
} 
I.1 reports the main estimates from this model. These estimates reveal the importance of liquidity concerns in a couple of ways. First, we can interpret the discount rate as implying that households would pay an interest rate of approximately $8 \%\left(\frac{1}{\beta}-1\right)$ to delay paying property taxes by a single day. ${ }^{79}$ This very high rate of discounting highlights the value of liquidity. Second, the effect of changes in taxes is only about $10\left(\approx \frac{\theta_{1}}{\theta_{2}}\right)$ times larger than changes in interest income. In a world without liquidity constraints, households would place a much smaller value on short-term interest relative to the value placed on a permanent discount on their taxes.

We now use the estimated model to quantify the liquidity value provided by the discounts. Panel B of Table I.1 shows the gain in consumer surplus relative to a world without discounts. ${ }^{80}$ Column (2) shows that taxpayers value discounts at between 3.26 and 10.35 percent of the value of their property taxes. Comparing these values to the deadlines in Column (3), we find higher values in years with later deadlines. This makes sense: discounts raise welfare more when they allow households to hold on to liquid assets longer. Later deadlines also lower the risk of facing a high hassle cost in the early days of the year. Column (4) lists the realized fiscal cost of the discounts as a percentage of the property tax. As would be expected, the value of the discounts in Column (2) is positively related to the fiscal costs. Finally, Column (5) displays the ratio of the value of the discounts to the fiscal cost (Columns (2) over (4)). This ratio would fall below unity if households incur higher hassle costs to obtain the discount. Conversely, this ratio would be greater than one if the value of liquidity exceeds both the additional hassle costs and the fiscal cost to the government. Column (5) shows that in years where households have a longer time to obtain the discounts, the value of the discount to households exceeds the fiscal cost of the discount. That is, when deadlines provide meaningful increases in liquidity, the welfare gains experienced by households exceed the fiscal costs to the government.

The results in this section provide further evidence that payments for property taxes interact with liquidity constraints. This result is evident both in reduced-form patterns that showcase the sensitivity of the timing of payments to discounts and in the estimates from the dynamic discrete choice model. Because we find a value for liquidity even among the households that are willing to pay in full, relaxing liquidity constraints for a broader set of households can lower the welfare cost of paying property taxes and improve the design of the property tax system.

\footnotetext{
${ }^{79}$ While this is a very high rate of discounting, it is also consistent with the very high interest rates charged by payday lenders in the US.

${ }^{80}$ Following Train (2009), consumer surplus is given by $\ln \left[\sum_{j=0,1} \exp \left\{v_{j}\left(t=0, y \mid\{\operatorname{Tax}(t, y)\}_{t}, \operatorname{Interest}_{y}\right)\right\}\right] \times \frac{1}{\theta_{2}}$. We evaluate welfare on the first day of the year $(t=0)$ given a daily profile of discounts $\{\operatorname{Tax}(t, y)\}_{t}$. We divide the log-sum by the coefficient on interest income to interpret this quantity as a monetary measure of consumer surplus. Finally, we evaluate this expression setting Interest $y$ to the average value in our sample.
} 
Table I.1: Dynamic Model of Payment Timing

Panel A. Model Estimates

\begin{tabular}{|c|c|c|c|c|}
\hline & $\begin{array}{c}(1) \\
\text { Tax Coefficient } \\
\theta_{1}\end{array}$ & $\begin{array}{c}(2) \\
\text { Interest Coeff } \\
\theta_{2}\end{array}$ & icient I & $\begin{array}{c}(3) \\
\text { Discount Factor } \\
\beta\end{array}$ \\
\hline Estimate & $\begin{array}{c}0.936^{* * *} \\
(0.180)\end{array}$ & $\begin{array}{c}0.096 \\
(0.064)\end{array}$ & & $\begin{array}{c}0.924^{* * *} \\
(0.041)\end{array}$ \\
\hline \multicolumn{5}{|c|}{ Panel B. Welfare Estimates } \\
\hline $\begin{array}{l}(1) \\
\text { Year Cons } \\
\text { Fro }\end{array}$ & $\begin{array}{l}\text { (2) } \\
\text { umer Surplus } \\
\text { m Discounts }\end{array}$ & $\begin{array}{c}(3) \\
\text { Discount } \\
\text { Deadlines }\end{array}$ & $\begin{array}{c}(4) \\
\text { Fiscal } \\
\text { Cost }\end{array}$ & $\begin{array}{c}\text { (5) } \\
\text { Relative Value } \\
\text { of Discounts }\end{array}$ \\
\hline 2009 & 10.35 & Jan 31, Feb 28 & 7.80 & 1.33 \\
\hline 2010 & 3.92 & Jan 31 & 4.95 & 0.79 \\
\hline 2011 & 3.26 & Jan 10, 17, 31 & 6.53 & 0.50 \\
\hline 2012 & 5.23 & Jan 17, 31 & 6.84 & 0.77 \\
\hline 2013 & 7.76 & Jan 31, Feb 28 & 6.95 & 1.12 \\
\hline
\end{tabular}

Notes: Panel A reports the parameter estimates from the dynamic discrete choice model presented in this Appendix. The parameters were estimated by solving Equation I.1 via non-linear least squares. The model parameters reflect the role of liquidity constraints through the low discount rate and the relatively high utility value of interest income. The underlying data on payment probabilities are weighted to reflect tax collections per day. Panel B uses the model estimates to compute the consumer surplus from discounts (as a percentage of tax payment). Discounts have a larger effect on consumer surplus when taxpayers face longer deadlines and when the discounts are more generous. In these cases, the value of the discounts is greater than the fiscal cost (also as a percentage of tax payment), showing that the government can lower the welfare cost of property taxes by providing liquidity to taxpayers. 
Figure I.1: Taxpayer Response to Super-Early-Bird and Early-Bird Discounts

A. 2009

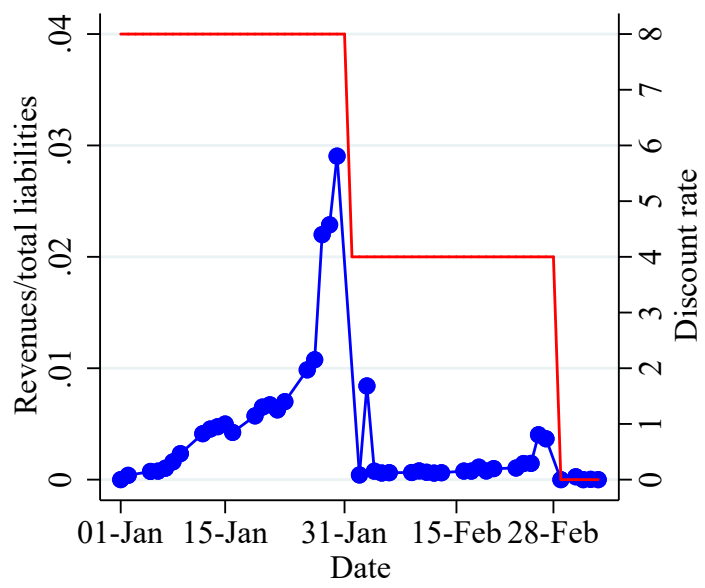

C. 2011

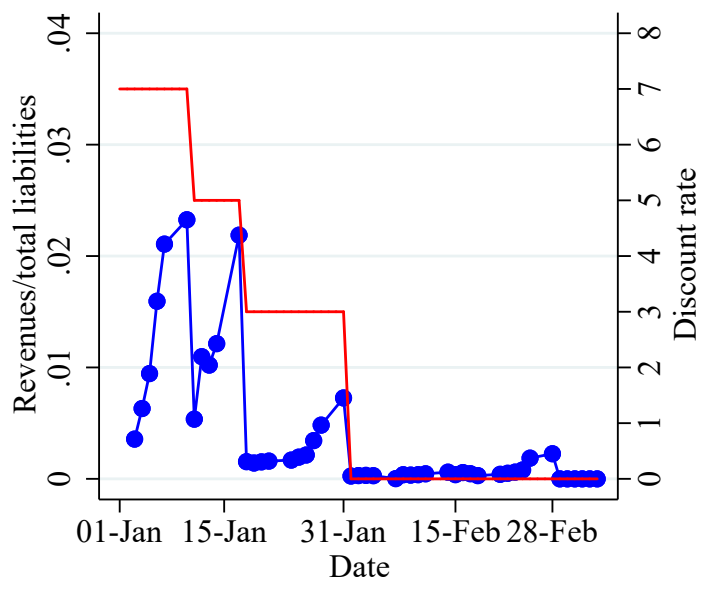

B. 2010

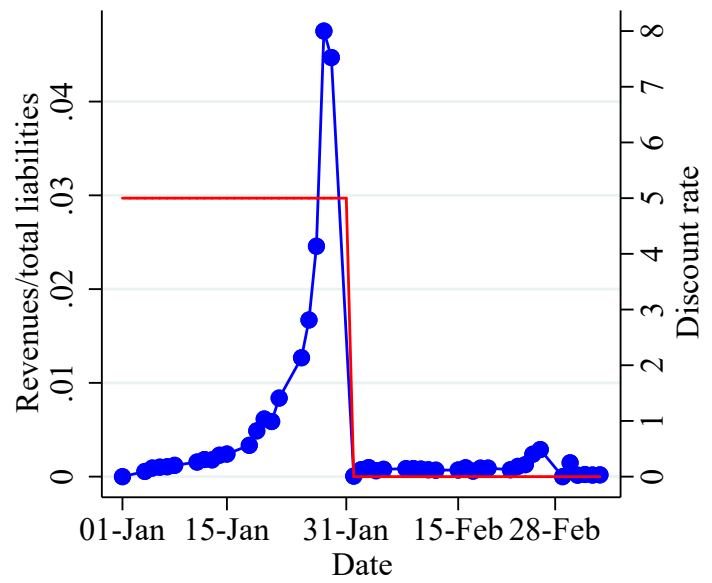

D. 2012

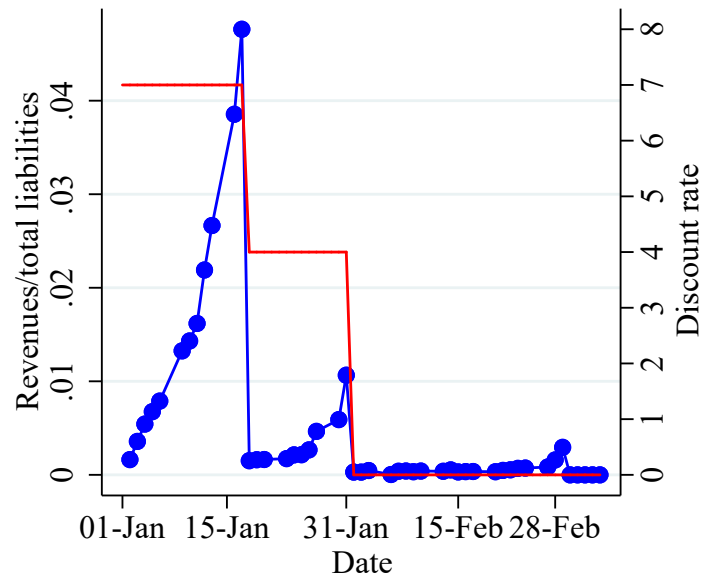

E. 2013

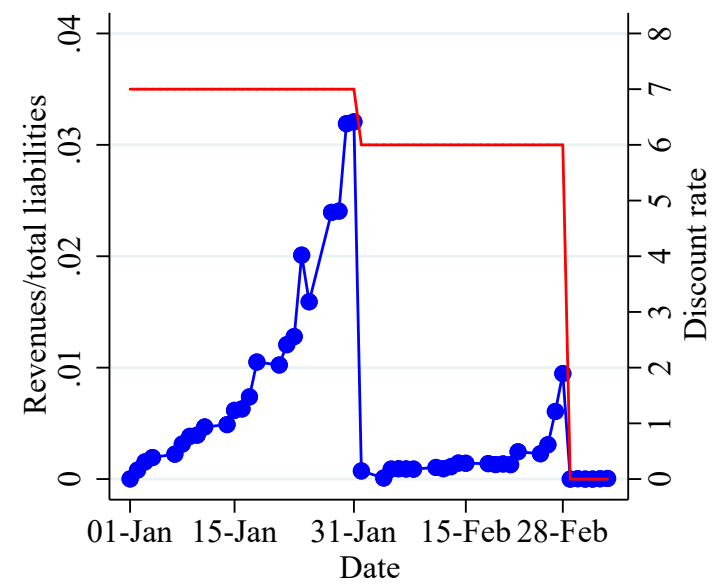

Notes: This figure plots the early-bird discount rates and the timing of property tax payments, as discussed in this appendix. The red line in each panel represents the annual super-early-bird and early-bird discount rates. The blue dots represent the revenues of the government each day, expressed as a fraction of the total yearly liabilities in Mexico City. 
Figure I.2: Estimates from Dynamic Model of Payment Timing

A. 2009

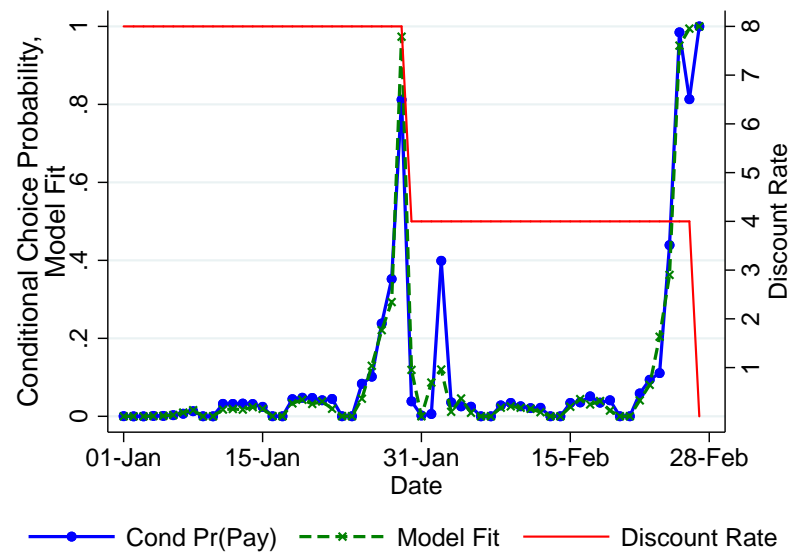

C. 2011

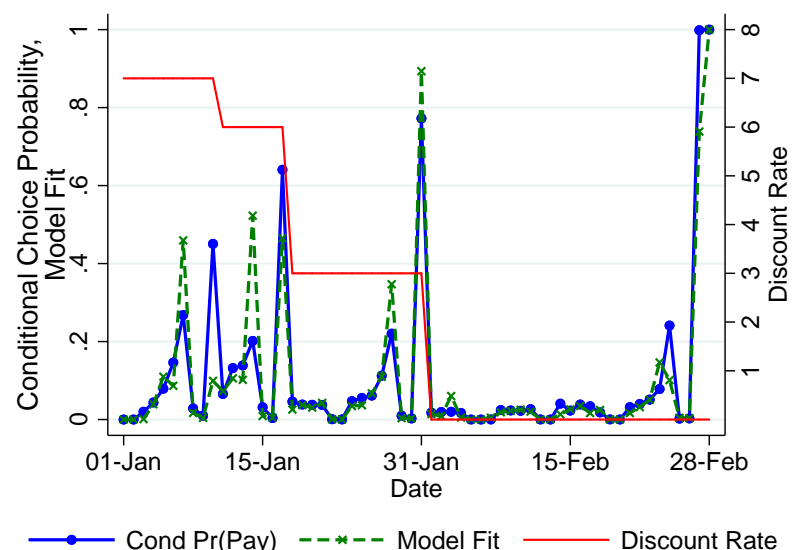

B. 2010

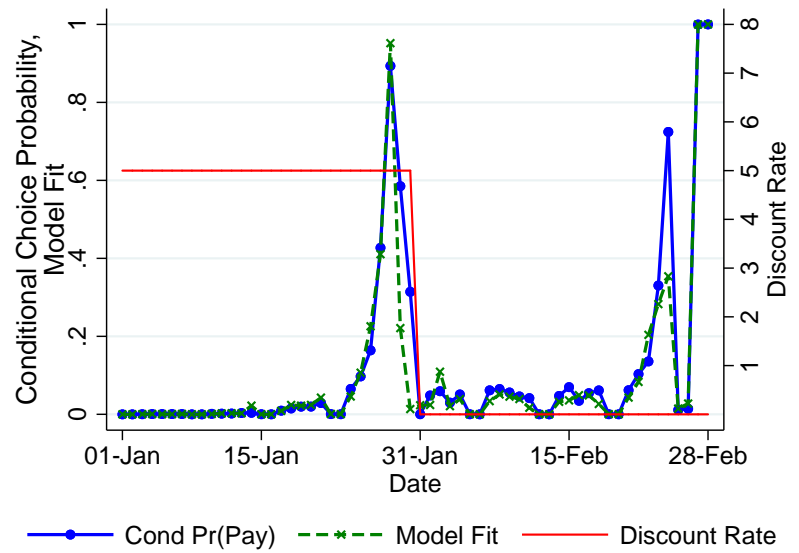

D. 2012

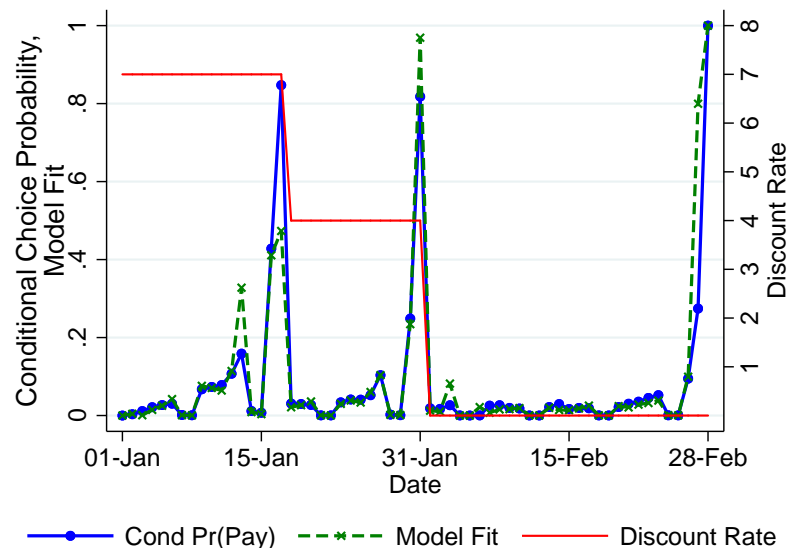

E. 2013

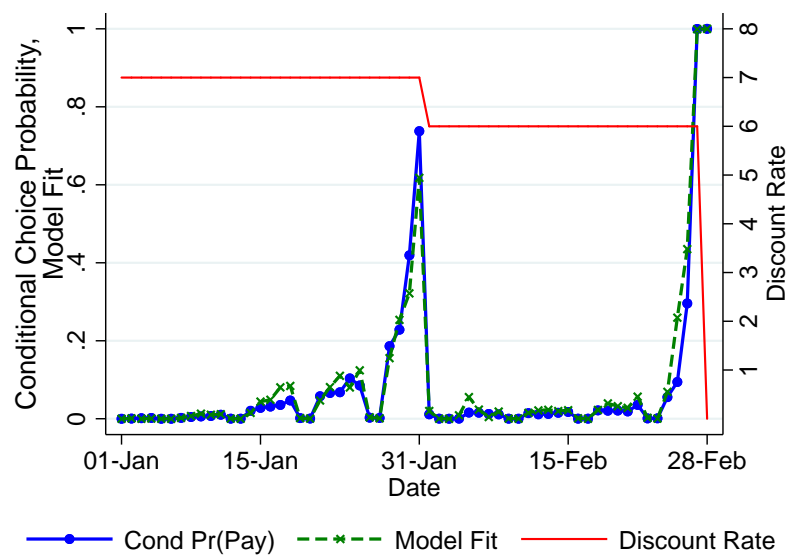

Notes: This figure displays estimates from the dynamic discrete choice model of payment timing presented in this appendix. The red lines display $P_{0}(t, y)$ : the probability of paying taxes on any given day conditional on not having paid. These probabilities are weighted to reflect tax collections per day. The blue lines display the corresponding model fit from the dynamic discrete choice model. The black lines display tax obligations net of discounts. 


\section{J Instrumental Variable Appendix}

\section{J.1 Construction of the Instrument for Property Tax Payments: Additional Details}

Because the 2010 and 2012 waves of the ENIGH do not measure construction and land area, we use the 2008 wave, which includes these data along with the other variables in the 2010 and 2012 waves, to assign a value of $Z_{i t}$ to a given property. Specifically, we use a multinomial logit to estimate the probability that a property with a given number of rooms belongs to a given land-constructionage-municipality-year bin using the 2008 data. Using these predicted probabilities, we compute the expectation of the average change in tax liability for each property in the ENIGH.

Table J.1: The Effect of Property Taxes on Consumption First-Stage IV Regressions - Predicting Property Tax Payment

\begin{tabular}{lccc}
\hline \hline & $(1)$ & $(2)$ & $(3)$ \\
\hline$Z$ & $.473^{* * *}$ & & $.299^{* * *}$ \\
$\tilde{Z}$ & $(.074)$ & & $(.084)$ \\
& & $-.741^{* * *}$ & $-.469^{* * *}$ \\
F-statistic (excluded instruments) & 40.61 & $(.094)$ & $(.115)$ \\
p-value (excluded instruments) & .000 & 61.62 & 14.66 \\
\hline
\end{tabular}

Notes: This table reports the first-stage results from the IV estimation discussed in Section 6.2. The second-stage results are reported in Table 4. $\mathrm{N}=2,649$. All regressions include delegación fixed effects and year dummies. Bootstrapped standard errors based on 1,000 replications are in parentheses. The outcome is log property tax payment. The instruments $Z$ and $\tilde{Z}$ are the constructed predicted change in the property tax liability and the predicted probability that a household's property is part of the treated cadastral value band in 2010 (band I), respectively. ${ }^{*} p<0.1$, ** $p<0.05,{ }^{* * *} p<0.01$.

Table J.2: The Effect of Property Taxes on Consumption Second-Stage Regressions with Alternative Instrument

\begin{tabular}{lcccc}
\hline & $(1)$ & $(2)$ & $(3)$ & $(4)$ \\
\hline $\log ($ Pay $)$ & -.006 & -.024 & .002 & -.012 \\
& $(.052)$ & $(.055)$ & $(.051)$ & $.053)$ \\
$\log ($ Pay $) \times \log ($ pc income $)$ & & $.066^{* * *}$ & & $.046^{* *}$ \\
$\log$ (Pay) $\times$ Lack of credit & & $(.024)$ & & $(.023)$ \\
$\log ($ pc income $)$ & & & $-.041^{* * *}$ & $-.035^{* * *}$ \\
& $.815^{* * *}$ & $.435^{* * *}$ & $. .007)$ & $(.006)$ \\
& $(.035)$ & $(.13)$ & $.782^{* * *}$ & $.52^{* * *}$ \\
\hline
\end{tabular}

Notes: This table is identical to Table 4 but reports results from using an alternative instrument $\tilde{Z}_{i t}$ : the predicted probability that a household's property is part of the treated cadastral value band in 2010 (band I). The results are qualitatively and quantitatively very similar to those in Table $4 .{ }^{*} p<0.1,{ }^{* *} p<0.05,{ }^{* * *} p<0.01$. 
Table J.3: The Effect of Property Taxes on Consumption

Second-Stage Regressions with Both Instruments

\begin{tabular}{lcccc}
\hline \hline & $(1)$ & $(2)$ & $(3)$ & $(4)$ \\
\hline $\log ($ Pay $)$ & -.021 & -.03 & -.011 & -.018 \\
$\log ($ Pay $) \times \log ($ pc income $)$ & $(.049)$ & $(.05)$ & $(.048)$ & $(.049)$ \\
& & $.063^{* * *}$ & & $.043^{*}$ \\
$\log ($ Pay $) \times$ Lack of credit & & $(.023)$ & & $(.023)$ \\
& & & $-.042^{* * *}$ & $-.035^{* * *}$ \\
$\log ($ pc income $)$ & $.824 * * *$ & $.455^{* * *}$ & $. .007)$ & $(.006)$ \\
& $(.033)$ & $(.127)$ & $.789 * * *$ & $.544^{* * *}$ \\
& & & $(.03)$ & $(.127)$ \\
\hline
\end{tabular}

Notes: This table is identical to Tables 4 and J.2 but uses both instruments $Z$ and $\tilde{Z}$ to predict property tax payment. The results are qualitatively and quantitatively very similar to those in Table $4 .{ }^{*} p<0.1,{ }^{* *} p<0.05,{ }^{* * *} p<0.01$.

Table J.4: Partial Effect of Tax Payment on Consumption Evaluated at Different Income-Credit Access Combinations

\begin{tabular}{|c|c|c|c|}
\hline & $\begin{array}{c}(1) \\
\mathrm{Z}\end{array}$ & $\begin{array}{l}(2) \\
\tilde{Z}\end{array}$ & $\begin{array}{c}(3) \\
\mathrm{Z} \& \tilde{Z}\end{array}$ \\
\hline Log-income (25th pctile), Credit access & $\begin{array}{c}.081 \\
(.056) \\
{[-.133, .052]}\end{array}$ & $\begin{array}{c}-.057 \\
(.062) \\
{[-.208, .009]}\end{array}$ & $\begin{array}{c}-.043 \\
(.053) \\
{[-.124, .038]}\end{array}$ \\
\hline Log-income (25th pctile), No credit access & $\begin{array}{c}-.121^{* *} \\
(.059) \\
{[-.174, .022]}\end{array}$ & $\begin{array}{c}-.092 \\
(.063) \\
{[-.24,-.025]}\end{array}$ & $\begin{array}{c}-.078 \\
(.055) \\
{[-.162, .008]}\end{array}$ \\
\hline Log-income (median), Credit access & $\begin{array}{c}-.04 \\
(.051) \\
{[-.096, .06]}\end{array}$ & $\begin{array}{c}-.038 \\
(.057) \\
{[-.173, .026]}\end{array}$ & $\begin{array}{c}-.019 \\
(.048) \\
{[-.097, .056]}\end{array}$ \\
\hline Log-income (median), No credit access & $\begin{array}{c}-.081 \\
(.055) \\
{[-.14, .026]}\end{array}$ & $\begin{array}{c}-.073 \\
(.059) \\
{[-.203,-.01]}\end{array}$ & $\begin{array}{c}-.055 \\
(.051) \\
{[-.134, .023]}\end{array}$ \\
\hline Log-income (75th pctile), Credit access & $\begin{array}{c}.008 \\
(.049) \\
{[-.058, .098]}\end{array}$ & $\begin{array}{c}-.013 \\
(.053) \\
{[-.132, .049]}\end{array}$ & $\begin{array}{c}.008 \\
(.047) \\
{[-.08, .084]}\end{array}$ \\
\hline Log-income (75th pctile), No credit access & $\begin{array}{c}-.032 \\
(.053) \\
{[-.106, .062]}\end{array}$ & $\begin{array}{c}-.048 \\
(.055) \\
{[-.166, .019]}\end{array}$ & $\begin{array}{c}-.027 \\
(.05) \\
{[-.118, .056]}\end{array}$ \\
\hline
\end{tabular}

Notes: This table reports the partial effects of tax payment on consumption, estimated with the IV strategy discussed in Section 6.2 and reported in Table 4, evaluated at different income quartile and credit access combinations. Bootstrapped standard errors based on 1,000 replications are in parentheses, and 90 percent bootstrap confidence intervals are in brackets. ${ }^{*} p<0.1,{ }^{* *} p<0.05,{ }^{* * *} p<0.01$. 


\section{K Revenue-Maximizing Tax Rates}

In this appendix, we assume that the government's single aim is to maximize tax revenue, and we use the different tax changes analyzed in Section 4 to estimate the revenue-maximizing tax rate. Our empirical results from Section 4 show that larger tax increases imply smaller revenue elasticities and that tax increases have a significant effect on the fraction of delinquent taxpayers. These results raise the possibility that further tax increases may have small or even null effects on revenue. To evaluate this possibility, we use our empirical estimates to characterize the degree to which current tax rates are close to the revenue-maximizing tax rate.

Building on the corporate tax literature (Clausing, 2007; Devereux, 2007; Kawano and Slemrod, 2015; Suárez Serrato and Zidar, 2018), we estimate a quadratic relation between taxes and revenue:

$$
\ln R e v_{t}=\beta_{1} \tau_{t}+\beta_{2}\left(\tau_{t}\right)^{2} .
$$

Revenue is a concave parabola of taxes when $\beta_{1}>0$ and $\beta_{2}<0$. Intuitively, $\beta_{1}>0$ implies that introducing a small tax raises revenue, and $\beta_{2}<0$ implies that the marginal impact on revenue $\left(\beta_{1}+2 \beta_{2} \tau_{t}\right)$ is smaller for higher tax rates. At the revenue-maximizing rate, the marginal impact of a tax increase is zero, which implies that revenue is maximized by $\tau^{*}=\frac{-\beta_{1}}{2 \beta_{2}}$. Key empirical questions are then whether $\beta_{2}<0$ and whether large values of $\beta_{2}$ imply small values of $\tau^{*}$.

To connect this framework to our results, write the effect of a tax change on revenue as:

$$
\underbrace{\frac{\Delta \ln R e v_{t}}{\Delta \tau_{t}}}_{\text {Semi-Elasticity: }}=\beta_{1}+2 \beta_{2} \tau_{t} \text {. }
$$

This expression implies that we can estimate $\beta_{1}$ and $\beta_{2}$ from multiple estimates of the revenue semielasticity at different values of $\tau_{t} \cdot{ }^{81}$ Let $\hat{\boldsymbol{\eta}}=\left[\hat{\eta}_{2010}, \hat{\eta}_{2011}, \hat{\eta}_{2012}\right]^{\prime}$ be the vector of semi-elasticities from the three tax changes, and define the matrix $\boldsymbol{W}=\left[\mathbf{1}_{t}, 2 \boldsymbol{\tau}_{\boldsymbol{t}}\right]$. Using a simple application of classical minimum distance (CMD), we estimate $\beta_{1}$ and $\beta_{2}$ as a linear combination of the semi-elasticities: $\left[\hat{\beta}_{1}, \hat{\beta}_{2}\right]^{\prime}=\left(\boldsymbol{W}^{\prime} \boldsymbol{W}\right)^{-1}\left(\boldsymbol{W}^{\prime} \hat{\boldsymbol{\eta}}\right){ }^{82}$ We then use these estimates to test whether $\beta_{2}<0$ and to study the implied revenue-maximizing rates $\tau^{*}$.

The elasticity and semi-elasticity estimates resulting from our estimations discussed Section 4 are displayed in Table K.1. Applying the method discussed above, we obtain estimates of $\beta_{2}=$ $1.64(S E=2.34)$ when using the regression discontinuity estimates of $\hat{\boldsymbol{\eta}}$ and $\beta_{2}=3.29(S E=0.74)$ when using the difference-in-difference estimates (Table K.2). ${ }^{83}$ The result that both estimates of $\beta_{2}$ are positive implies that current property tax rates are significantly below the revenue-maximizing rate. This result is driven by the fact that our semi-elasticity estimates are not decreasing in $\tau_{t}$. As Tables K.1 shows, we estimate larger semi-elasticities for larger values of $\tau_{t}$.

\footnotetext{
${ }^{81}$ One potential concern is that the three tax changes estimate effects from households in different parts of the home value distribution, leading to different elasticities. This is not the case. The thresholds for the three reforms were approximately $2.275,1.95$, and 1.625 million MXN. The three elasticities are based on comparable properties that are 325 thousand MXN-about 16 thousand USD - apart.

${ }^{82}$ See Chamberlain (1984) for a guide to CMD and Suárez Serrato and Zidar (2016) for a recent application.

${ }^{83}$ While we can reject the null hypothesis that $\beta_{2}<0$ with a p-value $<0.001$ when we use the DiD estimates, we cannot reject this hypothesis when we use the RD estimates. See Table K.2 for details. Importantly, this result is not driven by a lack of statistical precision. Estimates of $\beta_{1}$ and $\beta_{2}$ yield precisely estimated revenue semi-elasticities at the average tax rate of $0.010(S E=0.002, t-s t a t=5.29)$ for the regression discontinuity case and $0.012(S E=$ $0.001, t-s t a t=19.78)$ for the difference-in-difference case.
} 
While the point estimates for $\beta_{2}$ are positive, we also consider how uncertainty in these estimates affects our policy analysis. To explore the role of uncertainty, we simulate 10,000 values of $\beta_{1}$ and $\beta_{2}$ based on their joint distribution and characterize the resulting distribution of $\tau^{*}$. This exercise shows that 80 percent of the time, the revenue-maximizing rate is greater than 159 basis points. We also find that 90 percent of the simulated values yield estimates of $\tau^{*}$ above 73 basis points and that only 5 percent of the estimates are below 61 basis points. ${ }^{84}$ Given that the highest tax rate in the three reforms was 50 basis points, these results show that the government can raise the property tax rate by 20-50 percent with a very limited risk of going beyond the revenue-maximizing rate.

The policy takeaway from this analysis is that rigorous empirical evidence from recent tax increases shows that current tax rates are significantly below the revenue-maximizing tax rate. ${ }^{85}$

While the government may be able to collect additional tax revenue by taxing property at rates below $\tau^{*}$, the welfare costs from increasing tax rates or tightening enforcement may exceed the value that taxpayers obtain from using the additional revenue to provide public goods. For this reason, it is possible that the optimal tax rate may fall significantly below the revenue-maximizing rate. In addition, the revenue-maximizing analysis does not provide any guidance as to whether the government should rely on tax rate increases or enforcement actions to collect revenue. In Section 7 of the paper, we implement the welfare-maximizing model from Section 1 that incorporates these important insights.

Table K.1: The Effect of Tax Rates on Tax Payment - Semi-Elasticity Estimates

\begin{tabular}{|c|c|c|c|c|c|c|}
\hline & \multicolumn{3}{|c|}{ A. Regression Discontinuity } & \multicolumn{3}{|c|}{ B. Difference-in-Differences } \\
\hline & Payment & Payment in & Compliance & Payment & Payment in & Compliance \\
\hline & Amount & Full & Share & Amount & Full & Share \\
\hline & (1) & $(2)$ & $(3)$ & (4) & $(5)$ & $(6)$ \\
\hline & \multicolumn{6}{|c|}{ I. Estimates for the 2009-2010 Treatment } \\
\hline \multirow[t]{2}{*}{ Implied Elasticity } & .55 & -.822 & -.368 & .697 & -.617 & -.244 \\
\hline & $(.226)$ & $(.318)$ & $(.234)$ & $(.101)$ & $(.104)$ & $(.067)$ \\
\hline \multirow[t]{3}{*}{ Implied Semi-Elasticity } & .011 & -.016 & -.007 & .014 & -.012 & -.005 \\
\hline & $(.005)$ & $(.006)$ & $(.005)$ & $(.002)$ & $(.002)$ & $(.001)$ \\
\hline & \multicolumn{6}{|c|}{ II. Estimates for the 2010-2011 Treatment } \\
\hline \multirow[t]{2}{*}{ Implied Elasticity } & .475 & -.717 & -.407 & .728 & -.642 & -.300 \\
\hline & $(.108)$ & $(.170)$ & $(.107)$ & $(.085)$ & $(.064)$ & $(.043)$ \\
\hline \multirow[t]{3}{*}{ Implied Semi-Elasticity } & .01 & -.015 & -.009 & .015 & -.014 & -.006 \\
\hline & $(.002)$ & $(.004)$ & $(.002)$ & $(.022)$ & $(.001)$ & $(.001)$ \\
\hline & \multicolumn{6}{|c|}{ III. Estimates for the 2011-2012 Treatment } \\
\hline Implied Elasticity & .314 & -.658 & -.316 & .489 & -.747 & -.455 \\
\hline & $(.059)$ & $(.083)$ & $(.060)$ & $(.073)$ & $(.035)$ & $(.025)$ \\
\hline Implied Semi-Elasticity & .008 & -.016 & -.008 & .012 & -.018 & -.011 \\
\hline & $(.001)$ & $(.002)$ & $(.001)$ & $(.002)$ & $(.001)$ & $(-001)$ \\
\hline
\end{tabular}

Notes: This table reports the semi-elasticity estimates implied by our regression discontinuity and difference-indifference estimations, for which the estimates are reported in Table 2.

\footnotetext{
${ }^{84}$ These simulations are based on our regression discontinuity results. The difference-in-difference estimates imply larger revenue-maximizing rates in all cases.

${ }^{85}$ Our findings contrast with the results of Haughwout et al. (2004), who find that in three of four major US cities, property tax rates are close to the peak of the Laffer curve.
} 
Table K.2: Classical Minimum Distance Estimates of Revenue-Maximizing Tax Rates

\begin{tabular}{lcc}
\hline \hline & $(1)$ & $(2)$ \\
& RD Estimates & DiD Estimates \\
\hline$\beta_{1}$ & -0.005 & $-0.019^{* * *}$ \\
& $(0.020)$ & $(0.007)$ \\
$\beta_{2}$ & 1.640 & $3.293^{* * *}$ \\
& $(2.347)$ & $(0.738)$ \\
\hline Mean Semi-Elasticity & $0.010^{* * *}$ & $0.012^{* * *}$ \\
& $(0.002)$ & $(0.001)$ \\
\hline 20th Percentile of $\tau^{*}$ & 158.968 & 250.000 \\
10th Percentile of $\tau^{*}$ & 73.431 & 250.000 \\
5th Percentile of $\tau^{*}$ & 61.521 & 250.000 \\
\hline
\end{tabular}

Standard errors in parentheses.

${ }^{*} p<.1,{ }^{* *} p<.05,{ }^{* * *} p<.01$.

Notes: This table reports results for the classical minimum distance estimates of revenue-maximizing tax rates. Column (1) uses estimates from the RD estimation to estimate $\beta_{1}$ and $\beta_{2}$, while Column (2) uses estimates from the DiD estimation. In both cases, we find that $\beta_{2}>0$, indicating that current tax rates are substantially below the revenue-maximizing rates. For both cases, we report the mean semi-elasticity by evaluating the revenue curve at the average tax rate. Finally, the last panel reports estimates of revenue-maximizing tax rates $\tau^{*}$ from 10,000 simulated values of $\beta_{1}$ and $\beta_{2}$. We compute $\tau^{*}$ in each simulation and report the percentiles of this distribution. We top-code $\tau^{*}$ at 250 basis points when $\beta_{2}>0$. 